\title{
2-Arylacetamido-4-Phenylamino-5-Substituted Pyridazinones as Formyl Peptide Receptors Agonists
}

Claudia Vergelli, ${ }^{[a]}$ Igor A. Schepetkin,${ }^{[b]}$ Giovanna Ciciani, ${ }^{[\mathrm{ad}}$ Agostino Cilibrizzi,${ }^{[\mathrm{cc}]}$ Letizia Crocetti ${ }^{[\mathrm{a}]}$ Maria Paola Giovannoni,${ }^{[\mathrm{a}] *}$ Gabriella Guerrini, ${ }^{[\mathrm{a}]}$ Antonella Iacovone,${ }^{[\mathrm{a}]}$ Liliya N. Kirpotina,${ }^{[b]}$ Andrei I. Khlebnikov, ${ }^{[\mathrm{d}]}$ Richard D. Ye, ${ }^{[\mathrm{e}]}$ and Mark T. Quinn, ${ }^{[\mathrm{b}]}$

${ }^{a}$ NEUROFARBA, Sezione di Farmaceutica e Nutraceutica, Università degli Studi di Firenze, Via Ugo Schiff 6, 50019 Sesto Fiorentino, Italy.

${ }^{b}$ Department of Microbiology and Immunology, Montana State University, Bozeman, MT 59717, USA.

${ }^{c}$ Department of Chemistry, Imperial College London, South Kensington, London SW7 2AZ, UK.

${ }^{d}$ Department of Biotechnology and Organic Chemistry, Tomsk Polytechnic University, Tomsk 634050, Russia \& Department of Chemistry, Altai State Technical University, Barnaul, Russia.

${ }^{e}$ Institute of Chinese Medical Sciences, University of Macau, Macau SAR, China

* corresponding authors:

Maria Paola Giovannoni

Dipartimento di NEUROFARBA

Via Ugo Schiff 6

Sesto Fiorentino 50019 Firenze

Tel +39-055-4573682

E-mail mariapaola.giovannoni@ unifi.it

Key-words: formyl peptide receptor (FPR), agonist, pyridazin-3(2H)-one, neutrophil, $\mathrm{Ca}^{2+}$ mobilization 


\begin{abstract}
$N$-Formyl peptide receptors (FPRs: FPR1, FPR2, and FPR3) are G protein-coupled receptors that play key roles in modulating immune cells. FPRs represent potentially important therapeutic targets for the development of drugs that could enhance endogenous anti-inflammation systems associated with various pathologies, thereby reducing the progression of inflammatory conditions. Previously, we identified 2-arylacetamide pyridazin-3(2H)-ones as FPR1- or FPR2-selective agonists, as well as a large number of FPR1/FPR2-dual agonists and several mixed-agonists for the three FPR isoforms. Here, we report a new series of 2-arylacetamido-4-aniline pyridazin-3(2H)-ones substituted in position 5 as a further development of these FPR agonists. Chemical manipulation presented in this work resulted in mixed FPR agonists $\mathbf{8 a}, \mathbf{1 3} \mathbf{a}$ and $\mathbf{2 7} \mathbf{b}$, which had $\mathrm{EC}_{50}$ values in nanomolar range. In particular, compound 8a showed a preference for FPR1 $\left(\mathrm{EC}_{50}=45 \mathrm{nM}\right)$, while 13a and 27b showed a moderate preference for FPR2 $\left(\mathrm{EC}_{50}=35\right.$ and $61 \mathrm{nM}$, respectively). Thus, these compounds may represent valuable tools for studying FPR activation and signaling.
\end{abstract}




\section{Introduction}

Human formyl peptide receptors (FPR1, FPR2, and FPR3) are a family of versatile Gprotein-coupled receptors (GPCRs) that represent attractive therapeutic targets because of their involvement in a wide range of normal physiological processes, as well as pathological events associated with inflammatory conditions [1-4]. Originally identified in phagocytic leucocytes, FPRs mediates chemotaxis and activation of the majority of immune system cells in response to bacterial products and various inflammatory stimuli [3]. However, recent studies indicate that FPRs are also expressed in a variety of nonhematopoietic cells, such as lung epithelial cells, platelets, osteoblasts, and hepatocytes, suggesting a wider role for FPRs beyond inflammation and host defense [5].

FPR activation can induce pro- or anti-inflammatory responses, depending on the nature of the ligand and cell types involved. For example, FPRs have been reported to contribute to inflammation associated with amyloidosis and Alzheimer's disease, prion disease, human immunodeficiency virus, stomach ulcer, some cancers, nociception associated with inflammatory processes, chronic obstructive pulmonary disease (COPD), stroke and ischemia-reperfusion injury [6-13]. Conversely, stimulation of FPRs with certain agonists can also induce pro-resolving responses or endogenous anti-inflammatory systems [3]. Indeed, screening of commercial libraries and new synthetic compounds has resulted in the discovery of a number of small-molecule nonpeptide FPR agonists and antagonists with a wide range of chemical diversity and activities [14-16].

In previous studies, we identified several pyridazin-3(2H)-one-based derivatives that showed an interesting profile as FPR agonists, combining an appreciable potency and differential selectivity toward the three human FPR isoforms [17-21]. Key requirements for agonist activity of this class of compounds were the presence of a 4-bromophenylacetamide side chain at the N-2 position of the scaffold $[17,19]$ and the presence of a methyl group at C-6 [20]. Position 4 could be substituted with a benzyl or phenylamino group, resulting in compounds with micromolar activity (Figure 1, general structure A). 


\section{Figure 1}

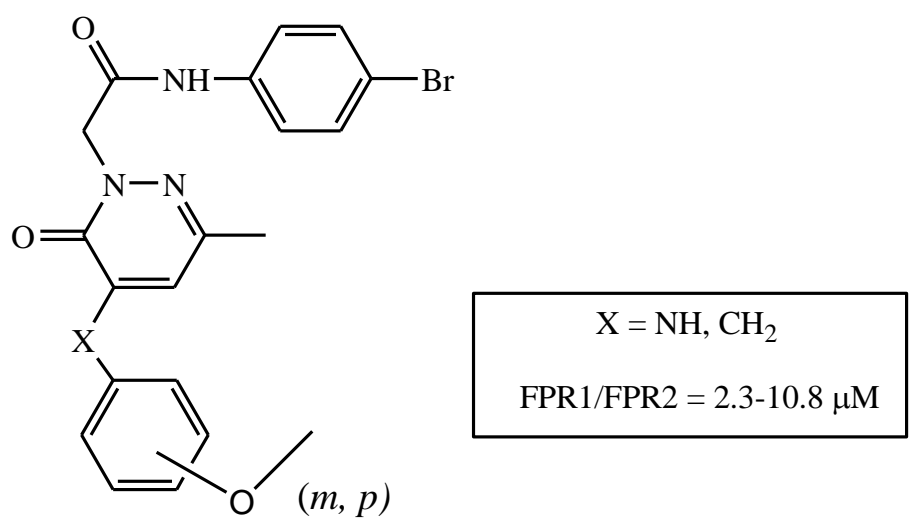

A

In the present study, we further investigated pyridazinone derivatives belonging to the series of 4-phenylamino derivatives (structure $\mathbf{A}, X=\mathrm{NH}$ ) which until now was only poorly studied [20]. In particular, we inserted at position 5 of the pyridazinone scaffold a variety of substituents, such as alkyl or acyl groups, ester, unsaturated chains, and pyrazole rings, in order to evaluate how such modifications affected target specificity and compound potency.

\section{Chemistry}

All compounds were synthesized as reported in Schemes 1-5, and the structures were confirmed using analytical and spectral data.

The synthetic pathway leading to the final compounds 6a-f bearing an acyl group at position 5 is outlined in Scheme 1. Previously described isoxazolo-pyridazinones of type 1 [22-25] were transformed into the corresponding 4-amino-5-acetyl derivatives $\mathbf{2 a - f}$ (2a-d [25]) by reductive cleavage with $10 \% \mathrm{Pd} / \mathrm{C}$ and $\mathrm{HCOONH}_{4}$ in ethanol. The products were then converted to the 4bromophenylacetamide derivatives $\mathbf{5 a - f}$ as follows. Intermediates $\mathbf{2 a}$ and $\mathbf{2 d , e}$ were alkylated with ethylbromoacetate under standard conditions to generate 3a [20] and 3d,e, which were transformed into the corresponding carboxylic acids $\mathbf{4 a}[22]$ and $\mathbf{4 d , e}$ through alkaline hydrolysis. These were transformed into the final amides of type 5 by treatment with 4-bromoaniline, ethyl chloroformate 
and triethylamine in THF. Compounds $\mathbf{5 b}, \mathbf{c}$ and $\mathbf{5 f}$ were obtained starting from their respective intermediates by a direct alkylation with $N$-(4-bromophenyl)-2-chloroacetamide [26] under standard conditions. Finally, a coupling reaction between 5a-f and 3-methoxybenzenboronic acid was carried out in the presence of copper(II)acetate and $\mathrm{Et}_{3} \mathrm{~N}$ to generate the final 5-alkyl pyridazinones 6a-f.

\section{Scheme 1}
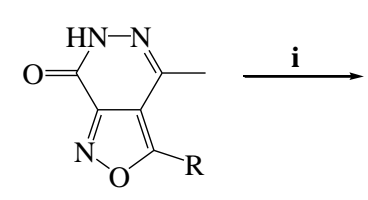

1a-f

\begin{tabular}{|l|l|}
\hline $\mathbf{1 - 6}$ & $\mathbf{R}$ \\
\hline $\mathbf{a}$ & $\mathrm{CH}_{3}$ \\
$\mathbf{b}$ & $\mathrm{C}_{2} \mathrm{H}_{5}$ \\
$\mathbf{c}$ & $\mathrm{C}_{3} \mathrm{H}_{7}$ \\
$\mathbf{d}$ & $\mathrm{C}_{4} \mathrm{H}_{9}$ \\
$\mathbf{e}$ & $\mathrm{cC}_{5} \mathrm{H}_{9}$ \\
$\mathbf{f}$ & $\mathrm{CC}_{6} \mathrm{H}_{11}$ \\
\hline
\end{tabular}<smiles>[R]C(=O)c1c(C)n[nH]c(=O)c1N</smiles>

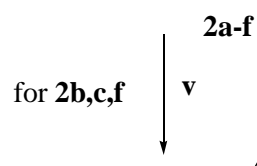

2a-f
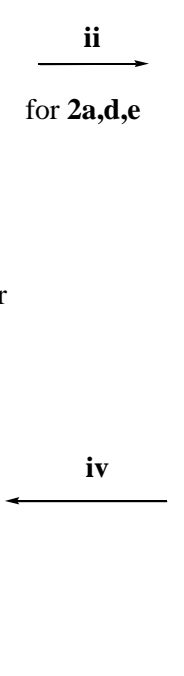<smiles>[R]C(=O)c1c(C)nn(CC(=O)OCC)c(=O)c1N</smiles><smiles>CCCCCCC</smiles><smiles>[R]C(=O)c1c(C)nn(CC(=O)O)c(=O)c1N</smiles>

5a-f<smiles>[R]C(=O)c1c(C)nn(CC(=O)Nc2ccc(Br)cc2)c(=O)c1Nc1cccc(OC)c1</smiles>

6a-f

Reagents and conditions: i) $10 \% \mathrm{Pd} / \mathrm{C}, \mathrm{HCOONH}_{4}$, anhydrous EtOH, reflux, $1 \mathrm{~h}$; ii) ethyl bromoacetate, $\mathrm{K}_{2} \mathrm{CO}_{3}$, anhydrous $\mathrm{CH}_{3} \mathrm{CN}$, reflux, $2 \mathrm{~h}$; iii) $6 \mathrm{~N} \mathrm{NaOH}, \mathrm{EtOH}, 60^{\circ} \mathrm{C}, 1 \mathrm{~h}$; iv) $\mathrm{Et}_{3} \mathrm{~N}$, anhydrous THF, ethyl chloroformate, 4bromoaniline, $-5{ }^{\circ} \mathrm{C}$, rt and then $17.5 \mathrm{~h}$; v) $\mathrm{N}$-(4-bromophenyl)-2-chloroacetamide, $\mathrm{K}_{2} \mathrm{CO}_{3}$, anhydrous $\mathrm{CH}_{3} \mathrm{CN}$, reflux, $2 \mathrm{~h}$; vi) 3-methoxybenzenboronic acid, $\left(\mathrm{CH}_{3} \mathrm{COO}\right)_{2} \mathrm{Cu}, \mathrm{Et}_{3} \mathrm{~N}$, anhydrous $\mathrm{CH}_{2} \mathrm{Cl}_{2}, \mathrm{rt}, 16 \mathrm{~h}$.

Synthetic routes used to obtain the 5-alkyl (11a-d) and 5-vinyl (13) derivatives are shown in Scheme 2. Intermediates 2a-d [25] were converted to the desired final compounds 11a-d through 
the following steps: reduction of the acetyl at C-5 with $\mathrm{NaBH}_{4}$ (compounds 7a-d), dehydratation with polyphosphoric acid (PPA) (8a-d), reduction of the vinyl group with a Parr instrument (9a-d), insertion of the fragment at N-2 (10a-d), and coupling with 3-methoxybenzeneboronic acid (11a-d). To obtain the final compound 13, direct alkylation with $N$-(4-bromophenyl)-2-chloroacetamide [26] on intermediate 8a was performed (compound 12), followed by a coupling reaction with 3methoxybenzenboronic acid.

\section{Scheme 2}<smiles>[R]C(=O)c1c(C)n[nH]c(=O)c1N</smiles>

2a-d

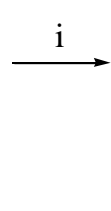<smiles>[Te][Te]=[Te]</smiles><smiles>[R]C(O)c1c(C)n[nH]c(=O)c1N</smiles>

a-d

\begin{tabular}{|l|l|}
\hline $\mathbf{2 , 7}$ & $\mathbf{R}$ \\
\hline $\mathbf{a}$ & $\mathrm{CH}_{3}$ \\
$\mathbf{b}$ & $\mathrm{C}_{2} \mathrm{H}_{5}$ \\
$\mathbf{c}$ & $\mathrm{C}_{3} \mathrm{H}_{7}$ \\
$\mathbf{d}$ & $\mathrm{C}_{4} \mathrm{H}_{9}$ \\
\hline
\end{tabular}<smiles>[R]CCc1c(C)nn(CC(=O)Nc2ccc(Br)cc2)c(=O)c1N</smiles>

10a-d

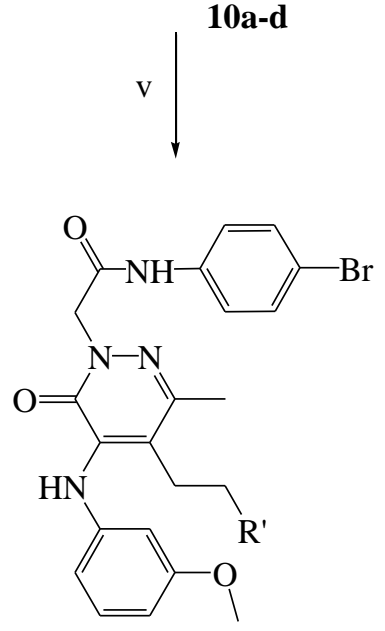

11a-d

\begin{tabular}{|c|l|}
\hline $\mathbf{8 - 1 1}$ & $\mathbf{R}^{\prime}$ \\
\hline $\mathbf{a}$ & $\mathrm{H}$ \\
$\mathbf{b}$ & $\mathrm{CH}_{3}$ \\
$\mathbf{c}$ & $\mathrm{C}_{2} \mathrm{H}_{5}$ \\
$\mathbf{d}$ & $\mathrm{C}_{3} \mathrm{H}_{7}$ \\
& \\
\hline
\end{tabular}<smiles>[R]C=Cc1c(C)n[nH]c(=O)c1N</smiles>

8a-d<smiles></smiles><smiles>[AlH2]</smiles><smiles>[R]CCc1c(C)n[nH]c(=O)c1N</smiles><smiles>C=Cc1c(C)nn(CC(=O)Nc2ccc(Br)cc2)c(=O)c1N</smiles>

12

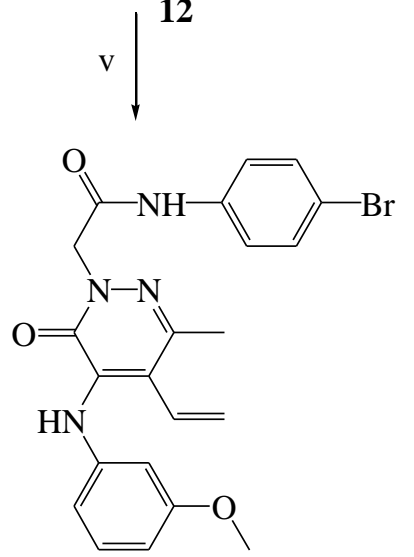

13

Reagents and conditions: i) $\mathrm{NaBH}_{4}, \mathrm{CH}_{3} \mathrm{OH}$, rt, 1 h; ii) PPA, reflux, 5 h; iii) $10 \% \mathrm{Pd} / \mathrm{C}$, anhydrous EtOH, $\mathrm{H}_{2}, \mathrm{Parr}, 30$ PSI, $3 \mathrm{~h}$; iv) $\mathrm{N}$-(4-bromophenyl)-2-chloroacetamide, $\mathrm{K}_{2} \mathrm{CO}_{3}$, anhydrous $\mathrm{CH}_{3} \mathrm{CN}$, reflux, 2-6 h; v) 3methoxybenzenboronic acid, $\left(\mathrm{CH}_{3} \mathrm{COO}\right)_{2} \mathrm{Cu}, \mathrm{Et}_{3} \mathrm{~N}$, anhydrous $\mathrm{CH}_{2} \mathrm{Cl}_{2}, \mathrm{rt}, 16 \mathrm{~h}$. 
Scheme 3 shows the synthetic pathway for compounds 17a-b and 18: intermediate 14 [27] was converted into the pyridazinone $\mathbf{1 5}$ through isoxazole ring cleavage using the appropriate alcohol and a catalytic amount of $\mathrm{Et}_{3} \mathrm{~N}$. Compounds of type $\mathbf{1 5}$ were then transformed into the final 17a,b following the same procedure reported in Schemes 1 and 2. Moreover, basic hydrolysis of the ester led to the final carboxylic derivative $\mathbf{1 8 .}$

\section{Scheme 3}

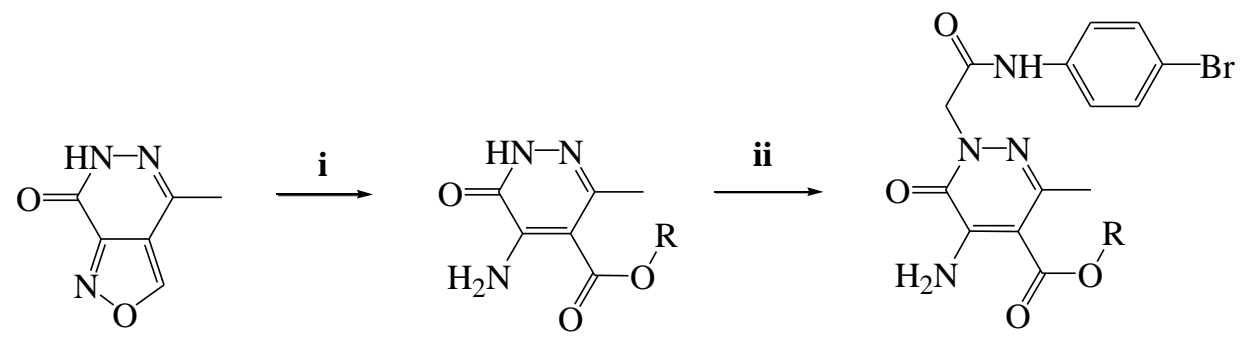

14

$15 \mathbf{a}, \mathbf{b}$

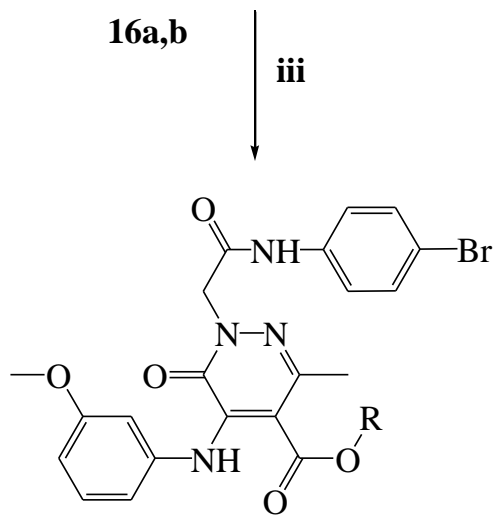

18

\begin{tabular}{|c|l|}
\hline $\mathbf{1 5 - 1 7}$ & $\mathbf{R}$ \\
\hline $\mathbf{a}$ & $\mathrm{CH}_{3}$ \\
$\mathbf{b}$ & $\mathrm{C}_{2} \mathrm{H}_{5}$ \\
\hline
\end{tabular}

17a,b

Reagents and conditions: i) $\mathrm{Et}_{3} \mathrm{~N}, \mathrm{MeOH}$ or $\mathrm{EtOH}, 60{ }^{\circ} \mathrm{C}, 4 \mathrm{~h}$; ii) $\mathrm{N}$-(4-bromophenyl)-2-chloroacetamide, $\mathrm{K}_{2} \mathrm{CO}_{3}$, anhydrous $\mathrm{CH}_{3} \mathrm{CN}$, reflux, 2-4 h; iii) 3-methoxybenzenboronic acid, $\left(\mathrm{CH}_{3} \mathrm{COO}\right)_{2} \mathrm{Cu}, \mathrm{Et} 3 \mathrm{~N}$, anhydrous $\mathrm{CH}_{2} \mathrm{Cl}_{2}, \mathrm{rt}, 16 \mathrm{~h}$; iv) $2 \mathrm{~N} \mathrm{NaOH}, \mathrm{EtOH}, \mathrm{rt}, 1 \mathrm{~h}$.

The pyrazolyl derivatives 25a,b were obtained following the procedures outlined in Scheme 4. Compound 19 [22] was transformed into the intermediated 20, as previously reported, and then was condensed with $N, N$-dimethylformamide dimethyl acetal to obtain derivative 21 . 
Treatment with $\mathrm{Mo}(\mathrm{CO})_{6}$ [28] led to 22. Condensation with hydrazine hydrate gave the C-5 pyrazolyl pyridazinone $\mathbf{2 3}$ which, in turn, was alkylated with iodomethane (compound 24) and coupled with 3-methoxybenzenboronic acid (25a,b).

\section{Scheme 4}

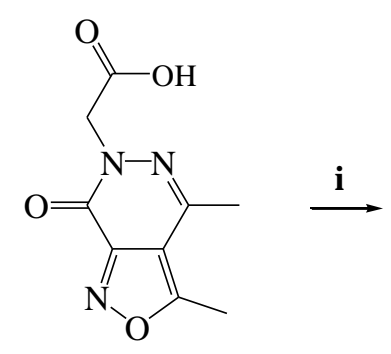

19<smiles>Cc1nn(CC(=O)Nc2ccc(Br)cc2)c(=O)c(N)c1-c1ccn(C)n1</smiles>

24<smiles>Cc1nn(CC(=O)Nc2ccc(Br)cc2)c(=O)c2noc(C)c12</smiles>

20<smiles>Cc1nn(CC(=O)Nc2ccc(Br)cc2)c(=O)c(N)c1-c1cc[nH]n1</smiles><smiles>Cc1nn(CC(=O)Nc2ccc(Br)cc2)c(=O)c2noc(/C=C/N(C)C)c12</smiles>

21 iii<smiles>Cc1nn(CC(=O)Nc2ccc(Br)cc2)c(=O)c(N)c1C(=O)/C=C/N(C)C</smiles>

22<smiles>C#CC</smiles><smiles>COc1ccc(Nc2c(-c3ccn(C)n3)c(C)nn(CC(=O)Nc3ccc(Br)cc3)c2=O)cc1</smiles>

\begin{tabular}{|c|c|}
\hline $\mathbf{2 5}$ & $\mathbf{O C H}_{\mathbf{3}}$ \\
\hline $\mathbf{a}$ & $m$ \\
$\mathbf{b}$ & $p$ \\
\hline
\end{tabular}

25a,b

Reagents and conditions: i) $\mathrm{Et}_{3} \mathrm{~N}$, anhydrous $\mathrm{THF}$, ethyl chloroformate, 4-bromoaniline, $-5^{\circ} \mathrm{C}$ and then $\mathrm{rt}$, $17.5 \mathrm{~h}$; ii) DMF/DMA, $90^{\circ} \mathrm{C}, 3 \mathrm{~h}$; iii) $\mathrm{Mo}(\mathrm{CO})_{6}, \mathrm{H}_{2} \mathrm{O}, \mathrm{CH}_{3} \mathrm{CN}$, reflux, 2h; iv) $\mathrm{N}_{2} \mathrm{H}_{4} \cdot \mathrm{H}_{2} \mathrm{O}$, EtOH, reflux, 3 h; v) $\mathrm{CH}_{3} \mathrm{I}, \mathrm{K}_{2} \mathrm{CO}_{3}$, anhydrous DMF, $90^{\circ} \mathrm{C}, 3 \mathrm{~h}$; vi) 3- or 4-methozybenzenboronic acid, $\left(\mathrm{CH}_{3} \mathrm{COO}\right)_{2} \mathrm{Cu}, \mathrm{Et}_{3} \mathrm{~N}$, anhydrous $\mathrm{CH}_{2} \mathrm{Cl}_{2}, \mathrm{rt}, 16 \mathrm{~h}$. 
Finally Scheme 5 describes the synthetic pathway leading to the final 5-unsubstituted pyridinone and pyridazinone derivatives $\mathbf{2 8 a - b}$, which were obtained starting from appropriate intermediates 26a [29] and 26b [30] following the usual synthetic procedures described in previous schemes.

\section{Scheme 5}

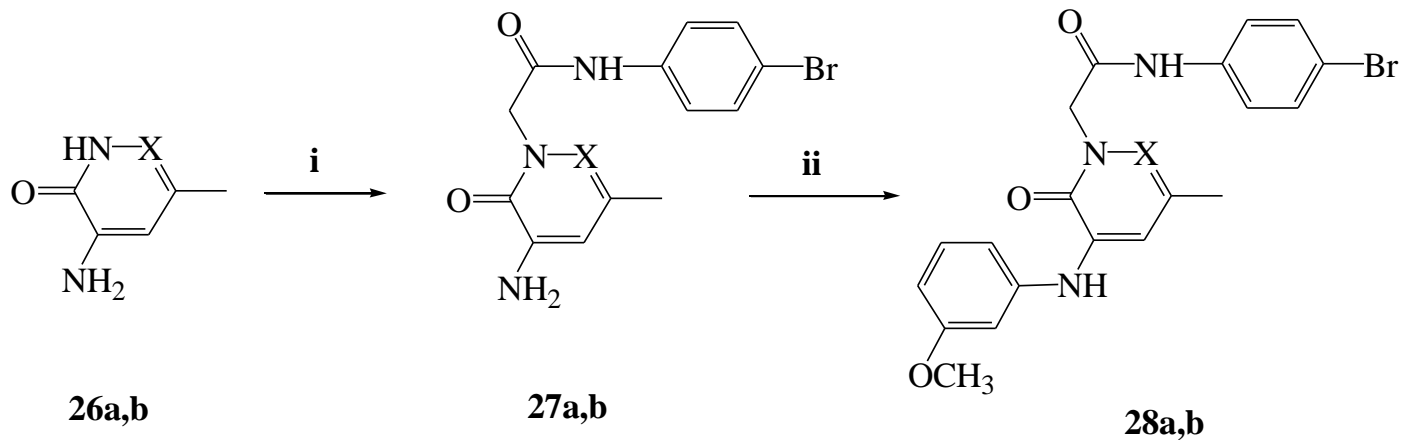

\begin{tabular}{|c|c|}
\hline $\mathbf{2 6 - 2 8}$ & $\mathbf{X}$ \\
\hline $\mathbf{a}$ & $\mathrm{C}$ \\
$\mathbf{b}$ & $\mathrm{N}$ \\
\hline
\end{tabular}

Reagents and conditions: i) N-(4-bromophenyl)-2-chloroacetamide, $\mathrm{K}_{2} \mathrm{CO}_{3}$, anhydrous $\mathrm{CH}_{3} \mathrm{CN}$, reflux, 6 h; ii) 3methoxybenzenboronic acid, $\left(\mathrm{CH}_{3} \mathrm{COO}\right)_{2} \mathrm{Cu}, \mathrm{Et}_{3} \mathrm{~N}$, anhydrous $\mathrm{CH}_{2} \mathrm{Cl}_{2}, \mathrm{rt}, 16 \mathrm{~h}$.

\section{Results and discussion}

\subsection{Biological results}

All new compounds were evaluated for their ability to induce intracellular $\mathrm{Ca}^{2+}$ flux in human HL-60 cells transfected with FPR1, FPR2, or FPR3, and the results are reported as $\mathrm{EC}_{50}$ values in Tables 1-2.

Analysis of compounds substituted with various groups at position 5 (Table 1) demonstrated that several were potent mixed FPR agonists. Among them, the acetyl derivative $8 \mathbf{a}$ was active in the nanomolar range and preferred FPR1 $\left(\mathrm{EC}_{50}=45 \mathrm{nM}\right)$. On the other hand, elongation of the 
aliphatic chain of keto(alkyl) derivatives (compounds 8b-d) was detrimental for FPR agonist activity. Although the butyl analogue 8d was selective for FPR1, it had only moderate activity $\left(\mathrm{EC}_{50}=15.6 \mu \mathrm{M}\right)$. Further modification at position 5, such as the introduction of cyclopentyl and cyclohexyl rings (8e-f), also led to decreased activity.

Replacement of the ketone at C-5 (Table 1) with a pyrazole resulted in two mixed FPR agonists with reasonable agonist activity (27a-b). These two agonists differ only in the position of the methoxy group of the aniline at C-4 (meta for $\mathbf{2 7 a}$ versus para for $\mathbf{2 7 b}$ ). Compound $\mathbf{2 7 b}$ was a potent FPR2 agonist $\left(\mathrm{EC}_{50}=35 \mathrm{nM}\right)$, although it did have some activity at the other two FPR subtypes (FPR2>FPR3>>FPR1). Elimination of the methoxyphenylamino group at C-4 of the pyridazinone (compound 26) led to decreased activity that was comparable to that of the other two 4-amino derivatives $\mathbf{2 4}$ and $\mathbf{2 5}$. Likewise, introduction of methyl or ethyl esters at C-5 of pyridazinone (19a-b) also led to compounds with micromolar activity. On the other hand, introduction of a carboxylic function in the same position (20) led to a slight increase of selectivity toward FPR1 $\left(\mathrm{EC}_{50}=0.6 \mu \mathrm{M}\right)$. Finally, the vinyl derivative 15 exhibited mixed agonist activity for the three FPR isoforms but had a higher preference for FPR1 and FPR2 $\left(\mathrm{EC}_{50}=0.23\right.$ and $0.11 \mu \mathrm{M}$, respectively).

Activities of the 5-alkyl derivatives 13a-d are presented in Table 2. Compound 13a, in which $\mathrm{R}=\mathrm{C}_{2} \mathrm{H}_{5}$, was the most potent of this series. It was active in the nanomolar range toward the three FPR subtypes but had a preference for FPR2 $\left(\mathrm{EC}_{50}=61 \mathrm{nM}\right)$. Elongation of the aliphatic chain was detrimental for activity, resulting in compounds with micromolar $\mathrm{EC}_{50}$ values for FPR1 and FPR2 and no activity at FPR3. Surprisingly, the 5-propyl derivative 13b was completely devoid of activity. This is likely due to the loss of H-bonding between this compound and the receptor (see molecular modeling details below). Furthermore, elimination of the C-5 substituent led to a compound 29a with high nanomolar agonist activity for FPR1 $\left(\mathrm{EC}_{50}=0.24 \mu \mathrm{M}\right)$. Finally, compound 29b exhibited moderate mixed agonist activity for FPR1 and FPR2, but was one order of 
magnitude lower in activity than 29a at FPR1, suggesting that the pyridonic scaffold was less appropriate compared with the pyridazinone scaffold.

Table 1. Activity of C-4 and C-5 substituted pyridazinones 8a-f, 15, 19a-b, 20, 24-26, 27a-b.
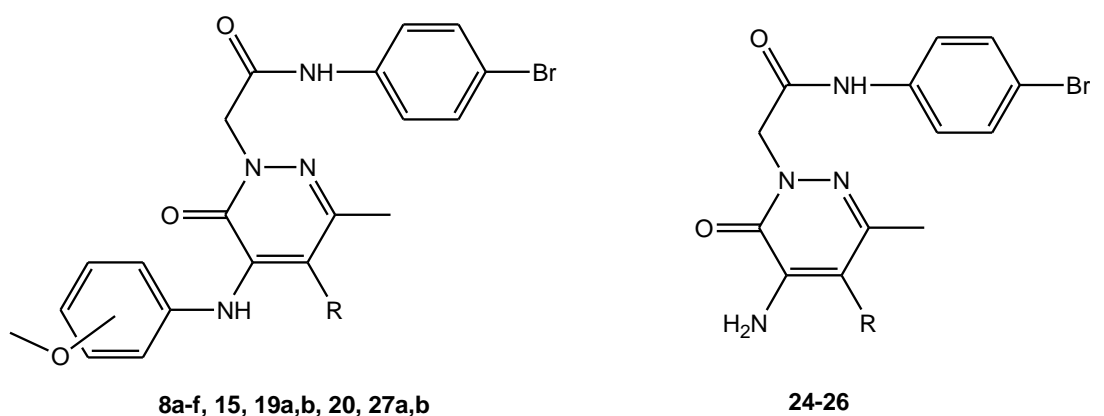

$8 a-f, 15,19 a, b, 20,27 a, b$

24-26

\begin{tabular}{|c|c|c|c|c|c|c|}
\hline Compd & $\mathrm{OCH}_{3}$ & $\mathrm{R}$ & hPMN $^{[a]}$ & FPR1-HL60 ${ }^{[a]}$ & FPR2-HL60 ${ }^{[a]}$ & FPR3-HL60 $0^{[a]}$ \\
\hline $8 \mathbf{a}$ & $\mathrm{m}$ & $\mathrm{COCH}_{3}$ & $\begin{array}{c}0.036 \pm 0.007 \\
(150)\end{array}$ & $\begin{array}{l}0.045 \pm 0.016 \\
(185)\end{array}$ & $\begin{array}{c}0.17 \pm 0.038 \\
(60)\end{array}$ & $\begin{array}{c}0.21 \pm 0.044 \\
(150)\end{array}$ \\
\hline $8 \mathbf{b}$ & $\mathrm{m}$ & $\mathrm{COCH}_{2} \mathrm{CH}_{3}$ & $5.5 \pm 1.6(110)$ & $2.7 \pm 0.8(130)$ & $0.78 \pm 0.1(190)$ & N.A. ${ }^{a}$ \\
\hline $8 c$ & $\mathrm{~m}$ & $\mathrm{CO}\left(\mathrm{CH}_{2}\right)_{2} \mathrm{CH}_{3}$ & $24.0 \pm 4.2(60)$ & $11.8 \pm 3.5(70)$ & $8.1 \pm 2.1(90)$ & N.A. ${ }^{a}$ \\
\hline $8 d$ & $\mathrm{~m}$ & $\mathrm{CO}\left(\mathrm{CH}_{2}\right)_{3} \mathrm{CH}_{3}$ & $8.0 \pm 2.6(90)$ & $15.6 \pm 2.6(45)$ & N.A. ${ }^{a}$ & N.A. ${ }^{a}$ \\
\hline $8 e$ & $\mathrm{~m}$ & $\mathrm{CO} c \mathrm{C}_{5} \mathrm{H}_{9}$ & $1.7 \pm 0.4(110)$ & $1.6 \pm 0.4(110)$ & $10.5 \pm 2.1(60)$ & N.A. ${ }^{a}$ \\
\hline $8 f$ & $\mathrm{~m}$ & $\mathrm{CO} c \mathrm{C}_{6} \mathrm{H}_{11}$ & $28.9 \pm 6.6(120)$ & $10.0 \pm 3.2(110)$ & $8.7 \pm 0.47(115)$ & N.A. ${ }^{a}$ \\
\hline 15 & $\mathrm{~m}$ & $\mathrm{CH}=\mathrm{CH}_{2}$ & $0.84 \pm 0.18(130)$ & $0.23 \pm 0.07(120)$ & $0.11 \pm 0.014$ & $6.0 \pm 2.1(75)$ \\
\hline $19 \mathbf{a}$ & $\mathrm{m}$ & $\mathrm{COOCH}_{3}$ & $22.1 \pm 5.3(25)$ & $4.4 \pm 0.6(25)$ & $2.3 \pm 0.49(60)$ & N.A. ${ }^{a}$ \\
\hline $19 b$ & $\mathrm{~m}$ & $\mathrm{COOCH}_{2} \mathrm{CH}_{3}$ & $6.1 \pm 1.7(95)$ & $2.5 \pm 0.7(90)$ & $1.9 \pm 0.03(110)$ & N.A. ${ }^{a}$ \\
\hline 20 & $\mathrm{~m}$ & $\mathrm{COOH}$ & $1.5 \pm 0.5(155)$ & $0.6 \pm 0.1(130)$ & $3.1 \pm 0.78(115)$ & $17.1 \pm 4.3(75)$ \\
\hline 24 & - & $\operatorname{COCHCHN}\left(\mathrm{CH}_{3}\right)_{2}$ & $9.3 \pm 2.3(105)$ & $5.1 \pm 1.7(120)$ & $5.7 \pm 2.3(50)$ & N.A. ${ }^{a}$ \\
\hline 25 & - & pyrazole & $11.8 \pm 2.4(140)$ & $8.4 \pm 1.5(135)$ & $13.5 \pm 1.8(60)$ & N.A. ${ }^{a}$ \\
\hline 26 & - & 1-methylpyrazole & $3.5 \pm 0.32(60)$ & $2.9 \pm 0.14(75)$ & $1.9 \pm 0.71(40)$ & N.A. \\
\hline $27 a$ & $\mathrm{~m}$ & 1-methylpyrazole & $0.59 \pm 0.21$ & $3.6 \pm 0.28$ & $0.59 \pm 0.18(90)$ & N.A. ${ }^{a}$ \\
\hline $27 \mathrm{~b}$ & $\mathrm{p}$ & 1-methylpyrazole & $0.30 \pm 0.044(130)$ & $4.0 \pm 0.89(115)$ & $0.035 \pm 0.1(120)$ & $0.67 \pm 0.22(110)$ \\
\hline
\end{tabular}

${ }^{[a]}$ Values, expressed as $\mathrm{EC}_{50}(\mu \mathrm{M})$ and Efficacy (\% in brackets) were evaluated in a $\mathrm{Ca}^{2+}$ flux assay. $\mathrm{EC}_{50}$ values represent the average mean of three independent experiments and were determined by nonlinear regression analysis of the concentration-response curves (5-6 points) generated using GraphPad Prism 5 with 95\% confidential interval ( $\mathrm{p}<$ 0.05). Efficacy (in brackets) is expressed as $\%$ of the response induced by $5 \mathrm{nM} f \mathrm{MLF}$ in human polymorphonuclear neutrophils (hPMN) and FPR1-HL60 cells or by $5 \mathrm{nM}$ WKYMVm in FPR2-HL60 and FPR3-HL60 cells. ${ }^{[b]}$ N.A., no activity (no response was observed during first 2 min after addition of compounds under investigation) considering the limits of efficacy $<20 \%$ and $\mathrm{EC}_{50}<50 \mu \mathrm{M}$. 
Table 2. Activity of C-4 and C-5 substituted pyridazinones 13a-d and 29a-b.

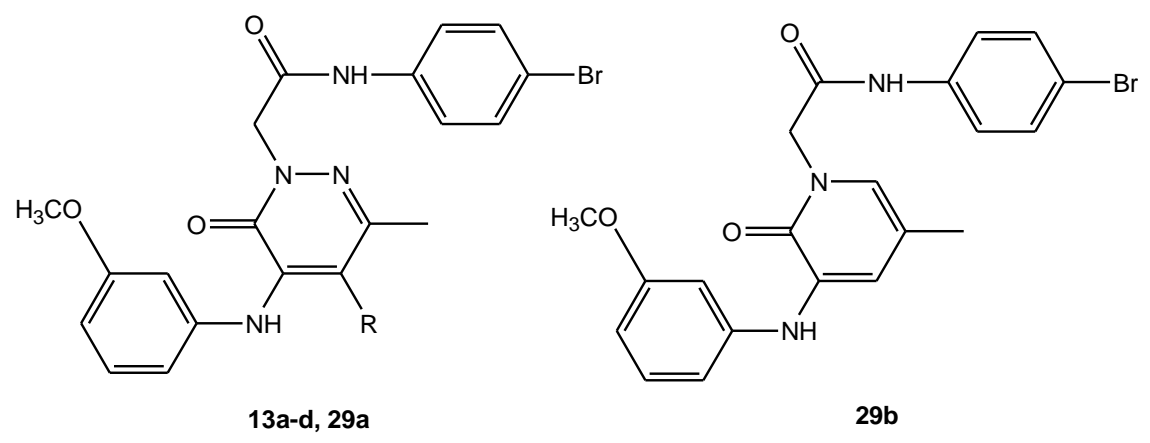

\begin{tabular}{|cccccc|}
\hline Compd & $\mathrm{R}$ & hPMN $^{[\mathrm{a}]}$ & FPR1-HL60 $^{[\mathrm{a}]}$ & FPR2-HL60 $^{[\mathrm{a}]}$ & FPR3-HL60 $^{[\mathrm{a}]}$ \\
\hline 13a & $\mathrm{CH}_{2} \mathrm{CH}_{3}$ & $0.34 \pm 0.11(115)$ & $0.18 \pm 0.004(185)$ & $0.061 \pm 0.022(35)$ & $0.46 \pm 0.014(35)$ \\
13b & $\mathrm{CH}_{2} \mathrm{CH}_{2} \mathrm{CH}_{3}$ & N.A. & N.A. & N.A. & N.A. \\
13c & $\left(\mathrm{CH}_{2}\right)_{3} \mathrm{CH}_{3}$ & $1.40 \pm 0.8(45)$ & $3.6 \pm 1.1(65)$ & $4.5 \pm 1.3(30)$ & N.A. \\
13d & $\left(\mathrm{CH}_{2}\right)_{4} \mathrm{CH}_{3}$ & $5.70 \pm 1.2(55)$ & $1.4 \pm 0.34(95)$ & $0.19 \pm 0.018(115)$ & N.A. \\
29a & $\mathrm{H}$ & $0.56 \pm 0.12(85)$ & $0.24 \pm 0.09(120)$ & $9.6 \pm 2.0(65)$ & N.A. \\
29b & - & $4.31 \pm 0.4(60)$ & $2.50 \pm 0.7(110)$ & $8.10 \pm 1.7(75)$ & N.A. \\
\hline
\end{tabular}

${ }^{[a]}$ Values, expressed as $\mathrm{EC}_{50}(\mu \mathrm{M})$ and Efficacy (\% in brackets) were evaluated in $\mathrm{Ca}^{2+}$ flux assay. $\mathrm{EC}_{50}$ values represent the average mean of three independent experiments and were determined by nonlinear regression analysis of the concentration-response curves (5-6 points) generated using GraphPad Prism 5 with $95 \%$ confidential interval ( $\mathrm{p}<0.05$ ). Efficacy (in brackets) is expressed as $\%$ of the response induced by 5 $\mathrm{nM} f$ MLF in human polymorphonuclear neutrophils (hPMN) and FPR1-HL60 cells or by $5 \mathrm{nM}$ WKYMVm in FPR2-HL60 and FPR3-HL60 cells. ${ }^{[\mathrm{b}]}$ N.A., no activity (no response was observed during first 2 min after addition of compounds under investigation) considering the limits of efficacy $<20 \%$ and $\mathrm{EC}_{50}<50 \mu \mathrm{M}$.

The most active derivatives (8a, 15 and $\mathbf{2 7 a - b}$ ) were also evaluated for chemoattractant activity in human neutrophils. As expected for FPR agonists, all four compounds had chemoattractant activity and induced this response in the micromolar range (Table 3).

Table 3. Chemoattractant activity of selected pyridazinones in human neutrophils

\begin{tabular}{|cc|}
\hline Compd & $\begin{array}{c}\mathrm{EC}_{50}(\mu \mathrm{M})^{[\mathrm{a}]} \text { in } \\
\text { migration assay }\end{array}$ \\
\hline $\mathbf{8 a}$ & $2.2 \pm 0.51$ \\
$\mathbf{1 5}$ & $1.2 \pm 0.24$ \\
$\mathbf{2 7 a}$ & $1.1 \pm 0.22$ \\
$\mathbf{2 7 b}$ & $0.45 \pm 0.17$ \\
\hline
\end{tabular}

${ }^{[a]}$ The data are presented as the mean \pm SD of three independent experiments with cells from different donors, in which median effective concentration values $\left(\mathrm{EC}_{50}\right)$ were determined by nonlinear regression analysis of the concentrationresponse curves (5-6 points) generated using GraphPad Prism 5 with 95\% confidential interval $(\mathrm{p}<0.05)$.

Some of the synthesized compounds were also evaluated for their ability to induce intracellular $\mathrm{Ca}^{2+}$ flux in mouse neutrophils and RBL cells transfected with Fpr1 or Fpr2 (Table 4). 
Although all compounds tested were active in human neutrophils, only eight of these compounds activated $\mathrm{Ca}^{2+}$ flux in mouse neutrophils. Of these, three compounds were also agonists for mouse Fpr1, mouse Fpr2, or both. The reason for this species-specific difference in activity is currently not understood; however, we and other group have observed quite different response patterns to some agonists and/or antagonists in human and mouse neutrophils [14].

Table 4. Activity of pyridazinones in mouse neutrophils and mouse Fpr-transfected RBL cells.

\begin{tabular}{|c|c|c|c|}
\hline Compd & $\mathrm{mPMN}^{[\mathrm{a}]}$ & mFpr1-RBL ${ }^{[\mathrm{a}]}$ & mFpr2-RBL ${ }^{[a]}$ \\
\hline $8 \mathbf{a}$ & N.A. ${ }^{[b]}$ & N.A. $^{[b]}$ & N.A. $^{[b]}$ \\
\hline $8 b$ & $8.4 \pm 2.6(75)$ & N.A. ${ }^{[b]}$ & N.A. ${ }^{[b]}$ \\
\hline $8 c$ & N.A. ${ }^{[b]}$ & N.A. ${ }^{[b]}$ & N.A. ${ }^{[b]}$ \\
\hline 8d & $24.1 \pm 6.1(105)$ & N.A. ${ }^{[b]}$ & N.A. ${ }^{[b]}$ \\
\hline $8 \mathbf{e}$ & $15.9 \pm 4.9(120)$ & N.A. ${ }^{[b]}$ & N.A. ${ }^{[b]}$ \\
\hline $8 f$ & N.A. ${ }^{[b]}$ & N.A. ${ }^{[b]}$ & N.A. ${ }^{[b]}$ \\
\hline 15 & $22.8 \pm 6.4(30)$ & N.A. ${ }^{[b]}$ & N.A. ${ }^{[b]}$ \\
\hline $19 \mathbf{a}$ & N.A. ${ }^{[b]}$ & N.A. ${ }^{[b]}$ & N.A. ${ }^{[b]}$ \\
\hline 19b & N.A. ${ }^{[b]}$ & N.A. ${ }^{[b]}$ & N.A. ${ }^{[b]}$ \\
\hline 20 & $1.0 \pm 0.34(100)$ & $4.7 \pm 1.3(50)$ & N.A. ${ }^{[b]}$ \\
\hline 24 & $13.5 \pm 3.7(50)$ & $6.7 \pm 2.1(55)$ & $9.4 \pm 2.7(65)$ \\
\hline 25 & N.A. ${ }^{[b]}$ & N.A. ${ }^{[b]}$ & N.A. ${ }^{[b]}$ \\
\hline 26 & $5.6 \pm 2.4(45)$ & N.A. ${ }^{[b]}$ & N.A. ${ }^{[b]}$ \\
\hline $27 a$ & N.A. ${ }^{[b]}$ & N.A. ${ }^{[b]}$ & N.A. ${ }^{[b]}$ \\
\hline $27 b$ & $6.0 \pm 1.9(80)$ & $18.5 \pm 4.1(25)$ & $18.3 \pm 3.8(35)$ \\
\hline
\end{tabular}

${ }^{[a]} T_{\text {The }} \mathrm{EC}_{50}(\mu \mathrm{M})$ and Efficacy (\% in brackets) were evaluated in $\mathrm{Ca}^{2+}$ flux assay. Values are expressed $\mathrm{EC}_{50}$ presented as the average mean of three independent experiments, in which $\mathrm{EC}_{50}$ values were determined by nonlinear regression analysis of the concentration-response curves (5-6 points) generated using GraphPad Prism 5 with 95\% confidential interval ( $\mathrm{p}$ 0.05). Efficacy (in brackets) is expressed as \% of the response induced by $5 \mathrm{nM}$ WKYMVm in mouse polymorphonuclear neutrophils (mPMN) or RBL cells transfected with mouse Fpr1 (mFpr1-RBL) or Fpr2 (mFpr2RBL). ${ }^{[b]}$ N.A., no activity (no response was observed during first 2 min after addition of compounds under investigation) considering the limits of efficacy $<20 \%$ and $\mathrm{EC}_{50}<50 \mu \mathrm{M}$.

\subsection{Molecular docking studies}

Our data suggest that larger substituents at position 5 may cause steric hindrance and that the optimal length of this group was two carbon atoms. To evaluate the role of steric hindrance from bulky acyl groups, we performed molecular docking of compounds $\mathbf{8 a}$ and $\mathbf{8 e}$ into the binding site of an FPR1 homology model and compounds 13a-c into the binding site of an FPR2 homology model. With each of these pairs, the compounds differ in size of acyl or alkyl groups at position 5 of the pyridazine heterocycle. 
As shown in Figure 2A, the best docking pose of 8a occupies areas of FPR1 characteristic of other FPR1 agonists [31]. For example, the $p$-bromo substituted aromatic ring of 8a is positioned near channel A, and the acetyl group enters cavity $\mathbf{B}$ (receptor regions designated as previously reported [31]). Additionally, strong H-bonds form between the carbonyl oxygen and anilide nitrogen atoms of $\mathbf{8 a}$ and Thr265 of FPR1, whereas a weaker H-bond is formed between the methoxy substituent and Arg205 (Figure 2B). These interactions may contribute to the agonist activity of compound 8a. Close contact of the acetyl group in 8a and FPR1 Leu198 was observed for the calculated ligand-receptor complex (Figure 2B), and the shortest interatomic distance between the acetyl oxygen and hydrogen atom of Leu198 located at the wall of cavity $\mathbf{C}$ was $\sim 2.7$ $\AA$, indicating close proximity of the agonist $\mathbf{8 a}$ and the receptor. Thus, a larger acyl group at position 5 of the heterocycle would be expected to hinder ligand orientation similar to $\mathbf{8 a}$. Indeed, the lowest-energy pose of compound 8e had a very different arrangement within the FPR1 binding site. The bulky cyclopentyl substituent prevented positioning the molecule near cavity $\mathbf{B}$, such that 8e leans toward hole $\mathbf{C}$ of FPR1 (Figure 2A). This difference in binding explains the decreased agonist activity for $\mathbf{8 e}$ and its analogs with large acyl groups. 


\section{Figure 2}
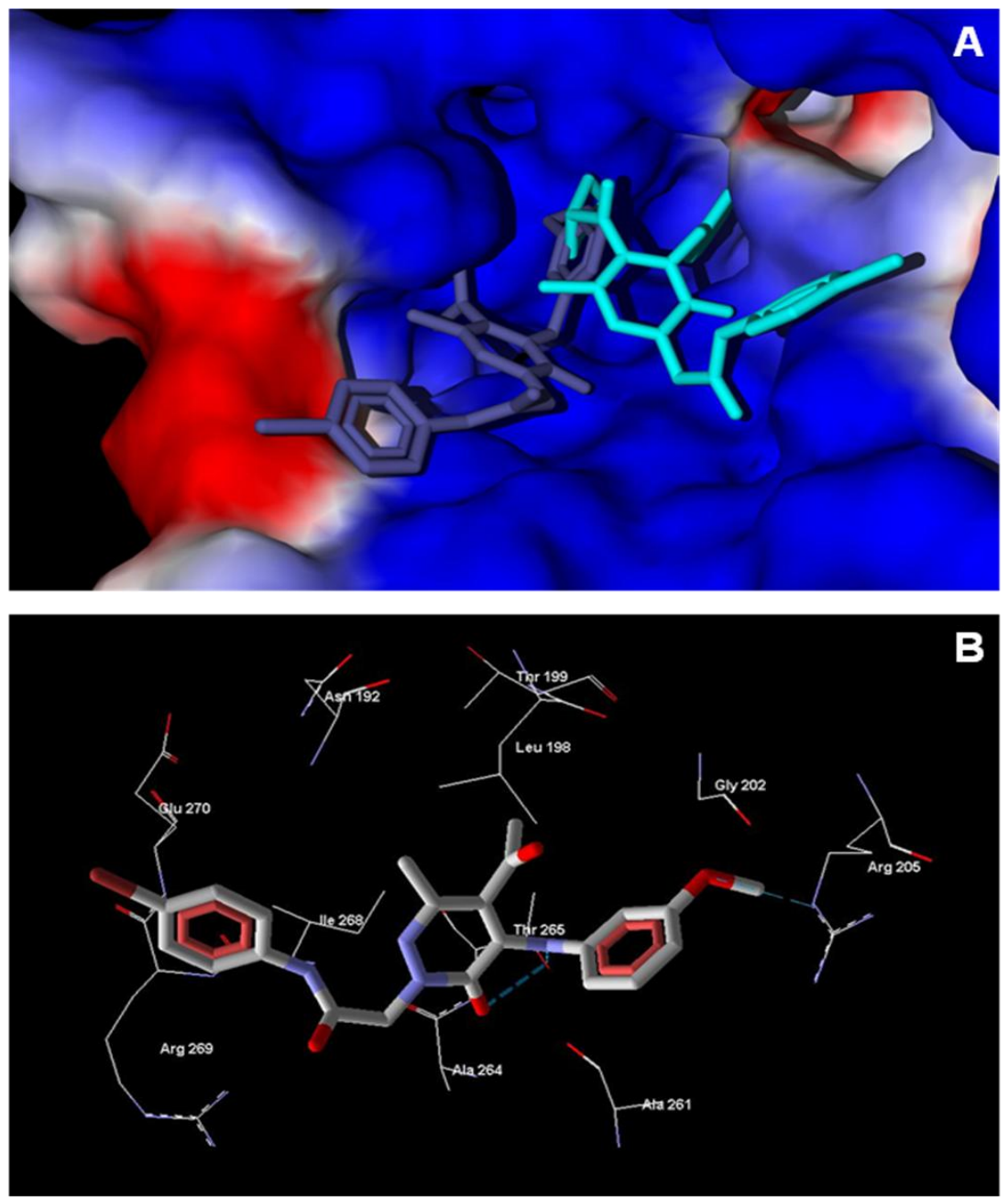

A homology model of FPR2 was similarly used to perform molecular docking with 13a-c.

These molecules have quite subtle differences in structure and are oriented in the binding site with brominated benzene rings directed deep into the binding site (Figure 3A). This orientation of the $p$ bromophenyl moiety is analogous to that observed previously for parent compounds [20]. Agonist 13a with an ethyl substituent at position 5 of the pyridazine ring is H-bonded with Thr177, while the $m$-methoxyphenyl substituent occupies a hydrophobic subpocket surrounded by Ala181, Gly264, Leu268, Tyr277, and Ile279 (Figure 3B). Changing the alkyl substituent from ethyl to $n$ butyl in compound 13c led to flipping of the molecule so that the butyl chain of this ligand was now located in the hydrophobic subpocket, while the $m$-methoxyphenyl group formed an H-bond with Asn171 (Figure 3C). For 13b, a flipped pose similar to 13c was obtained. However, the substituted 
pyridazine 13b did not form H-bonds with the receptor, which likely led to decreased affinity of the propyl derivative and complete lack of biological activity (see Table 2).

Figure 3
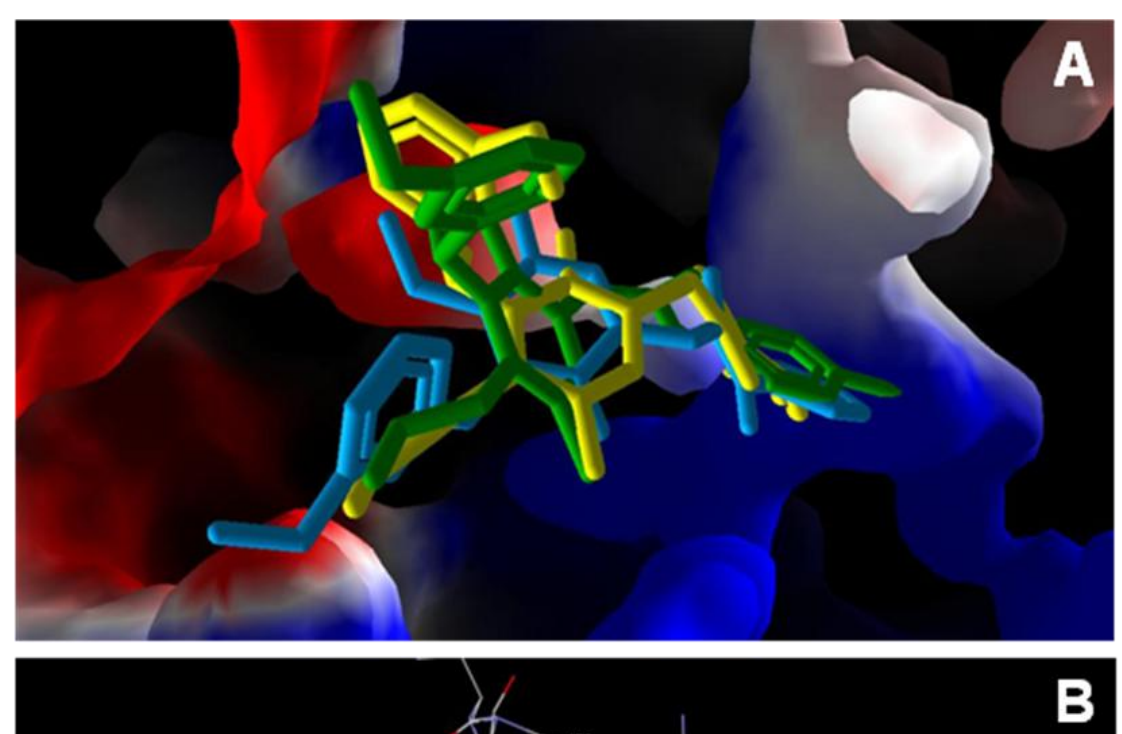

$\mathbf{B}$
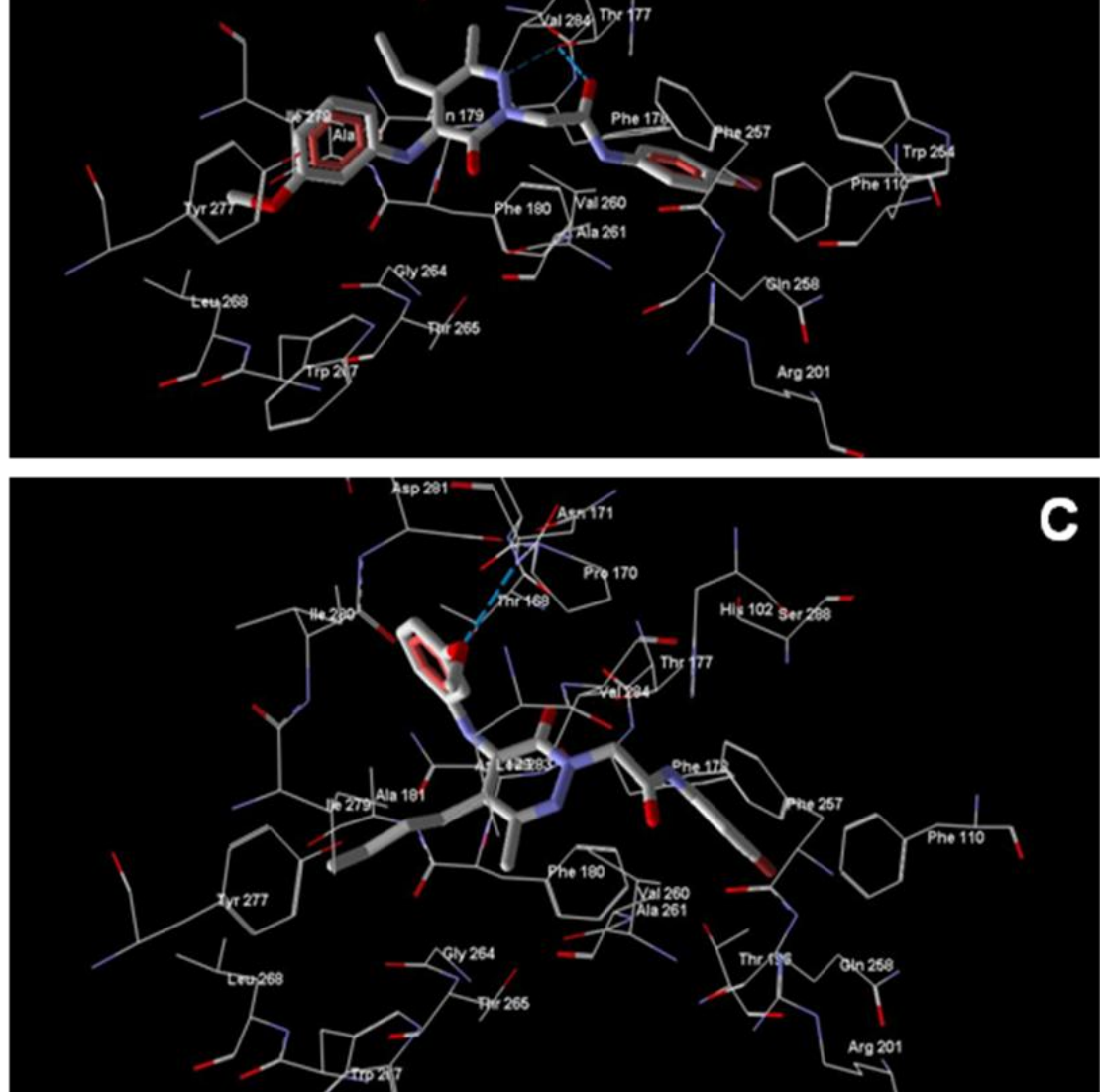
Thus, larger substituents in position 5 of the pyridazine heterocycle cause steric effects on the binding modes of the ligands in the FPR1 and FPR2 binding sites, which is consistent with their reduced or lost agonist activity.

\section{Conclusions}

We describe the synthesis of new series of C-5 substituted 2-arylacetamide pyridazin-3(2H)ones that exhibit improved potency and selectivity toward FPR isoforms. Biological analysis of these compounds confirmed the suitability of pyridazinone-based compounds as a relevant system to develop novel human FPR agonists. Indeed, the majority of compounds described herein were mixed FPR agonists, with compounds $\mathbf{8 a}$ and $\mathbf{2 7} \mathbf{b}$ being the most potent $\left(\mathrm{EC}_{50}\right.$ values in the nanomolar range). Overall, we show that modification of position C-5 of the pyridazinone ring in 2-arylacetamide pyridazin-3(2H)-ones represents an effective approach for the development of active FPR agonists. These compounds represent valuable tools for studying FPR activation and signaling in inflammatory conditions.

\section{Experimental section}

\subsection{Chemistry}

Reagents and starting materials were obtained from commercial sources. Extracts were dried over $\mathrm{Na}_{2} \mathrm{SO}_{4}$, and the solvents were removed under reduced pressure. All reactions were monitored by thin layer chromatography (TLC) using commercial plates precoated with Merck silica gel 60 F254. Visualization was performed by UV fluorescence $\left(\lambda_{\max }=254 \mathrm{~nm}\right)$ or by staining with iodine or potassium permanganate. Chromatographic separations were performed on a silica gel column using gravity chromatography (Kieselgel 40, 0.063-0.200 mm; Merck), flash chromatography (Kieselgel 40, 0.040-0.063 mm; Merck), or silica gel preparative TLC (Kieselgel $60 \mathrm{~F}_{254}, 20$ x $20 \mathrm{~cm}, 2 \mathrm{~mm}$ ). Yields refer to chromatographically and spectroscopically pure compounds, unless otherwise stated. 
Compounds were named following IUPAC rules, as applied by Beilstein-Institut AutoNom 2000 (4.01.305) or CA Index Name. All melting points were determined on a microscope hot stage Büchi apparatus and are uncorrected. The identity and purity of intermediates and final compounds were determined through NMR analysis and TLC chromatography. ${ }^{1} \mathrm{H}$ NMR, ${ }^{13} \mathrm{C}$ NMR and NOESY spectra were recorded with Avance 400 instruments (Bruker Biospin Version 002 with SGU).

Chemical shifts $(\delta)$ are reported in ppm to the nearest $0.01 \mathrm{ppm}$ (for ${ }^{1} \mathrm{H}$ NMR) or $0.1 \mathrm{ppm}$ (for ${ }^{13} \mathrm{C}$ NMR), using the solvent as an internal standard. Coupling constants ( $J$ values) of ${ }^{1} \mathrm{H}$ NMR are given in $\mathrm{Hz}$ and were calculated using 'TopSpin 1.3' software rounded to the nearest $0.1 \mathrm{~Hz}$. Microanalyses were performed with a Perkin-Elmer 260 elemental analyzer for $\mathrm{C}, \mathrm{H}$, and $\mathrm{N}$, and the results were within $\pm 0.4 \%$ of the theoretical values, unless otherwise stated.

\subsubsection{General procedures for $2 \mathrm{e}$ and $2 \mathrm{f}$}

Ammonium formate $(3.11 \mathrm{mmol})$ and $10 \% \mathrm{Pd} / \mathrm{C}(0.05 \mathrm{mmol})$ were added to a solution of the appropriate intermediate 1e and $\mathbf{1 f}$ [22-24] $(1.04 \mathrm{mmol})$ in $5 \mathrm{~mL}$ of anhydrous $\mathrm{EtOH}$, and the reaction was refluxed for $1 \mathrm{~h}$. After cooling, $20 \mathrm{~mL}$ of $\mathrm{CH}_{2} \mathrm{Cl}_{2}$ were added to the mixture, and the precipitate was removed by filtration under vacuum. The organic layer was then evaporated, and the

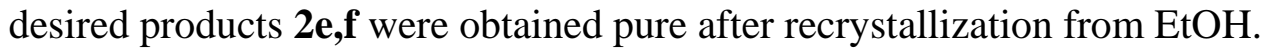

5.1.1.1. 4-Amino-5-cyclopentanecarbonyl-6-methylpyridazin-3(2H)-one, $2 \mathrm{e}$. Yield $=98 \% ; \mathrm{mp}=$ $225-227{ }^{\circ} \mathrm{C}(\mathrm{EtOH}) .{ }^{1} \mathrm{H}-\mathrm{NMR}\left(\mathrm{CDCl}_{3}\right) \delta 1.62-1.72\left(\mathrm{~m}, 2 \mathrm{H}, \mathrm{cC}_{5} \mathrm{H}_{9}\right) ; 1.73-1.81\left(\mathrm{~m}, 2 \mathrm{H}, \mathrm{cC}_{5} \mathrm{H}_{9}\right) ; 1.83-$ $1.89\left(\mathrm{~m}, 4 \mathrm{H}, \mathrm{cC}_{5} \mathrm{H}_{9}\right) ; 2.45\left(\mathrm{~s}, 3 \mathrm{H}, \mathrm{CH}_{3}\right) ; 3.44$ (quin, $\left.1 \mathrm{H}, \mathrm{cC}_{5} \mathrm{H}_{9}, J=7.6 \mathrm{~Hz}\right) ; 6.76($ exch br s, $2 \mathrm{H}$, $\mathrm{NH}_{2}$ ); 7.98 (exch br s, $\left.1 \mathrm{H}, \mathrm{NH}\right)$. Anal. Calcd for $\mathrm{C}_{11} \mathrm{H}_{15} \mathrm{~N}_{3} \mathrm{O}_{2}$ (221.26): C, 59.71; H, 6.83; N, 18.99; Found: C, 59.52; H, 6.84; N, 18.95.

5.1.1.2. 4-Amino-5-cyclohexanecarbonyl-6-methylpyridazin-3(2H)-one, $2 \mathrm{f}$. Yield $=96 \% ; \mathrm{mp}=$ 232-234 ${ }^{\circ} \mathrm{C}(\mathrm{EtOH}) .{ }^{1} \mathrm{H}-\mathrm{NMR}\left(\mathrm{CDCl}_{3}\right) \delta 1.20-1.40\left(\mathrm{~m}, 2 \mathrm{H}, \mathrm{cC}_{6} \mathrm{H}_{11}\right) ; 1.40-1.60\left(\mathrm{~m}, 2 \mathrm{H}, \mathrm{cC}_{6} \mathrm{H}_{11}\right)$; 1.60-1.80 (m, $\left.2 \mathrm{H}, \mathrm{cC}_{6} \mathrm{H}_{11}\right) ; 1.80-1.90\left(\mathrm{~m}, 4 \mathrm{H}, \mathrm{cC}_{6} \mathrm{H}_{11}\right) ; 2.53\left(\mathrm{~s}, 3 \mathrm{H}, \mathrm{CH}_{3}\right) ; 2.90-2.93(\mathrm{~m}, 1 \mathrm{H}$, 
$\mathrm{cC}_{6} \mathrm{H}_{11}$ ); ); 7.21 (exch br s, $2 \mathrm{H}, \mathrm{NH}_{2}$ ); 8.56 (exch br s, $1 \mathrm{H}, \mathrm{NH}$ ). Anal. Calcd for $\mathrm{C}_{12} \mathrm{H}_{17} \mathrm{~N}_{3} \mathrm{O}_{2}$ (235.28): C, 61.26; H, 7.28; N, 17.86; Found: C, 61.11; H, 7.27; N, 17.89.

\subsubsection{General procedures for $3 d$ and $3 e$}

To a solution of the appropriate substrate $2 \mathbf{d}[25]$ and $\mathbf{2 e}(1.60 \mathrm{mmol})$ in anhydrous $\mathrm{CH}_{3} \mathrm{CN}$ $(5 \mathrm{~mL}), \mathrm{K}_{2} \mathrm{CO}_{3}(3.20 \mathrm{mmol})$ and ethyl bromoacetate $(2.40 \mathrm{~mol})$ were added. The solution was stirred for 2-3 h at reflux, and the solvent was evaporated. The residue was mixed with ice-cold water $(10 \mathrm{~mL})$ and the precipitate was recovered by suction and recrystallized from ethanol (compound 3d); alternatively, for compound 3e, the suspension was extracted with $\mathrm{CH}_{2} \mathrm{Cl}_{2}(3 \times 15$ $\mathrm{mL}$ ) and the organic layer was dried over $\mathrm{Na}_{2} \mathrm{SO}_{4}$ and evaporated in vacuo. Finally, $3 \mathrm{e}$ was purified by column flash chromatography using cyclohexane/ethyl acetate 1:1 as eluent.

5.1.2.1. (5-Amino-3-methyl-6-oxo-4-pentanoylpyridazin-1(6H)-yl)acetic acid ethyl ester, $3 d$. Yield $=97 \% ; \mathrm{mp}=92-94{ }^{\circ} \mathrm{C}(\mathrm{EtOH}) .{ }^{1} \mathrm{H}-\mathrm{NMR}\left(\mathrm{CDCl}_{3}\right) \delta 0.94\left(\mathrm{t}, 3 \mathrm{H}, \mathrm{CH}_{2} \mathrm{CH}_{2} \mathrm{CH}_{3}, \mathrm{~J}=7.2 \mathrm{~Hz}\right)$; 1.29 (t, 3H, $\mathrm{OCH}_{2} \mathrm{CH}_{3}, J=7.2 \mathrm{~Hz}$ ); 1.36 (sext, $2 \mathrm{H}, \mathrm{CH}_{2} \mathrm{CH}_{2} \mathrm{CH}_{3}, J=7.2 \mathrm{~Hz}$ ); 1.68 (quin, 2H, $\left.\mathrm{COCH}_{2} \mathrm{CH}_{2}, J=7.2 \mathrm{~Hz}\right) ; 2.48\left(\mathrm{~s}, 3 \mathrm{H}, \mathrm{N}=\mathrm{CCH}_{3}\right) ; 2.82\left(\mathrm{t}, 2 \mathrm{H}, \mathrm{COCH}_{2} \mathrm{CH}_{2}, J=7.2 \mathrm{~Hz}\right) ; 4.24(\mathrm{q}, 2 \mathrm{H}$, $\mathrm{OCH}_{2} \mathrm{CH}_{3}, J=7.2 \mathrm{~Hz}$ ); $4.81\left(\mathrm{~s}, 2 \mathrm{H}, \mathrm{NCH}_{2}\right) ; 8.89$ (exch br s, $2 \mathrm{H}, \mathrm{NH}_{2}$ ). Anal. Calcd for $\mathrm{C}_{14} \mathrm{H}_{21} \mathrm{~N}_{3} \mathrm{O}_{4}$ (295.33): C, 56.94; H, 7.17; N, 14.23; Found: C, 57.08; H, 7.16; N, 14.27.

\subsubsection{2. (5-Amino-4-cyclopentanecarbonyl-3-methyl-6-oxopyridazin-1(6H)-yl)acetic acid ethyl}

ester, 3e. Yield $=64 \% ; \mathrm{mp}=83-85{ }^{\circ} \mathrm{C}(\mathrm{EtOH}) .{ }^{1} \mathrm{H}-\mathrm{NMR}\left(\mathrm{CDCl}_{3}\right) \delta 1.29\left(\mathrm{t}, 3 \mathrm{H}, \mathrm{CH}_{2} \mathrm{CH}_{3}, J=7.2\right.$ $\mathrm{Hz}) ; 1.61-1.65\left(\mathrm{~m}, 2 \mathrm{H}, \mathrm{cC}_{5} \mathrm{H}_{9}\right) ; 1.74-1.79\left(\mathrm{~m}, 2 \mathrm{H}, \mathrm{cC}_{5} \mathrm{H}_{9}\right) ; 1.80-1.89\left(\mathrm{~m}, 4 \mathrm{H}, \mathrm{cC}_{5} \mathrm{H}_{9}\right) ; 2.43(\mathrm{~s}, 3 \mathrm{H}$, $\left.\mathrm{N}=\mathrm{CCH}_{3}\right) ; 3.45\left(\mathrm{~m}, 1 \mathrm{H}, \mathrm{cC}_{5} \mathrm{H}_{9}\right) ; 4.24\left(\mathrm{q}, 2 \mathrm{H}, \mathrm{CH}_{2} \mathrm{CH}_{3}, J=7.2 \mathrm{~Hz}\right) ; 4.81\left(\mathrm{~s}, 2 \mathrm{H}, \mathrm{NCH}_{2}\right) ; 6.87(\mathrm{exch}$ br s, $2 \mathrm{H}, \mathrm{NH}_{2}$ ). Anal. Calcd for $\mathrm{C}_{15} \mathrm{H}_{21} \mathrm{~N}_{3} \mathrm{O}_{4}$ (307.34): C, 58.62; H, 6.89; N, 13.67; Found: C, 58.47; $\mathrm{H}, 6.88 ; \mathrm{N}, 13.71$.

\subsubsection{General procedures for $4 \mathrm{~d}$ and $4 \mathrm{e}$}

To a solution of the suitable ester $3 \mathbf{d}$ and $3 \mathbf{e}(0.49-0.58 \mathrm{mmol})$ in $96 \% \mathrm{EtOH}(5 \mathrm{~mL}), 6 \mathrm{~N}$ $\mathrm{NaOH}(3 \mathrm{~mL})$ was added. The reaction was carried out at $60^{\circ} \mathrm{C}$ for $1-2 \mathrm{~h}$. After evaporation of the solvent, the mixture was diluted with ice-cold water, acidified with $6 \mathrm{~N} \mathrm{HCl}$, and extracted with 
$\mathrm{CH}_{2} \mathrm{Cl}_{2}(3 \times 15 \mathrm{~mL})$. The organic layer was dried over $\mathrm{Na}_{2} \mathrm{SO}_{4}$ and evaporated in vacuo to give desired final compounds, which were purified by crystallization from ethanol.

5.1.3.1. (5-Amino-3-methyl-6-oxo-4-pentanoylpyridazin-1(6H)-yl)acetic acid, 4d. Yield = 98\%; $\mathrm{mp}=97-99{ }^{\circ} \mathrm{C}(\mathrm{EtOH}) .{ }^{1} \mathrm{H}-\mathrm{NMR}\left(\mathrm{CDCl}_{3}\right) \delta 0.93\left(\mathrm{t}, 3 \mathrm{H}, \mathrm{CH}_{2} \mathrm{CH}_{3}, J=7.2 \mathrm{~Hz}\right) ; 1.36(\mathrm{sext}, 2 \mathrm{H}$, $\mathrm{CH}_{2} \mathrm{CH}_{3}, J=7.2 \mathrm{~Hz}$ ); 1.66 (quin, $2 \mathrm{H}, \mathrm{COCH}_{2} \mathrm{CH}_{2}, J=7.2 \mathrm{~Hz}$ ); $2.48\left(\mathrm{~s}, 3 \mathrm{H}, \mathrm{N}=\mathrm{CCH}_{3}\right.$ ); 2.81 (t, $2 \mathrm{H}$, $\mathrm{COCH}_{2} \mathrm{CH}_{2}, J=7.2 \mathrm{~Hz}$ ); $4.87\left(\mathrm{~s}, 2 \mathrm{H}, \mathrm{NCH}_{2}\right.$ ); 5.32 (exch br s, $\left.1 \mathrm{H}, \mathrm{OH}\right) ; 7.45$ (exch s br, $2 \mathrm{H}, \mathrm{NH}_{2}$ ). Anal. Calcd for $\mathrm{C}_{12} \mathrm{H}_{17} \mathrm{~N}_{3} \mathrm{O}_{4}$ (267.28): C, 53.92; H, 6.41; N, 15.72; Found: $\mathrm{C}, 54.08 ; \mathrm{H}, 6.40$; , 15.68 .

5.1.3.2. (5-Amino-4-cyclopentanecarbonyl-3-methyl-6-oxopyridazin-1(6H)-yl)acetic acid, 4 e. Yield $=73 \% ; \mathrm{mp}=168-169{ }^{\circ} \mathrm{C}(\mathrm{EtOH}) .{ }^{1} \mathrm{H}-\mathrm{NMR}\left(\mathrm{CDCl}_{3}\right) \delta 1.60-1.70\left(\mathrm{~m}, 2 \mathrm{H}, \mathrm{cC}_{5} \mathrm{H}_{9}\right) ; 1.71-1.80$ $\left(\mathrm{m}, 2 \mathrm{H}, \mathrm{cC}_{5} \mathrm{H}_{9}\right) ; 1.81-1.91\left(\mathrm{~m}, 4 \mathrm{H}, \mathrm{cC}_{5} \mathrm{H}_{9}\right) ; 2.45\left(\mathrm{~s}, 3 \mathrm{H}, \mathrm{CH}_{3}\right) ; 3.45\left(\mathrm{~m}, 1 \mathrm{H}, \mathrm{cC}_{5} \mathrm{H}_{9}\right) ; 4.88(\mathrm{~s}, 2 \mathrm{H}$, $\mathrm{NCH}_{2}$ ); 5.03 (exch br s, $\left.1 \mathrm{H}, \mathrm{OH}\right) ; 6.89$ (exch br s, $2 \mathrm{H}, \mathrm{NH}_{2}$ ). Anal. Calcd for $\mathrm{C}_{13} \mathrm{H}_{17} \mathrm{~N}_{3} \mathrm{O}_{4}(279.29$ ): C, 55.91; H, 6.14; N, 15.05; Found: C, 55.76; H, 6.13; N, 15.09.

\subsubsection{General procedures for $5 \mathrm{a}$, and $5 \mathrm{~d}-\mathrm{e}$}

To a cooled $\left(-5^{\circ} \mathrm{C}\right)$ and stirred solution of the appropriate substrate $\mathbf{4 a}, \mathbf{4 d - e}(\mathbf{4 a}$ [22]) (0.98 mmol) in anhydrous tetrahydrofuran $(5 \mathrm{~mL}), \mathrm{Et}_{3} \mathrm{~N}(3.43 \mathrm{mmol})$ was added. After $0.5 \mathrm{~h}$, the mixture was allowed to warm up to $0{ }^{\circ} \mathrm{C}$, and ethyl chloroformate $(1.02 \mathrm{mmol})$ was added. After $1 \mathrm{~h}, 4$ bromoaniline $(1.96 \mathrm{mmol})$ was added. The reaction was carried out at room temperature for $16 \mathrm{~h}$. The mixture was then concentrated in vacuo, diluted with cold water $(20-30 \mathrm{~mL})$, and extracted with $\mathrm{CH}_{2} \mathrm{Cl}_{2}(3 \times 15 \mathrm{~mL})$. The organic layer was dried over $\mathrm{Na}_{2} \mathrm{SO}_{4}$ and evaporated to obtain crude final compounds, which were purified by crystallization from ethanol for compound $\mathbf{5 a}$ and by column flash chromatography using cyclohexane/ethyl acetate 1:1 as eluent, followed by recrystallization from $\mathrm{EtOH}$, for compounds $\mathbf{5} \mathbf{d}$ and $\mathbf{5 e}$.

5.1.4.1. 2-(4-Acetyl-5-amino-3-methyl-6-oxopyridazin-1(6H)-yl)-N-(4-bromophenyl) acetamide, 5a. Yield $=90 \% ; \mathrm{mp}=240-242{ }^{\circ} \mathrm{C}(\mathrm{EtOH}) .{ }^{1} \mathrm{H}-\mathrm{NMR}\left(\mathrm{CDCl}_{3}\right) \delta 2.57\left(\mathrm{~s}, 3 \mathrm{H}, \mathrm{COCH}_{3}\right)$; $2.60\left(\mathrm{~s}, 3 \mathrm{H}, \mathrm{N}=\mathrm{CCH}_{3}\right) ; 4.90\left(\mathrm{~s}, 2 \mathrm{H}, \mathrm{NCH}_{2}\right) ; 7.54$ (s, 4H, Ar); 8.50 (exch br s, 1H, NH); 6.32 (exch 
br s, $2 \mathrm{H}, \mathrm{NH}_{2}$ ). Anal. Calcd for $\mathrm{C}_{15} \mathrm{H}_{15} \mathrm{BrN}_{4} \mathrm{O}_{3}$ (379.21): C, 47.51; H, 3.99; N, 14.77; Found: C, 47.64; H, 3.98; N, 14.80.

\subsubsection{2-(5-Amino-3-methyl-6-oxo-4-pentanoylpyridazin-1(6H)-yl)- $N$-(4-bromophenyl)} acetamide, 5d. Yield $=42 \% ; \mathrm{mp}=164-165^{\circ} \mathrm{C}(\mathrm{EtOH}) .{ }^{1} \mathrm{H}-\mathrm{NMR}\left(\mathrm{CDCl}_{3}\right) \delta 0.93\left(\mathrm{t}, 3 \mathrm{H}, \mathrm{CH}_{2} \mathrm{CH}_{3,} J\right.$ $=7.2 \mathrm{~Hz}$ ); 1.35 (sext, $2 \mathrm{H}, \mathrm{CH}_{2} \mathrm{CH}_{3} J=7.2 \mathrm{~Hz}$ ); 1.67 (quin, $2 \mathrm{H}, \mathrm{COCH}_{2} \mathrm{CH}_{2}, J=7.2 \mathrm{~Hz}$ ); 2.51 (s, $\left.3 \mathrm{H}, \mathrm{N}=\mathrm{CCH}_{3}\right) ; 2.82\left(\mathrm{t}, 2 \mathrm{H}, \mathrm{COCH}_{2} \mathrm{CH}_{2}, J=7.2 \mathrm{~Hz}\right) ; 4.88\left(\mathrm{~s}, 2 \mathrm{H}, \mathrm{NCH}_{2}\right) ; 7.38(\mathrm{~s}, 4 \mathrm{H}, \mathrm{Ar}) ; 8.63$ (exch br s, $1 \mathrm{H}, \mathrm{NH}$ ); 8.56 (exch br s, $2 \mathrm{H}, \mathrm{NH}_{2}$ ). Anal. Calcd for $\mathrm{C}_{18} \mathrm{H}_{21} \mathrm{BrN}_{4} \mathrm{O}_{3}$ (421.29): C, 51.32; H, 5.02; N, 13.30; Found: C, 51.46; H, 5.02; N, 13.27.

5.1.4.3. 2-(5-Amino-4-cyclopentanecarbonyl-3-methyl-6-oxopyridazin-1(6H)-yl)- $N$-(4bromophenyl)acetamide, 5e. Yield $=19 \% ; \mathrm{mp}=179-181{ }^{\circ} \mathrm{C}(\mathrm{EtOH}) .{ }^{1} \mathrm{H}-\mathrm{NMR}\left(\mathrm{CDCl}_{3}\right) \delta 1.61-$ $1.71\left(\mathrm{~m}, 2 \mathrm{H}, \mathrm{cC}_{5} \mathrm{H}_{9}\right) ; 1.72-1.82\left(\mathrm{~m}, 2 \mathrm{H}, \mathrm{cC}_{5} \mathrm{H}_{9}\right) ; 1.83-1.92\left(\mathrm{~m}, 4 \mathrm{H}, \mathrm{cC}_{5} \mathrm{H}_{9}\right) ; 2.48\left(\mathrm{~s}, 3 \mathrm{H}, \mathrm{CH}_{3}\right) ; 3.45$ (m, $\left.1 \mathrm{H}, \mathrm{cC}_{5} \mathrm{H}_{9}\right) ; 4.89$ (s, 2H, $\left.\mathrm{NCH}_{2}\right) ; 6.89$ (exch br s, 2H, $\left.\mathrm{NH}_{2}\right) ; 7.40$ (s, 4H, Ar); 8.66 (exch br s, 1H, NH). Anal. Calcd for $\mathrm{C}_{19} \mathrm{H}_{21} \mathrm{BrN}_{4} \mathrm{O}_{3}$ (433.30): C, 52.67; H, 4.89; N, 12.93; Found: C, 52.49; H, $4.88 ; \mathrm{N}, 12.91$.

\subsubsection{General procedures for $5 b, c, 5 f$}

A mixture of the appropriate intermediate $\mathbf{2 b}$-c or $\mathbf{2 f}(0.96 \mathrm{mmol}), \mathrm{K}_{2} \mathrm{CO}_{3}(1.93 \mathrm{mmol})$ and $\mathrm{N}$-(4-bromophenyl)-2-chloroacetamide [26] (0.96-1.20 mmol) in $\mathrm{CH}_{3} \mathrm{CN}$ (10-15 mL) was refluxed under stirring for 2-6 h. The mixture was then concentrated in vacuo, and ice cold water was added. After $1 \mathrm{~h}$ stirring in an ice-bath, the precipitate was recovered by suction to obtain pure compound 5b-c. For compound $\mathbf{5 f}$ further purification was performed by column chromatography using cyclohexane/ethyl acetate 1:2 as eluent.

5.1.5.1. 2-(5-Amino-3-methyl-6-oxo-4-propionylpyridazin-1(6H)-yl)- $N$-(4-bromophenyl) acetamide, 5b. Yield $=98 \% ; \mathrm{mp}=174-175^{\circ} \mathrm{C}(\mathrm{EtOH}) .{ }^{1} \mathrm{H}-\mathrm{NMR}\left(\mathrm{CDCl}_{3}\right) \delta 1.22\left(\mathrm{t}, 3 \mathrm{H}, \mathrm{CH}_{2} \mathrm{CH}_{3}, J\right.$ $=7.2 \mathrm{~Hz}) ; 2.56\left(\mathrm{~s}, 3 \mathrm{H}, \mathrm{N}=\mathrm{CCH}_{3}\right) ; 2.88\left(\mathrm{q}, 2 \mathrm{H}, \mathrm{CH}_{2} \mathrm{CH}_{3}, J=7.2 \mathrm{~Hz}\right) ; 4.90\left(\mathrm{~s}, 2 \mathrm{H}, \mathrm{NCH}_{2}\right) ; 7.43$ (s, $4 \mathrm{H}$, Ar); 8.55 (exch br s, $1 \mathrm{H}, \mathrm{NH}) ; 8.76$ (exch br s, $2 \mathrm{H}, \mathrm{NH}_{2}$ ). Anal. Calcd for $\mathrm{C}_{16} \mathrm{H}_{17} \mathrm{BrN}_{4} \mathrm{O}_{3}$ (393.24): C, 48.87; H, 4.36; N, 14.25; Found: C, 48.99; H, 4.35; N, 14.21. 
acetamide, 5c. Yield $=96 \% ; \mathrm{mp}=161-163{ }^{\circ} \mathrm{C}(\mathrm{EtOH}) .{ }^{1} \mathrm{H}-\mathrm{NMR}\left(\mathrm{CDCl}_{3}\right) \delta 0.99\left(\mathrm{t}, 3 \mathrm{H}, \mathrm{CH}_{2} \mathrm{CH}_{3}, J\right.$ $=7.2 \mathrm{~Hz}) ; 1.75\left(\mathrm{sext}, 2 \mathrm{H}, \mathrm{CH}_{2} \mathrm{CH}_{3}, J=7.2 \mathrm{~Hz}\right) ; 2.54\left(\mathrm{~s}, 3 \mathrm{H}, \mathrm{N}=\mathrm{CCH}_{3}\right) ; 2.83\left(\mathrm{t}, 2 \mathrm{H}, \mathrm{COCH}_{2}, J=7.2\right.$ $\mathrm{Hz}) ; 4.90$ (s, 2H, $\mathrm{NCH}_{2}$ ); 7.43 (s, 4H, Ar); 8.57 (exch br s, 1H, NH); 9.04 (exch br s, 2H, $\mathrm{NH}_{2}$ ). Anal. Calcd for $\mathrm{C}_{17} \mathrm{H}_{19} \mathrm{BrN}_{4} \mathrm{O}_{3}$ (407.26): C, 50.14; H, 4.70; N, 13.76; Found: $\mathrm{C}, 50.05 ; \mathrm{H}, 4.69$; N, 13.73.

5.1.5.3. 2-(5-Amino-4-cyclohexanecarbonyl-3-methyl-6-oxopyridazin-1(6H)-yl)- $N$-(4bromophenyl $)$ acetamide, 5f. Yield $=53 \% ; \mathrm{mp}=97-99{ }^{\circ} \mathrm{C}(\mathrm{EtOH}) .{ }^{1} \mathrm{H}-\mathrm{NMR}\left(\mathrm{CDCl}_{3}\right) \delta 1.20-1.40$ $\left(\mathrm{m}, 2 \mathrm{H}, \mathrm{cC}_{6} \mathrm{H}_{11}\right) ; 1.40-1.60\left(\mathrm{~m}, 2 \mathrm{H}, \mathrm{cC}_{6} \mathrm{H}_{11}\right) ; 1.60-1.80\left(\mathrm{~m}, 2 \mathrm{H}, \mathrm{cC}_{6} \mathrm{H}_{11}\right) ; 1.80-1.90\left(\mathrm{~m}, 4 \mathrm{H}, \mathrm{cC}_{6} \mathrm{H}_{11}\right)$; $2.44\left(\mathrm{~s}, 3 \mathrm{H}, \mathrm{CH}_{3}\right) ; 2.91-2.98\left(\mathrm{~m}, 1 \mathrm{H}, \mathrm{cC}_{6} \mathrm{H}_{11}\right) ; 4.89\left(\mathrm{~s}, 2 \mathrm{H}, \mathrm{NCH}_{2}\right) ; 6.73\left(\right.$ exch br s, $\left.2 \mathrm{H}, \mathrm{NH}_{2}\right) ; 7.38$ (s, 4H, Ar); 8.70 (exch br s, $1 \mathrm{H}, \mathrm{NH}$ ). Anal. Calcd for $\mathrm{C}_{20} \mathrm{H}_{23} \mathrm{BrN}_{4} \mathrm{O}_{3}$ (447.33): C, 53.70; H, 5.18; N, 12.52; Found: C, 53.85; H, 5.17; N, 12.56.

\subsubsection{General procedures for $6 a-f$}

To a suspension of the appropriate intermediate 5a-f (0.91 mmol), copper(II) acetate (1.36 mmol), 3-methoxyphenylboronic acid (0.91-1.82 mmol) in $\mathrm{CH}_{2} \mathrm{Cl}_{2}(10 \mathrm{~mL})$, and $\mathrm{Et}_{3} \mathrm{~N}(1.82 \mathrm{mmol})$ were added, and the mixture was stirred at room temperature for $16 \mathrm{~h}$. The suspension was extracted with $15 \%$ aqueous ammonia $(3 \times 10 \mathrm{~mL})$, and the organic layer was washed with water $(10 \mathrm{~mL})$ and dried over $\mathrm{Na}_{2} \mathrm{SO}_{4}$. After removal of the solvent in vacuo, the final desired compounds were purified by column flash chromatography using as eluent $\mathrm{CH}_{2} \mathrm{Cl}_{2} / \mathrm{MeOH} 98: 2$, for compounds $6 \mathbf{b - f}$ and cycloexane/ethyl acetate 1:3 for compound 6a. Compounds $\mathbf{6 d}$ and $\mathbf{6 e}$ were further purified by recrystallization from cyclohexane.

\subsubsection{2-[4-Acetyl-5-(3-methoxyphenylamino)-3-methyl-6-oxopyridazin-1(6H)-yl]- $N-(4-$} bromophenyl)acetamide, 6a. Yield $=41 \% ; \mathrm{mp}=115-116{ }^{\circ} \mathrm{C}(\mathrm{EtOH}) .{ }^{1} \mathrm{H}-\mathrm{NMR}\left(\mathrm{CDCl}_{3}\right) \delta 1.92(\mathrm{~s}$, $\left.3 \mathrm{H}, \mathrm{COCH}_{3}\right) ; 2.24\left(\mathrm{~s}, 3 \mathrm{H}, \mathrm{N}=\mathrm{C}-\mathrm{CH}_{3}\right) ; 3.80\left(\mathrm{~s}, 3 \mathrm{H}, \mathrm{OCH}_{3}\right) ; 4.97\left(\mathrm{~s}, 2 \mathrm{H}, \mathrm{NCH}_{2}\right) ; 6.61(\mathrm{~s}, 1 \mathrm{H}, \mathrm{Ar})$; $6.68(\mathrm{~d}, 1 \mathrm{H}, \mathrm{Ar}, J=8.4 \mathrm{~Hz}) ; 6.74(\mathrm{~d}, 1 \mathrm{H}, \mathrm{Ar}, J=8.0 \mathrm{~Hz}) ; 7.24(\mathrm{~m}, 1 \mathrm{H}, \mathrm{Ar}) ; 7.42-7.48$ (m, 4H, Ar); 8.5 (exch br s, $1 \mathrm{H}, \mathrm{NH}) ; 9.21$ (exch br s, $1 \mathrm{H}, \mathrm{NH}) .{ }^{13} \mathrm{C}-\mathrm{NMR}\left(\mathrm{CDCl}_{3}\right) \delta 19.6\left(\mathrm{CH}_{3}\right) ; 31.2\left(\mathrm{CH}_{3}\right)$; 
$55.3\left(\mathrm{CH}_{3}\right) ; 57.0\left(\mathrm{CH}_{2}\right) ; 108.1(\mathrm{CH}) ; 112.0(\mathrm{CH}) ; 115.9(\mathrm{CH}) ; 116.6(\mathrm{C}) ; 117.0(\mathrm{C}) ; 121.4(2 \mathrm{CH})$; $130.5(\mathrm{CH}) ; 131.8(2 \mathrm{CH}) ; 136.7(\mathrm{C}) ; 137.7(\mathrm{C}) ; 139.6(\mathrm{C}) ; 144.3(\mathrm{C}) ; 146.6(\mathrm{C}) ; 157.6(\mathrm{C}) ; 160.4$ (C); 164.9 (C). Anal. Calcd for $\mathrm{C}_{22} \mathrm{H}_{21} \mathrm{BrN}_{4} \mathrm{O}_{4}$ (485.33): C, 54.44; H, 4.36; N, 11.54; Found: C, $54.57 ; \mathrm{H}, 4.35 ; \mathrm{N}, 11.57$.

5.1.6.2. $\quad N$-(4-Bromophenyl)-2-[5-(3-methoxyphenylamino)-3-methyl-6-oxo-4-propionyl pyridazin-1(6H)-yl $]$ acetamide, 6b. Yield $=10 \% ; \mathrm{mp}=87-89{ }^{\circ} \mathrm{C}(\mathrm{EtOH}) .{ }^{1} \mathrm{H}-\mathrm{NMR}\left(\mathrm{CDCl}_{3}\right) \delta 0.57$ $\left(\mathrm{t}, 3 \mathrm{H}, \mathrm{CH}_{2} \mathrm{CH}_{3} J=7.2 \mathrm{~Hz}\right) ; 2.19\left(\mathrm{~s}, 3 \mathrm{H}, \mathrm{N}=\mathrm{CCH}_{3}\right) ; 2.28\left(\mathrm{q}, 2 \mathrm{H}, \mathrm{CH}_{2} \mathrm{CH}_{3}, J=7.2 \mathrm{~Hz}\right) ; 3.81(\mathrm{~s}, 3 \mathrm{H}$, $\left.\mathrm{OCH}_{3}\right) ; 4.97\left(\mathrm{~s}, 2 \mathrm{H}, \mathrm{NCH}_{2}\right) ; 6.60(\mathrm{~s}, 1 \mathrm{H}, \mathrm{Ar}) ; 6.67(\mathrm{~d}, 1 \mathrm{H}, \mathrm{Ar}, J=8.4 \mathrm{~Hz}) ; 6.73(\mathrm{~d}, 1 \mathrm{H}, \mathrm{Ar}, J=8.4$ $\mathrm{Hz}$ ); 7.24 (t, 1H, Ar, $J=8.4 \mathrm{~Hz}) ; 7.45$ (s, 4H, Ar); 7.69 (exch br s, 1H, NH); 8.61 (exch br s, 1H, NH). ${ }^{13} \mathrm{C}-\mathrm{NMR}\left(\mathrm{CDCl}_{3}\right) \delta 14.1\left(\mathrm{CH}_{3}\right) ; 20.3\left(\mathrm{CH}_{3}\right) ; 37.6\left(\mathrm{CH}_{2}\right) ; 55.4\left(\mathrm{CH}_{3}\right) ; 57.5\left(\mathrm{CH}_{2}\right) ; 108.5(\mathrm{CH}) ;$ $112.3(\mathrm{CH}) ; 115.3(\mathrm{CH}) ; 116.5(\mathrm{C}) ; 117.0(\mathrm{C}) ; 121.5(2 \times \mathrm{CH}) ; 130.5(\mathrm{CH}) ; 132.0(2 \times \mathrm{CH}) ; 136.6$ (C); $137.4(\mathrm{C}) ; 139.7$ (C); 144.6 (C); 146.5 (C); 157.6 (C); 160.6 (C); 165.1 (C). Anal. Calcd for $\mathrm{C}_{23} \mathrm{H}_{23} \mathrm{BrN}_{4} \mathrm{O}_{4}$ (499.36): C, 55.32; H, 4.64; N, 11.22; Found: C, 55.47; H, 4.63; N, 11.18.

5.1.6.3.

$N$-(4-Bromophenyl)-2-[4-butyryl-5-(3-methoxyphenylamino)-3-methyl-6-oxo pyridazin-1(6H)-yl]acetamide, 6c. Yield $=11 \% ; \mathrm{mp}=113-115{ }^{\circ} \mathrm{C}(\mathrm{EtOH}) .{ }^{1} \mathrm{H}-\mathrm{NMR}\left(\mathrm{CDCl}_{3}\right) \delta$ $0.67\left(\mathrm{t}, 3 \mathrm{H}, \mathrm{CH}_{2} \mathrm{CH}_{3} \mathrm{~J}=7.2 \mathrm{~Hz}\right) ; 1.09$ (sext, $\left.2 \mathrm{H}, \mathrm{CH}_{2} \mathrm{CH}_{3}, J=7.2 \mathrm{~Hz}\right) ; 2.19$ (s, 3H, N=CCH ); 2.22 (t, 2H, $\left.\mathrm{COCH}_{2}, J=7.2 \mathrm{~Hz}\right) ; 3.80\left(\mathrm{~s}, 3 \mathrm{H}, \mathrm{OCH}_{3}\right) ; 4.97\left(\mathrm{~s}, 2 \mathrm{H}, \mathrm{NCH}_{2}\right) ; 6.60(\mathrm{~s}, 1 \mathrm{H}, \mathrm{Ar}) ; 6.67(\mathrm{~d}, 1 \mathrm{H}$, Ar, $J=8.0 \mathrm{~Hz}) ; 6.73(\mathrm{~d}, 1 \mathrm{H}, \mathrm{Ar}, J=8.0 \mathrm{~Hz}) ; 7.23(\mathrm{t}, 1 \mathrm{H}, \mathrm{Ar}, J=8.0 \mathrm{~Hz}) ; 7.42-7.47(\mathrm{~m}, 4 \mathrm{H}, \mathrm{Ar})$; 7.69 (exch br s, $1 \mathrm{H}, \mathrm{NH}) ; 8.57$ (exch br s, $1 \mathrm{H}, \mathrm{NH}) .{ }^{13} \mathrm{C}-\mathrm{NMR}\left(\mathrm{CDCl}_{3}\right) \delta 13.5\left(\mathrm{CH}_{3}\right) ; 16.3\left(\mathrm{CH}_{2}\right)$; $20.3\left(\mathrm{CH}_{3}\right) ; 46.2\left(\mathrm{CH}_{2}\right) ; 55.4\left(\mathrm{CH}_{3}\right) ; 57.5\left(\mathrm{CH}_{2}\right) ; 108.3(\mathrm{CH}) ; 112.3(\mathrm{CH}) ; 115.1(\mathrm{CH}) ; 116.6(\mathrm{C})$; $117.0(\mathrm{C}) ; 121.5(2 \times \mathrm{CH}) ; 130.5(\mathrm{CH}) ; 132.0(2 \times \mathrm{CH}) ; 136.6(\mathrm{C}) ; 137.3(\mathrm{C}) ; 139.7$ (2 x C); 144.6 (C); $157.6(\mathrm{C}) ; 160.5(\mathrm{C}) ; 165.0(\mathrm{C})$. Anal. Calcd for $\mathrm{C}_{24} \mathrm{H}_{25} \mathrm{BrN}_{4} \mathrm{O}_{4}(513.38)$ : $\mathrm{C}, 56.15 ; \mathrm{H}, 4.91 ; \mathrm{N}$, 10.91; Found: C, 56.63; H, 4.90; N, 10.88 .

5.1.6.4. $\quad N$-(4-Bromophenyl)-2-[5-(3-methoxyphenylamino)-3-methyl-6-oxo-4-pentanoyl pyridazin-1(6H)-yl]acetamide, 6d. Yield $=13 \% ; \mathrm{mp}=96-98{ }^{\circ} \mathrm{C}$ (cyclohexane). ${ }^{1} \mathrm{H}-\mathrm{NMR}\left(\mathrm{CDCl}_{3}\right)$ $\delta 0.73\left(\mathrm{t}, 3 \mathrm{H}, \mathrm{CH}_{2} \mathrm{CH}_{3}, J=7.2 \mathrm{~Hz}\right) ; 0.93-1.06\left(\mathrm{~m}, 4 \mathrm{H},\left(\mathrm{CH}_{2}\right)_{2} \mathrm{CH}_{3}\right) ; 2.17\left(\mathrm{~s}, 3 \mathrm{H}, \mathrm{N}=\mathrm{CCH}_{3}\right) ; 2.22(\mathrm{t}$, 
$\left.2 \mathrm{H}, \mathrm{COCH}_{2} \mathrm{CH}_{2}, J=7.2 \mathrm{~Hz}\right) ; 3.78\left(\mathrm{~s}, 3 \mathrm{H}, \mathrm{OCH}_{3}\right) ; 4.95\left(\mathrm{~s}, 2 \mathrm{H}, \mathrm{NCH}_{2}\right) ; 6.58(\mathrm{~s}, 1 \mathrm{H}, \mathrm{Ar}) ; 6.64(\mathrm{dd}$, $1 \mathrm{H}, \operatorname{Ar}, J=8.4 \mathrm{~Hz}, J=2.4 \mathrm{~Hz}) ; 6.71(\mathrm{dd}, 1 \mathrm{H}, \mathrm{Ar}, J=8.4 \mathrm{~Hz}, J=2.4 \mathrm{~Hz}) ; 7.12(\mathrm{t}, 1 \mathrm{H}, \mathrm{Ar}, J=8.4$ $\mathrm{Hz}) ; 7.44$ (s, 4H, Ar); 7.66 (exch br s, $1 \mathrm{H}, \mathrm{NH}) ; 8.56$ (exch br s, $1 \mathrm{H}, \mathrm{NH}) .{ }^{13} \mathrm{C}-\mathrm{NMR}\left(\mathrm{CDCl}_{3}\right) \delta 13.0$ $\left(\mathrm{CH}_{3}\right) ; 17.5\left(\mathrm{CH}_{2}\right) ; 20.1\left(\mathrm{CH}_{3}\right) ; 24.7\left(\mathrm{CH}_{2}\right) ; 44.1\left(\mathrm{CH}_{2}\right) ; 55.4\left(\mathrm{CH}_{3}\right) ; 57.5\left(\mathrm{CH}_{2}\right) ; 108.3(\mathrm{CH}) ; 112.3$ $(\mathrm{CH}) ; 115.1(\mathrm{CH}) ; 116.6(\mathrm{C}) ; 117.1(\mathrm{C}) ; 121.4(2 \times \mathrm{CH}) ; 129.8(\mathrm{CH}) ; 132.0(2 \times \mathrm{CH}) ; 136.5(\mathrm{C})$; 137.3 (C); 139.6 (C); 144.6 (C); 146.5 (C); 154.6 (C); 160.6 (C); 164.1 (C). Anal. Calcd for $\mathrm{C}_{25} \mathrm{H}_{27} \mathrm{BrN}_{4} \mathrm{O}_{4}$ (527.41): C, 56.93; H, 5.16; N, 10.62; Found: C, 57.03; H, 5.15; N, 10.57.

\subsubsection{5. $N$-(4-Bromophenyl)-2-[4-cyclopentanecarbonyl-5-(3-methoxyphenylamino)-3-methyl-} 6-oxopyridazin-1(6H)-yl]acetamide, 6e. Yield = 11\%; $\mathrm{mp}=140-142{ }^{\circ} \mathrm{C}($ cyclohexane $) .{ }^{1} \mathrm{H}-\mathrm{NMR}$ $\left(\mathrm{CDCl}_{3}\right) \delta 1.13-1.22\left(\mathrm{~m}, 2 \mathrm{H}, \mathrm{cC}_{5} \mathrm{H}_{9}\right) ; 1.29-1.36\left(\mathrm{~m}, 2 \mathrm{H}, \mathrm{cC}_{5} \mathrm{H}_{9}\right) ; 1.37-1.43\left(\mathrm{~m}, 2 \mathrm{H}, \mathrm{cC}_{5} \mathrm{H}_{9}\right) ; 1.53(\mathrm{~m}$, $\left.2 \mathrm{H}, \mathrm{cC}_{5} \mathrm{H}_{9}\right) ; 2.19\left(\mathrm{~s}, 3 \mathrm{H}, \mathrm{N}=\mathrm{CCH}_{3}\right) ; 3.04$ (quin, $1 \mathrm{H}, \mathrm{cC}_{5} \mathrm{H}_{9}, J=7.6 \mathrm{~Hz}$ ); $3.87\left(\mathrm{~s}, 3 \mathrm{H}, \mathrm{OCH}_{3}\right) ; 4.97$ (s, 2H, $\left.\mathrm{NCH}_{2}\right) ; 6.56(\mathrm{~s}, 1 \mathrm{H}, \mathrm{Ar}) ; 6.67(\mathrm{dd}, 1 \mathrm{H}, \mathrm{Ar}, J=8.4 \mathrm{~Hz}, J=2.4 \mathrm{~Hz}) ; 6.71(\mathrm{dd}, 1 \mathrm{H}, \mathrm{Ar}, J=8.4 \mathrm{~Hz}$, $J=2.4 \mathrm{~Hz}) ; 7.22(\mathrm{t}, 1 \mathrm{H}, \mathrm{Ar}, J=8.4 \mathrm{~Hz}) ; 7.44-7.47(\mathrm{~m}, 4 \mathrm{H}, \mathrm{Ar}) ; 8.54($ exch br s, 1H, NH); 9.98 (exch br s, 1H, NH). ${ }^{13} \mathrm{C}-\mathrm{NMR}\left(\mathrm{CDCl}_{3}\right) \delta 20.9\left(\mathrm{CH}_{3}\right) ; 22.7\left(\mathrm{CH}_{2}\right) ; 25.8\left(\mathrm{CH}_{2}\right) ; 28.3\left(\mathrm{CH}_{2}\right) ; 31.9$ $\left(\mathrm{CH}_{2}\right) ; 52.2(\mathrm{CH}) ; 55.4\left(\mathrm{CH}_{3}\right) ; 57.6\left(\mathrm{CH}_{2}\right) ; 107.5(\mathrm{CH}) ; 112.0(\mathrm{CH}) ; 114.6(\mathrm{CH}) ; 116.6(\mathrm{C}) ; 119.0$ (C); $121.5(2 \times \mathrm{CH}) ; 130.5(\mathrm{CH}) ; 132.0(2 \times \mathrm{CH}) ; 136.6(\mathrm{C}) ; 137.5(\mathrm{C}) ; 138.5(\mathrm{C}) ; 145.2(\mathrm{C}) ; 147.3$ (C); 157.8 (C); 160.4 (C); 165.3 (C). Anal. Calcd for $\mathrm{C}_{26} \mathrm{H}_{27} \mathrm{BrN}_{4} \mathrm{O}_{4}$ (539.42): C, 57.89; H, 5.05; N, 10.39; Found: C, 57.70; H, 5.05; N, 10.42.

5.1.6.6. $\quad N$-(4-Bromophenyl)-2-[4-cyclohexanecarbonyl-5-(3-methoxyphenylamino)-3-methyl6-oxopyridazin-1(6)-yl]acetamide, 6f. Yield $=34 \% ; \mathrm{mp}=181-183{ }^{\circ} \mathrm{C}(\mathrm{EtOH}) .{ }^{1} \mathrm{H}-\mathrm{NMR}\left(\mathrm{CDCl}_{3}\right)$ $\delta$ 0.80-1.00 (m, 8H, $\left.\mathrm{cC}_{6} \mathrm{H}_{11}\right) ; 1.40-1.60\left(\mathrm{~m}, 2 \mathrm{H}, \mathrm{cC}_{6} \mathrm{H}_{11}\right) ; 2.00\left(\mathrm{~s}, 3 \mathrm{H}, \mathrm{N}=\mathrm{CCH}_{3}\right) ; 2.46-2.50(\mathrm{~m}, 1 \mathrm{H}$, $\left.\mathrm{cC}_{6} \mathrm{H}_{11}\right) ; 3.68\left(\mathrm{~s}, 3 \mathrm{H}, \mathrm{OCH}_{3}\right) ; 4.87\left(\mathrm{~s}, 2 \mathrm{H}, \mathrm{NCH}_{2}\right) ; 6.60-6.62(\mathrm{~m}, 3 \mathrm{H}, \mathrm{Ar}) ; 7.12-7.17$ (m, 1H, Ar); 7.56-7.47 (m, 4H, Ar); 8.82 (exch br s, $1 \mathrm{H}, \mathrm{NH}) ; 10.44$ (exch br s, $1 \mathrm{H}, \mathrm{NH}) .{ }^{13} \mathrm{C}-\mathrm{NMR}\left(\mathrm{CDCl}_{3}\right) \delta$ $20.6\left(\mathrm{CH}_{3}\right) ; 25.8\left(2 \times \mathrm{CH}_{2}\right) ; 27.6\left(2 \times \mathrm{CH}_{2}\right) ; 29.5\left(\mathrm{CH}_{2}\right) ; 51.3(\mathrm{CH}) ; 55.5\left(\mathrm{CH}_{3}\right) ; 55.6\left(\mathrm{CH}_{2}\right) ; 108.2$ $(\mathrm{CH}) ; 111.1(\mathrm{CH}) ; 115.2(\mathrm{CH}) ; 115.6(\mathrm{C}) ; 115.8(\mathrm{C}) ; 121.6(2 \times \mathrm{CH}) ; 130.3(\mathrm{CH}) ; 132.1(2 \times \mathrm{CH})$; 
138.1 (C); 138.5 (C); 141.6 (2 x C); 142.6 (C); 157.1 (C); 160.3 (C); 165.7 (C). Anal. Calcd for $\mathrm{C}_{27} \mathrm{H}_{29} \mathrm{BrN}_{4} \mathrm{O}_{4}$ (553.45): C, 58.59; H, 5.28; N, 10.12; Found: C, 58.40; H, 5.27; N, 10.09 .

\subsubsection{General procedures for $7 \mathrm{a}-\mathrm{d}$}

To a cooled $\left(0{ }^{\circ} \mathrm{C}\right)$ suspension of compounds $2 \mathbf{a}-\mathbf{d}(1.20 \mathrm{mmol})$ in $5 \mathrm{~mL}$ of $\mathrm{MeOH}, \mathrm{NaBH}_{4}$ (3.59-7.18 mmol) was slowly added, and the mixture was stirred for $1 \mathrm{~h}$ at room temperature. After cooling, cold water was added $(10 \mathrm{~mL})$ and compound $7 \mathbf{a}$ was recovered by filtration under vacuum. For compounds $\mathbf{7 b}$-d the suspension was extracted with ethyl acetate $(3 \times 10 \mathrm{~mL})$ and the organic layer was dried over $\mathrm{Na}_{2} \mathrm{SO}_{4}$ and evaporated to obtain crude final compounds, which were purified by crystallization from ethanol.

5.1.7.1. 4-Amino-5-(1-hydroxyethyl)-6-methylpyridazin-3(2H)-one, 7a. Yield =49\%; $\mathrm{mp}=>300$ ${ }^{\circ} \mathrm{C}(\mathrm{MeOH}) .{ }^{1} \mathrm{H}-\mathrm{NMR}\left(\mathrm{DMSO}-d_{6}\right) \delta 1.28\left(\mathrm{~d}, 3 \mathrm{H}, \mathrm{CHCH}_{3}, J=6.4 \mathrm{~Hz}\right) ; 2.09\left(\mathrm{~s}, 3 \mathrm{H}, \mathrm{N}=\mathrm{CCH}_{3}\right) ; 4.78$ (q, $1 \mathrm{H}, \mathrm{CH}, J=6.4 \mathrm{~Hz}$ ); 5.98 (exch br s, $1 \mathrm{H}, \mathrm{NH}) ; 8.56$ (exch br s, 2H, $\mathrm{NH}_{2}$ ). Anal. Calcd for $\mathrm{C}_{7} \mathrm{H}_{11} \mathrm{~N}_{3} \mathrm{O}_{2}$ (169.18): C, 49.70; H, 6.55; N, 24.84; Found: C, 49.85; H, 6.56; N, 24.79.

5.1.7.2. 4-Amino-5-(1-hydroxypropyl)-6-methylpyridazin-3(2H)-one, $7 \mathrm{~b}$. Yield = 74\%; $\mathrm{mp}=$ 184-189 ${ }^{\circ} \mathrm{C}(\mathrm{EtOH}) .{ }^{1} \mathrm{H}-\mathrm{NMR}\left(\mathrm{DMSO}-d_{6}\right) \delta 0.86\left(\mathrm{t}, 3 \mathrm{H}, \mathrm{CH}_{2} \mathrm{CH}_{3}, J=7.2 \mathrm{~Hz}\right) ; 1.56-1.61(\mathrm{~m}, 1 \mathrm{H}$, $\left.\mathrm{CH}_{2} \mathrm{CH}_{3}\right) ; 1.65-1.70\left(\mathrm{~m}, 1 \mathrm{H}, \mathrm{CH}_{2} \mathrm{CH}_{3}\right) ; 2.09\left(\mathrm{~s}, 3 \mathrm{H}, \mathrm{N}=\mathrm{CCH}_{3}\right) ; 4.49-4.54(\mathrm{~m}, 1 \mathrm{H}, \mathrm{CHOH}) ; 8.56$ (exch br s, $2 \mathrm{H}, \mathrm{NH}_{2}$ ); 12.26 (exch br s, $1 \mathrm{H}, \mathrm{NH}$ ). Anal. Calcd for $\mathrm{C}_{8} \mathrm{H}_{13} \mathrm{~N}_{3} \mathrm{O}_{2}$ (183.21): C, 52.45; $\mathrm{H}$, 7.15; N, 22.94; Found: C, 52.57; H, 7.17; N, 22.89 .

5.1.7.3. 4-Amino-5-(1-hydroxybutyl)-6-methylpyridazin-3(2H)-one, 7c. Yield = 72\%; $\mathrm{mp}=212$ $215{ }^{\circ} \mathrm{C}(\mathrm{EtOH}) .{ }^{1} \mathrm{H}-\mathrm{NMR}\left(\mathrm{DMSO}-d_{6}\right) \delta 0.86\left(\mathrm{t}, 3 \mathrm{H}, \mathrm{CH}_{2} \mathrm{CH}_{3}, J=7.2 \mathrm{~Hz}\right) ; 1.24-1.30(\mathrm{~m}, 2 \mathrm{H}$, $\left.\mathrm{CH}_{2} \mathrm{CH}_{2} \mathrm{CH}_{3}\right) ; 1.40-1.49\left(\mathrm{~m}, 2 \mathrm{H}, \mathrm{CH}_{2} \mathrm{CH}_{2} \mathrm{CH}_{3}\right) ; 2.07$ (s, 3H, N=CCH$) ; 4.60(\mathrm{~m}, 1 \mathrm{H}, \mathrm{CHOH}) ; 8.92$ (exch br s, $2 \mathrm{H}, \mathrm{NH}_{2}$ ); 12.26 (exch br s, $1 \mathrm{H}, \mathrm{NH}$ ). Anal. Calcd for $\mathrm{C}_{9} \mathrm{H}_{15} \mathrm{~N}_{3} \mathrm{O}_{2}$ (197.23): C, 54.81; $\mathrm{H}$, 7.67; N, 21.30; Found: C, 54.66; H, 7.69; N, 21.36.

5.1.7.4. 4-Amino-5-(1-hydroxypentyl)-6-methylpyridazin-3(2H)-one, 7d. Yield = 74\%; $\mathrm{mp}=$ 206-208 ${ }^{\circ} \mathrm{C}(\mathrm{EtOH}) .{ }^{1} \mathrm{H}-\mathrm{NMR}\left(\mathrm{DMSO}-d_{6}\right) \delta 0.85\left(\mathrm{t}, 3 \mathrm{H}, \mathrm{CH}_{2} \mathrm{CH}_{3}, J=7.2 \mathrm{~Hz}\right) ; 1.18-1.30(\mathrm{~m}, 4 \mathrm{H}$, $\left.\mathrm{CH}_{2} \mathrm{CH}_{2} \mathrm{CH}_{2} \mathrm{CH}_{3}\right) ; 1.40-1.71\left(\mathrm{~m}, 2 \mathrm{H}, \mathrm{CH}_{2} \mathrm{CH}_{2} \mathrm{CH}_{2} \mathrm{CH}_{3}\right) ; 2.08\left(\mathrm{~s}, 3 \mathrm{H}, \mathrm{N}=\mathrm{CCH}_{3}\right) ; 4.58(\mathrm{~m}, 1 \mathrm{H}$, 
CHOH); 5.52 (exch br d, 1H, OH); 5.91 (exch br s, $\left.2 \mathrm{H}, \mathrm{NH}_{2}\right) ; 12.59$ (exch br s, $\left.1 \mathrm{H}, \mathrm{NH}\right)$. Anal. Calcd for $\mathrm{C}_{10} \mathrm{H}_{17} \mathrm{~N}_{3} \mathrm{O}_{2}$ (211.26): C, 56.85; H, 8.11; N, 19.89; Found: C, 57.01; H, 8.12; N, 19.83 .

\subsubsection{General procedures for 8 a-d}

A stirred suspension of appropriate intermediates 7a-d $(1.20 \mathrm{mmol})$ in PPA $(29.5-55.1$ mmol) was heated at $90-110{ }^{\circ} \mathrm{C}$ for $2-5 \mathrm{~h}$. After cooling, ice-cold water was added, and the mixture was neutralized by slow addition of $6 \mathrm{~N} \mathrm{NaOH}$. The resulting suspension was extracted with ethyl acetate, and the organic phase was dried over $\mathrm{Na}_{2} \mathrm{SO}_{4}$. Evaporation of the solvent under vacuum resulted in final compounds 8a-b. Instead, for compounds 8c-d, after neutralization, was observed the formation of a precipitate, which was recovered by suction.

5.1.8.1. 4-Amino-6-methyl-5-vinylpyridazin-3(2H)-one, 8a. Yield $=90 \% ; \mathrm{mp}=270-272{ }^{\circ} \mathrm{C}$ (EtOH). ${ }^{1} \mathrm{H}-\mathrm{NMR}\left(\mathrm{CDCl}_{3}\right) \delta 2.22\left(\mathrm{~s}, 3 \mathrm{H}, \mathrm{CH}_{3}\right) ; 5.19\left(\right.$ exch br s, $\left.2 \mathrm{H}, \mathrm{NH}_{2}\right) ; 5.61(\mathrm{~d}, 1 \mathrm{H}, \mathrm{CH}-H, J=$ $18 \mathrm{~Hz}) ; 5.74(\mathrm{~d}, 1 \mathrm{H}, \mathrm{CH}-H, J=12 \mathrm{~Hz}) ; 6.46(\mathrm{dd}, 1 \mathrm{H}, \mathrm{CH}, J=18 \mathrm{~Hz}, J=12 \mathrm{~Hz}) ; 8.03$ (exch br s, 1H, NH). Anal. Calcd for $\mathrm{C}_{7} \mathrm{H}_{9} \mathrm{~N}_{3} \mathrm{O}$ (151.17): C, 55.62; H, 6.00; N, 27.80; Found: C, 55.75; H, $5.99 ; \mathrm{N}, 27.74$.

5.1.8.2. 4-Amino-6-methyl-5-propenylpyridazin-3(2H)-one, 8b. Yield =62\%; $\mathrm{mp}=264-266{ }^{\circ} \mathrm{C}$ (EtOH). ${ }^{1} \mathrm{H}-\mathrm{NMR}\left(\mathrm{CDCl}_{3}\right) \delta 1.84\left(\mathrm{~d}, 3 \mathrm{H}, \mathrm{CH}_{3} \mathrm{CH}, \mathrm{J}=6.8 \mathrm{~Hz}\right) ; 2.10\left(\mathrm{~s}, 3 \mathrm{H}, \mathrm{CH}_{3}\right) ; 5.92-5.97(\mathrm{~m}, 1 \mathrm{H}$, $\left.\mathrm{CH}=\mathrm{CH}-\mathrm{CH}_{3}\right) ; 6.01-6.13\left(\mathrm{~m}, 1 \mathrm{H}, \mathrm{CH}=\mathrm{CH}-\mathrm{CH}_{3}\right) ; 6.89$ (exch br s, 2H, $\left.\mathrm{NH}_{2}\right) ; 12.30($ exch br s, $1 \mathrm{H}$, NH). Anal. Calcd for $\mathrm{C}_{8} \mathrm{H}_{11} \mathrm{~N}_{3} \mathrm{O}$ (165.19): C, 58.17; H, 6.71; N, 25.44; Found: C, 58.03; H, 6.70; N, 25.51 .

5.1.8.3. 4-Amino-5-but-1-enyl-6-methylpyridazin-3(2H)-one, 8c. Yield = 42\%; $\mathrm{mp}=257-259{ }^{\circ} \mathrm{C}$ $(\mathrm{EtOH}) .{ }^{1} \mathrm{H}-\mathrm{NMR}\left(\mathrm{CDCl}_{3}\right) \delta 1.11-1.16\left(\mathrm{~m}, 3 \mathrm{H}, \mathrm{CH}_{2} \mathrm{CH}_{3}, \mathrm{~J}=7.2 \mathrm{~Hz}\right) ; 1.82-1.91(\mathrm{~m}, 2 \mathrm{H}$, $\left.\mathrm{CHCH}_{2} \mathrm{CH}_{3}\right) ; 2.38\left(\mathrm{~s}, 3 \mathrm{H}, \mathrm{N}=\mathrm{CCH}_{3}\right) ; 4.57-4.63\left(\mathrm{~m}, 1 \mathrm{H}, \mathrm{CH}=\mathrm{CH}-\mathrm{CH}_{2}\right) ; 5.03\left(\mathrm{~m}, 1 \mathrm{H}, \mathrm{CH}=\mathrm{CH}-\mathrm{CH}_{3}\right)$; 5.55 (exch br s, $1 \mathrm{H}, \mathrm{NH}$ ); 6.59 (exch br s, $2 \mathrm{H}, \mathrm{NH}_{2}$ ). Anal. Calcd for $\mathrm{C}_{9} \mathrm{H}_{13} \mathrm{~N}_{3} \mathrm{O}$ (179.22): C, 60.32; H, 7.31; N, 23.45; Found: C, 60.48; H, 6.58; N, 23.39.

5.1.8.4. 4-Amino-6-methyl-5-pent-1-enylpyridazin-3(2H)-one, 8d. Yield = 90\%; $\mathrm{mp}=216-218$ ${ }^{\circ} \mathrm{C}$ dec. (EtOH). ${ }^{1} \mathrm{H}-\mathrm{NMR}\left(\mathrm{CDCl}_{3}\right) \delta 0.96\left(\mathrm{t}, 3 \mathrm{H}, \mathrm{CH}_{2} \mathrm{CH}_{3}, \mathrm{~J}=7.4 \mathrm{~Hz}\right) ; 1.48-1.53(\mathrm{~m}, 2 \mathrm{H}$, 
$\left.\mathrm{CH}_{2} \mathrm{CH}_{2} \mathrm{CH}_{3}\right) ; 2.19\left(\mathrm{~s}, 3 \mathrm{H}, \mathrm{N}=\mathrm{CCH}_{3}\right) ; 2.21-2.26\left(\mathrm{~m}, 2 \mathrm{H}, \mathrm{CH}_{2} \mathrm{CH}_{2} \mathrm{CH}_{3}\right) ; 5.06$ (exch br s, $\left.2 \mathrm{H}, \mathrm{NH}_{2}\right)$; 6.02-6.09 (m, 2H, $\left.\mathrm{CH}=\mathrm{CH}-\mathrm{CH}_{2}\right) ; 8.03$ (exch br s, $1 \mathrm{H}, \mathrm{NH}$ ). Anal. Calcd for $\mathrm{C}_{10} \mathrm{H}_{15} \mathrm{~N}_{3} \mathrm{O}(193.25)$ : C, 62.15; H, 7.82; N, 21.74; Found: C, 62.31; H, 7.83; N, 21.78.

\subsubsection{General procedures for 9 a-d}

Compound 8a-d $(0.46 \mathrm{mmol})$ was subjected to catalytic reduction with $10 \% \mathrm{Pd} / \mathrm{C}(0.23$ $\mathrm{mmol})$ in EtOH $(20 \mathrm{~mL})$ for $3 \mathrm{~h}$ in a Parr instrument at 30 PSI. The catalyst was filtered off, and the solvent was evaporated under vacuum, affording in the final compounds.

5.1.9.1. 4-Amino-5-ethyl-6-methylpyridazin-3(2H)-one, 9a. Yield $=56 \% ; \mathrm{mp}=260-262{ }^{\circ} \mathrm{C}$ (EtOH). ${ }^{1} \mathrm{H}-\mathrm{NMR}\left(\mathrm{CDCl}_{3}\right) \delta 1.13\left(\mathrm{t}, 3 \mathrm{H}, \mathrm{CH}_{2} \mathrm{CH}_{3}, \mathrm{~J}=7.6 \mathrm{~Hz}\right) ; 2.25\left(\mathrm{~s}, 3 \mathrm{H}, \mathrm{N}=\mathrm{CCH}_{3}\right) ; 2.39(\mathrm{q}, 2 \mathrm{H}$, $\mathrm{CH}_{2} \mathrm{CH}_{3}, \mathrm{~J}=7.6 \mathrm{~Hz}$ ); 6.81 (exch br s, $2 \mathrm{H}, \mathrm{NH}_{2}$ ); 8.03 (exch br s, $1 \mathrm{H}, \mathrm{NH}$ ). Anal. Calcd for $\mathrm{C}_{7} \mathrm{H}_{11} \mathrm{~N}_{3} \mathrm{O}$ (153.18): C, 54.89; H, 7.24; N, 27.43; Found: C, 54.76; H, 7.23; N, 27.51.

5.1.9.2. 4-Amino-6-methyl-5-propylpyridazin-3(2H)-one, 9b. Yield $=85 \% ; \mathrm{mp}=242-244{ }^{\circ} \mathrm{C}$ dec. (EtOH). ${ }^{1} \mathrm{H}-\mathrm{NMR}\left(\mathrm{CDCl}_{3}\right) \delta 0.91\left(\mathrm{t}, 3 \mathrm{H}, \mathrm{CH}_{2} \mathrm{CH}_{3}, \mathrm{~J}=7.2 \mathrm{~Hz}\right) ; 1.34-1.40(\mathrm{~m}, 2 \mathrm{H}$, $\left.\mathrm{CH}_{2} \mathrm{CH}_{2} \mathrm{CH}_{3}\right) ; 2.09\left(\mathrm{~s}, 3 \mathrm{H}, \mathrm{N}=\mathrm{CCH}_{3}\right) ; 2.28-2.33\left(\mathrm{~m}, 2 \mathrm{H}, \mathrm{CH}_{2} \mathrm{CH}_{2} \mathrm{CH}_{3}\right) ; 5.89$ (exch br s, $\left.2 \mathrm{H}, \mathrm{NH}_{2}\right) ;$ 12.18 (exch br s, $1 \mathrm{H}, \mathrm{NH}$ ). Anal. Calcd for $\mathrm{C}_{8} \mathrm{H}_{13} \mathrm{~N}_{3} \mathrm{O}$ (167.21): C, 57.46; H, 7.84; N, 25.13; Found: C, 57.59; H, 7.83; N, 25.06.

5.1.9.3. 4-Amino-5-butyl-6-methylpyridazin-3(2H)-one, 9c. Yield $=82 \% ; \mathrm{mp}=205-206{ }^{\circ} \mathrm{C}$ $(\mathrm{EtOH}) .{ }^{1} \mathrm{H}-\mathrm{NMR} \quad\left(\mathrm{CDCl}_{3}\right) \quad \delta \quad 0.96\left(\mathrm{t}, \quad 3 \mathrm{H}, \quad \mathrm{CH}_{2} \mathrm{CH}_{3}, \quad \mathrm{~J}=7.2 \mathrm{~Hz}\right) ; 1.43-1.50 \quad(\mathrm{~m}, 4 \mathrm{H}$, $\left.\mathrm{CH}_{2} \mathrm{CH}_{2} \mathrm{CH}_{2} \mathrm{CH}_{3}\right) ; 2.34$ (s, 3H, N= $\left.\mathrm{CCH}_{3}\right) ; 2.38$ (t, $2 \mathrm{H}, \mathrm{CH}_{2} \mathrm{CH}_{2} \mathrm{CH}_{2} \mathrm{CH}_{3}, \mathrm{~J}=7.2 \mathrm{~Hz}$ ); 6.03 (exch br s, $2 \mathrm{H}, \mathrm{NH}_{2}$ ); 11.89 (exch br s, $1 \mathrm{H}, \mathrm{NH}$ ). Anal. Calcd for $\mathrm{C}_{9} \mathrm{H}_{15} \mathrm{~N}_{3} \mathrm{O}$ (181.23): C, 59.64; H, 8.34; N, 23.19; Found: C, 59.77; H, 8.33; N, 23.12.

5.1.9.4. 4-Amino-6-methyl-5-pentylpyridazin-3(2H)-one, 9d. Yield $=70 \% ; \mathrm{mp}=230-232{ }^{\circ} \mathrm{C}$ $(\mathrm{EtOH}) . \quad{ }^{1} \mathrm{H}-\mathrm{NMR} \quad\left(\mathrm{CDCl}_{3}\right) \quad \delta \quad 0.90 \quad\left(\mathrm{t}, \quad 3 \mathrm{H}, \quad \mathrm{CH}_{2} \mathrm{CH}_{3}, \quad \mathrm{~J}=7.2 \mathrm{~Hz}\right) ; \quad 1.35-1.40 \quad(\mathrm{~m}, \quad 4 \mathrm{H}$, $\left.\mathrm{CH}_{2} \mathrm{CH}_{2} \mathrm{CH}_{2} \mathrm{CH}_{3}\right) ; 1.45-1.53\left(\mathrm{~m}, 2 \mathrm{H}, \mathrm{CH}_{2} \mathrm{CH}_{2} \mathrm{CH}_{2} \mathrm{CH}_{3}\right) ; 2.26\left(\mathrm{~s}, 3 \mathrm{H}, \mathrm{N}=\mathrm{CCH}_{3}\right) ; 2.34-2.40(\mathrm{~m}, 2 \mathrm{H}$, $\mathrm{CH}_{2} \mathrm{C}_{4} \mathrm{H}_{9}$ ); 4.86 (exch br s, $1 \mathrm{H}, \mathrm{NH}$ ); 6.88 (exch br s, $2 \mathrm{H}, \mathrm{NH}_{2}$ ). Anal. Calcd for $\mathrm{C}_{10} \mathrm{H}_{17} \mathrm{~N}_{3} \mathrm{O}$ (195.26): C, 61.51; H, 8.78; N, 21.52; Found: C, 61.70; H, 8.77; N, 21.56. 


\subsubsection{General procedures for $10 \mathrm{a}-\mathrm{d}$}

Compounds 10a-d were obtained starting from 9a-d following the same procedure described for $\mathbf{5 b}$ - c and $\mathbf{5 f}$. For compounds $\mathbf{1 0 b}-\mathbf{d}$ the suspension was extracted with ethyl acetate (3x $15 \mathrm{~mL})$; the organic layer was dried over $\mathrm{Na}_{2} \mathrm{SO}_{4}$ and evaporated to give desired final compounds which were purified by column chromatography using cyclohexane/ethyl acetate $1: 2$ (for $\mathbf{1 0 b}$ and $\mathbf{1 0 d}$ ) or cyclohexane/ethyl acetate 1:3 (for 10c) as eluents.

5.1.10.1. 2-(5-Amino-4-ethyl-3-methyl-6-oxopyridazin-1(6H)-yl)-N-(4-bromophenyl) acetamide, 10a. Yield $=74 \% ; \mathrm{mp}=206-208{ }^{\circ} \mathrm{C}(\mathrm{EtOH}) .{ }^{1} \mathrm{H}-\mathrm{NMR}\left(\mathrm{CDCl}_{3}\right) \delta 1.14\left(\mathrm{t}, 3 \mathrm{H}, \mathrm{CH}_{2} \mathrm{CH}_{3}\right.$, $\mathrm{J}=7.6 \mathrm{~Hz}) ; 2.28\left(\mathrm{~s}, 3 \mathrm{H}, \mathrm{N}=\mathrm{CCH}_{3}\right) ; 2.41\left(\mathrm{q}, 2 \mathrm{H}, \mathrm{CH}_{2} \mathrm{CH}_{3}, \mathrm{~J}=7.6 \mathrm{~Hz}\right) ; 4.89\left(\mathrm{~s}, 2 \mathrm{H}, \mathrm{NCH}_{2}\right) ; 6.88$ (exch br s, $\left.2 \mathrm{H}, \mathrm{NH}_{2}\right) ; 7.36-7.40(\mathrm{~m}, 4 \mathrm{H}, \mathrm{Ar}) ; 9.00$ (exch br s, 1H, NH). Anal. Calcd for $\mathrm{C}_{15} \mathrm{H}_{17} \mathrm{BrN}_{4} \mathrm{O}_{2}$ (365.23): C, 49.33; H, 4.69; N, 15.34; Found: C, 49.21; H, 4.68; N, 15.38.

5.1.10.2. 2-(5-Amino-3-methyl-6-oxo-4-propylpyridazin-1(6H)-yl)-N-(4-bromophenyl) acetamide, 10b. Yield $=19 \% ; \mathrm{mp}=197-199{ }^{\circ} \mathrm{C}$ dec. $(\mathrm{EtOH}) .{ }^{1} \mathrm{H}-\mathrm{NMR}\left(\mathrm{CDCl}_{3}\right) \delta 1.02(\mathrm{t}, 3 \mathrm{H}$, $\left.\mathrm{CH}_{2} \mathrm{CH}_{3}, \mathrm{~J}=7.2 \mathrm{~Hz}\right) ; 1.51-1.59\left(\mathrm{~m}, 2 \mathrm{H}, \mathrm{CH}_{2} \mathrm{CH}_{2} \mathrm{CH}_{3}\right) ; 2.27\left(\mathrm{~s}, 3 \mathrm{H}, \mathrm{N}=\mathrm{CCH}_{3}\right) ; 2.37(\mathrm{t}, 2 \mathrm{H}$, $\left.\mathrm{CH}_{2} \mathrm{CH}_{2} \mathrm{CH}_{3}, \mathrm{~J}=7.2 \mathrm{~Hz}\right) ; 4.89\left(\mathrm{~s}, 2 \mathrm{H}, \mathrm{NCH}_{2}\right) ; 6.84$ (exch br s, $\left.2 \mathrm{H}, \mathrm{NH}_{2}\right) ; 7.35-7.41$ (m, 4H, Ar); 9.04 (exch br s, $1 \mathrm{H}, \mathrm{NH}$ ). Anal. Calcd for $\mathrm{C}_{16} \mathrm{H}_{19} \mathrm{BrN}_{4} \mathrm{O}_{2}$ (379.25): C, 50.67; H, 5.05; N, 14.77; Found: C, 50.53; H, 5.06; N, 14.74.

5.1.10.3. 2-(5-Amino-4-butyl-3-methyl-6-oxopyridazin-1(6H)-yl)-N-(4-bromophenyl) acetamide, 10c. Yield $=26 \%$; oil. ${ }^{1} \mathrm{H}-\mathrm{NMR}\left(\mathrm{CDCl}_{3}\right) \delta 0.96\left(\mathrm{t}, 3 \mathrm{H},\left(\mathrm{CH}_{2}\right)_{3} \mathrm{CH}_{3}, \mathrm{~J}=7.2 \mathrm{~Hz}\right) ; 1.43$ $1.50\left(\mathrm{~m}, 4 \mathrm{H}, \mathrm{CH}_{2} \mathrm{CH}_{2} \mathrm{CH}_{2} \mathrm{CH}_{3}\right) ; 2.34\left(\mathrm{~s}, 3 \mathrm{H}, \mathrm{N}=\mathrm{CCH}_{3}\right) ; 2.38\left(\mathrm{t}, 2 \mathrm{H}, \mathrm{CH}_{2}\left(\mathrm{CH}_{2}\right)_{2} \mathrm{CH}_{3}, \mathrm{~J}=6.4 \mathrm{~Hz}\right)$; 4.90 (s, 2H, $\mathrm{NCH}_{2}$ ); 6.59 (exch br s, 2H, $\mathrm{NH}_{2}$ ); 7.34-7.40 (m, 4H, Ar); 8.87 (exch br s, 1H, NH). Anal. Calcd for $\mathrm{C}_{17} \mathrm{H}_{21} \mathrm{BrN}_{4} \mathrm{O}_{2}$ (393.28): C, 51.92; H, 5.38; N, 14.25; Found: C, 51.76; H, 5.07; N, 14.22.

5.1.10.4. 2-(5-Amino-3-methyl-6-oxo-4-pentylpyridazin-1(6H)-yl)-N-(4-bromophenyl) acetamide, 10d. Yield $=75 \% ; \mathrm{mp}=167-171{ }^{\circ} \mathrm{C}(\mathrm{EtOH}) .{ }^{1} \mathrm{H}-\mathrm{NMR}\left(\mathrm{CDCl}_{3}\right) \delta 0.90(\mathrm{t}, 3 \mathrm{H}$, $\left.\left(\mathrm{CH}_{2}\right)_{4} \mathrm{CH}_{3}, \quad \mathrm{~J}=7.2 \mathrm{~Hz}\right) ; 1.34-1.39\left(\mathrm{~m}, \quad 4 \mathrm{H}, \quad\left(\mathrm{CH}_{2}\right)_{2} \mathrm{CH}_{2} \mathrm{CH}_{2} \mathrm{CH}_{3}\right) ; \quad 1.47-1.52 \quad(\mathrm{~m}, \quad 2 \mathrm{H}$, 
$\left.\mathrm{CH}_{2} \mathrm{CH}_{2}\left(\mathrm{CH}_{2}\right)_{2} \mathrm{CH}_{3}\right) ; 2.26\left(\mathrm{~s}, 3 \mathrm{H}, \mathrm{N}=\mathrm{CCH}_{3}\right) ; 2.33-2.38\left(\mathrm{~m}, 2 \mathrm{H}, \mathrm{CH}_{2}\left(\mathrm{CH}_{2}\right)_{3} \mathrm{CH}_{3}\right) ; 4.88(\mathrm{~s}, 2 \mathrm{H}$, $\mathrm{NCH}_{2}$ ); 6.59 (exch br s, 2H, $\mathrm{NH}_{2}$ ); 7.36-7.41 (m, 4H, Ar); 9.04 (exch br s, 1H, NH). Anal. Calcd for $\mathrm{C}_{18} \mathrm{H}_{23} \mathrm{BrN}_{4} \mathrm{O}_{2}$ (407.30): C, 53.08; H, 5.69; N, 13.76; Found: C, 53.26; H, 5.68; N, 13.79.

\subsubsection{General procedures for 11a-d}

Compounds 11a-d were obtained starting from 10a-d following the same procedure described for 6a-f. The final desired compounds were purified by column chromatography using as eluent $\mathrm{CH}_{2} \mathrm{Cl}_{2} / \mathrm{MeOH}$ 98:2 for compounds 11a, $\mathrm{CH}_{2} \mathrm{Cl}_{2} / \mathrm{MeOH}$ 99:1 for 11c and cyclohexane/ethyl acetate 1:2 for compounds $\mathbf{1 1 b}$ and $\mathbf{1 1 d}$.

5.1.11.1. N-(4-Bromophenyl)-2-[4-ethyl-5-(3-methoxyphenylamino)-3-methyl-6-oxopyridazin1(6H)-yl]acetamide, 11a. Yield $=18 \% ; \mathrm{mp}=81-84{ }^{\circ} \mathrm{C}(\mathrm{EtOH}) .{ }^{1} \mathrm{H}-\mathrm{NMR}\left(\mathrm{CDCl}_{3}\right) \delta 0.88(\mathrm{t}, 3 \mathrm{H}$, $\left.\mathrm{CH}_{2} \mathrm{CH}_{3}, \mathrm{~J}=7.2 \mathrm{~Hz}\right) ; 2.28\left(\mathrm{~s}, 3 \mathrm{H}, \mathrm{N}=\mathrm{CCH}_{3}\right) ; 2.30-2.36\left(\mathrm{~m}, 2 \mathrm{H}, \mathrm{CH}_{2} \mathrm{CH}_{3}\right) ; 3.78\left(\mathrm{~s}, 3 \mathrm{H}, \mathrm{CH}_{3} \mathrm{O}\right) ; 4.93$ (s, 2H, $\left.\mathrm{NCH}_{2}\right) ; 6.51-6.66$ (m, 3H, Ar); 7.01 (exch br s, 1H, NH); 7.19 (t, 1H, Ar, J = 8.2 Hz); 7.327.39 (m, 4H, Ar); 9.11 (exch br s, $1 \mathrm{H}, \mathrm{NH}$ ). Anal. Calcd for $\mathrm{C}_{22} \mathrm{H}_{23} \mathrm{BrN}_{4} \mathrm{O}_{3}$ (471.35): C, 56.06; $\mathrm{H}$, 4.92; N, 11.89; Found: C, 56.21; H, 4.91; N, 11.92.

5.1.11.2. N-(4-Bromophenyl)-2-[5-(3-methoxyphenylamino)-3-methyl-6-oxo-4-propyl pyridazin-1(6H)-yl]acetamide, 11b. Yield = 18\%; oil. ${ }^{1} \mathrm{H}-\mathrm{NMR}\left(\mathrm{CDCl}_{3}\right) \delta 0.66\left(\mathrm{t}, 3 \mathrm{H},\left(\mathrm{CH}_{2}\right)_{2} \mathrm{CH}_{3}\right.$, $\mathrm{J}=7.2 \mathrm{~Hz}) ; 1.26-1.32\left(\mathrm{~m}, 2 \mathrm{H}, \mathrm{CH}_{2} \mathrm{CH}_{2} \mathrm{CH}_{3}\right) ; 2.23-2.31\left(\mathrm{~m}, 2 \mathrm{H}, \mathrm{CH}_{2} \mathrm{CH}_{2} \mathrm{CH}_{3}\right) ; 2.35(\mathrm{~s}, 3 \mathrm{H}$, $\left.\mathrm{N}=\mathrm{CCH}_{3}\right) ; 3.78\left(\mathrm{~s}, 3 \mathrm{H}, \mathrm{OCH}_{3}\right) ; 4.92\left(\mathrm{~s}, 2 \mathrm{H}, \mathrm{NCH}_{2}\right) ; 6.52-6.68(\mathrm{~m}, 4 \mathrm{H}, \mathrm{Ar}) ; 6.84($ exch br s, 1H, $\mathrm{NH})$; 7.35-7.42 (m, 4H, Ar); 9.04 (exch br s, 1H, NH). Anal. Calcd for $\mathrm{C}_{23} \mathrm{H}_{25} \mathrm{BrN}_{4} \mathrm{O}_{3}$ (485.37): C, 56.91; H, 5.19; N, 11.54; Found: C, 56.73; H, 5.20; N, 11.51.

5.1.11.3. N-(4-Bromophenyl)-2-[4-butyl-5-(3-methoxyphenylamino)-3-methyl-6-oxopyridazin1(6H)-yl]acetamide, 11c. Yield $=15 \%$; oil. ${ }^{1} \mathrm{H}-\mathrm{NMR}\left(\mathrm{CDCl}_{3}\right) \delta 0.68\left(\mathrm{t}, 3 \mathrm{H},\left(\mathrm{CH}_{2}\right)_{3} \mathrm{CH}_{3}, \mathrm{~J}=7.2\right.$ $\mathrm{Hz}) ; 1.00-1.08\left(\mathrm{~m}, 4 \mathrm{H}, \mathrm{CH}_{2} \mathrm{CH}_{2} \mathrm{CH}_{2} \mathrm{CH}_{3}\right) ; 2.24-2.30\left(\mathrm{~m}, 2 \mathrm{H}, \mathrm{CH}_{2} \mathrm{CH}_{2} \mathrm{CH}_{2} \mathrm{CH}_{3}\right) ; 2.33(\mathrm{~s}, 3 \mathrm{H}$, $\left.\mathrm{N}=\mathrm{CCH}_{3}\right) ; 3.78\left(\mathrm{~s}, 3 \mathrm{H}, \mathrm{OCH}_{3}\right) ; 4.93\left(\mathrm{~s}, 2 \mathrm{H}, \mathrm{NCH}_{2}\right) ; 6.60-6.69(\mathrm{~m}, 4 \mathrm{H}, \mathrm{Ar}) ; 6.84($ exch br s, 1H, $\mathrm{NH})$; 7.35-7.42 (m, 4H, Ar); 9.01 (exch br s, 1H, NH). Anal. Calcd for $\mathrm{C}_{24} \mathrm{H}_{27} \mathrm{BrN}_{4} \mathrm{O}_{3}$ (499.40): C, 57.72; H, 5.45; N, 11.22; Found: C, 57.85; H, 5.46; N, 11.25. 


\subsubsection{N-(4-Bromophenyl)-2-[5-(3-methoxyphenylamino)-3-methyl-6-oxo-4-pentyldazin-}

1(6H)-yl]acetamide, 11d. Yield = 16\%; oil. ${ }^{1} \mathrm{H}-\mathrm{NMR}\left(\mathrm{CDCl}_{3}\right) \delta 0.68\left(\mathrm{t}, 3 \mathrm{H},\left(\mathrm{CH}_{2}\right)_{4} \mathrm{CH}_{3}, \mathrm{~J}=7.2\right.$ $\mathrm{Hz})$; 0.98-1.01 (m, 2H, $\left.\left(\mathrm{CH}_{2}\right)_{3} \mathrm{CH}_{2} \mathrm{CH}_{3}\right) ; 1.08-1.14\left(\mathrm{~m}, 2 \mathrm{H},\left(\mathrm{CH}_{2}\right)_{2} \mathrm{CH}_{2} \mathrm{CH}_{2} \mathrm{CH}_{3}\right) ; 1.24-1.29(\mathrm{~m}, 4 \mathrm{H}$, $\left.\mathrm{CH}_{2} \mathrm{CH}_{2} \mathrm{CH}_{2} \mathrm{CH}_{3}\right) ; 2.31\left(\mathrm{~s}, 3 \mathrm{H}, \mathrm{N}=\mathrm{CCH}_{3}\right) ; 3.77\left(\mathrm{~s}, 3 \mathrm{H}, \mathrm{OCH}_{3}\right) ; 4.92\left(\mathrm{~s}, 2 \mathrm{H}, \mathrm{NCH}_{2}\right) ; 6.50-6.69(\mathrm{~m}$, 4H, Ar); 6.91 (exch br s, 1H, NH); 7.33-7.39 (m, 4H, Ar); 9.06 (exch br s, 1H, NH). Anal. Calcd for $\mathrm{C}_{25} \mathrm{H}_{29} \mathrm{BrN}_{4} \mathrm{O}_{3}$ (513.43): C, 58.48; H, 5.69; N, 10.91; Found: C, 58.31; H, 5.70; N, 10.97.

\subsubsection{2-(5-Amino-3-methyl-6-oxo-4-vinylpyridazin-1 $(6 \mathrm{H})-y \mathrm{l})-\mathrm{N}$-(4-bromophenyl)acetamide,}

12. Compound $\mathbf{1 2}$ was obtained following the same procedure described for $\mathbf{5 b} \mathbf{b}$, $\mathbf{5} \mathbf{f}$ starting from 8a, followed by purification with column flash chromatography using cyclohexane/ethyl acetate 1:4 as eluent. Yield $=52 \% ; \mathrm{mp}=194-196{ }^{\circ} \mathrm{C}(\mathrm{EtOH}) .{ }^{1} \mathrm{H}-\mathrm{NMR}\left(\mathrm{CDCl}_{3}\right) \delta 2.26\left(\mathrm{~s}, 3 \mathrm{H}, \mathrm{N}=\mathrm{CCH}_{3}\right) ; 4.96$ $\left(\mathrm{s}, 2 \mathrm{H}, \mathrm{NCH}_{2}\right) ; 5.26\left(\right.$ exch br s, $\left.2 \mathrm{H}, \mathrm{NH}_{2}\right) ; 5.64(\mathrm{~d}, 1 \mathrm{H}, \mathrm{CHCH}-H, J=18 \mathrm{~Hz}) ; 5.78(\mathrm{~d}, 1 \mathrm{H}, \mathrm{CHCH}-$ $H, J=12 \mathrm{~Hz}) ; 6.47\left(\mathrm{dd}, 1 \mathrm{H}, C H \mathrm{HH}_{2}, J=18 \mathrm{~Hz}, J=12 \mathrm{~Hz}\right) ; 7.38(\mathrm{~m}, 4 \mathrm{H}, \mathrm{Ar}) ; 9.00($ exch br s, $1 \mathrm{H}$, NH). Anal. Calcd for $\mathrm{C}_{15} \mathrm{H}_{15} \mathrm{BrN}_{4} \mathrm{O}_{2}$ (363.21): C, 49.60; H, 4.16; N, 15.43; Found: C, 49.76; H, $4.17 ; \mathrm{N}, 15.39$.

\subsubsection{3. $\quad N$-(4-Bromophenyl)-2-[5-(3-methoxyphenylamino)-3-methyl-6-oxo-4-vinylpyridazin-} 1(6H)-yl]acetamide, 13. Compound 13 was obtained starting from 12 following the general procedure described for 6a-f. The residue was purified by crystallization from ethanol, followed by column flash chromatography using $\mathrm{CH}_{2} \mathrm{Cl}_{2} / \mathrm{MeOH}$ 98:2 as eluent. Yield $=39 \% ; \mathrm{mp}=182-184{ }^{\circ} \mathrm{C}$ $(\mathrm{EtOH}) .{ }^{1} \mathrm{H}-\mathrm{NMR}\left(\mathrm{CDCl}_{3}\right) \delta 2.32\left(\mathrm{~s}, 3 \mathrm{H}, \mathrm{N}=\mathrm{CCH}_{3}\right) ; 3.79\left(\mathrm{~s}, 3 \mathrm{H}, \mathrm{OCH}_{3}\right) ; 5.00\left(\mathrm{~s}, 2 \mathrm{H}, \mathrm{NCH}_{2}\right) ; 5.07$ $(\mathrm{d}, 1 \mathrm{H}, \mathrm{CHCH}-H, J=18 \mathrm{~Hz}) ; 5.29(\mathrm{~d}, 1 \mathrm{H}, \mathrm{CHCH}-H, J=12 \mathrm{~Hz}) ; 6.24\left(\mathrm{dd}, 1 \mathrm{H}, \mathrm{CHCH}_{2}, J=18 \mathrm{~Hz}\right.$, $J=12 \mathrm{~Hz}) ; 6.41(\mathrm{~s}, 1 \mathrm{H}, \mathrm{Ar}) ; 6.48(\mathrm{~d}, 1 \mathrm{H}, \mathrm{Ar}, J=8.0 \mathrm{~Hz}) ; 6.63(\mathrm{~d}, 1 \mathrm{H}, \mathrm{Ar}, J=8.0 \mathrm{~Hz}) ; 7.18(\mathrm{t}, 1 \mathrm{H}$, Ar, $J=8.0 \mathrm{~Hz}$ ); $7.38(\mathrm{~m}, 4 \mathrm{H}, \mathrm{Ar}) ; 7.51$ (exch br s, $1 \mathrm{H}, \mathrm{NH}) ; 9.09$ (exch br s, $1 \mathrm{H}, \mathrm{NH}) .{ }^{13} \mathrm{C}-\mathrm{NMR}$ $\left(\mathrm{CDCl}_{3}\right) \delta 21.0\left(\mathrm{CH}_{3}\right) ; 55.3\left(\mathrm{CH}_{3}\right) ; 57.5\left(\mathrm{CH}_{2}\right) ; 108.4(\mathrm{CH}) ; 109.4(\mathrm{CH}) ; 114.8(\mathrm{CH}) ; 116.8(\mathrm{C})$; $117.0(\mathrm{C}) ; 121.4(2 \times \mathrm{CH}) ; 121.9\left(\mathrm{CH}_{2}\right) ; 129.2(2 \times \mathrm{CH}) ; 131.8(2 \times \mathrm{CH}) ; 135.9(\mathrm{C}) ; 136.8(\mathrm{C})$; 139.9 (C); 147.3 (C); 158.2 (C); 159.9 (C); 165.3 (C). Anal. Calcd for $\mathrm{C}_{22} \mathrm{H}_{21} \mathrm{BrN}_{4} \mathrm{O}_{3}$ (469.33): C, 56.30; H, 4.51; N, 11.94; Found: C, 56.48; H, 4.50; N, 11.91. 


\subsubsection{General procedures for $15 a$ and $15 b$}

A catalytic amount of $\mathrm{Et}_{3} \mathrm{~N}(0.20 \mathrm{~mL})$ was added to a solution of $\mathbf{1 4}$ [27] (1.32 mmol) in 3 $\mathrm{mL}$ of appropriate solvent $(\mathrm{MeOH}$ for $\mathbf{1 5 a}$ or $\mathrm{EtOH}$ for $\mathbf{1 5 b})$, and the reaction was carried out at $60^{\circ} \mathrm{C}$ for $4 \mathrm{~h}$. After cooling, the precipitate was recovered by suction to obtain pure $\mathbf{1 5 a}-\mathbf{b}$.

5.1.14.1. Methyl 5-amino-1,6-dihydro-3-methyl-6-oxopyridazine-4-carboxylate, 15a. Yield = $99 \% ; \mathrm{mp}=253-254{ }^{\circ} \mathrm{C}(\mathrm{MeOH}) .{ }^{1} \mathrm{H}-\mathrm{NMR}\left(\mathrm{CDCl}_{3}\right) \delta 2.49\left(\mathrm{~s}, 3 \mathrm{H}, \mathrm{N}=\mathrm{CCH}_{3}\right) ; 3.94(\mathrm{~s}, 3 \mathrm{H}$, $\left.\mathrm{COOCH}_{3}\right) ; 5.43($ exch br s, $1 \mathrm{H}, \mathrm{NH}) ; 8.23$ (exch br s, $2 \mathrm{H}, \mathrm{NH}_{2}$ ). Anal. Calcd for $\mathrm{C}_{7} \mathrm{H}_{9} \mathrm{~N}_{3} \mathrm{O}_{3}$ (183.16): C, 45.90; H, 4.95; N, 22.94; Found: C, 45.76; H, 4.94; N, 22.99.

5.1.14.2. Ethyl 5-amino-1,6-dihydro-3-methyl-6-oxopyridazine-4-carboxylate, 15b. Yield = $73 \% ; \mathrm{mp}=226-228{ }^{\circ} \mathrm{C}(\mathrm{EtOH}) .{ }^{1} \mathrm{H}-\mathrm{NMR}\left(\mathrm{CDCl}_{3}\right) \delta 1.43\left(\mathrm{t}, 3 \mathrm{H}, \mathrm{CH}_{2} \mathrm{CH}_{3}, J=7.2 \mathrm{~Hz}\right) ; 2.50(\mathrm{~s}, 3 \mathrm{H}$, $\left.\mathrm{N}=\mathrm{CCH}_{3}\right) ; 4.40\left(\mathrm{q}, 2 \mathrm{H}, \mathrm{CH}_{2} \mathrm{CH}_{3}, J=7.2 \mathrm{~Hz}\right) ; 5.86$ (exch br s, $\left.1 \mathrm{H}, \mathrm{NH}\right) ; 8.87$ (exch br s, $\left.2 \mathrm{H}, \mathrm{NH}_{2}\right)$. Anal. Calcd for $\mathrm{C}_{8} \mathrm{H}_{11} \mathrm{~N}_{3} \mathrm{O}_{3}$ (197.19): C, 48.73; H, 5.62; N, 21.31; Found: C, 48.86; H, 5.61; N, 21.36.

\subsubsection{General procedures for $16 \mathrm{a}$ and $16 \mathrm{~b}$}

Compounds 16a-b were obtained starting from 15a-b following the same procedure described for 5b-c, and 5f.

\subsubsection{Methyl 1-[(4-bromophenylcarbamoyl)methyl]-5-amino-1,6-dihydro-3-methyl-6-} oxopyridazine-4-carboxylate, 16a. Yield $=98 \% ; \mathrm{mp}=197-199{ }^{\circ} \mathrm{C}(\mathrm{EtOH}) .{ }^{1} \mathrm{H}-\mathrm{NMR}\left(\mathrm{CDCl}_{3}\right) \delta$ $2.51\left(\mathrm{~s}, 3 \mathrm{H}, \mathrm{N}=\mathrm{CCH}_{3}\right) ; 3.94\left(\mathrm{~s}, 3 \mathrm{H}, \mathrm{OCH}_{3}\right) ; 4.90\left(\mathrm{~s}, 2 \mathrm{H}, \mathrm{NCH}_{2}\right) ; 7.43(\mathrm{~s}, 4 \mathrm{H}, \mathrm{Ar}) ; 8.50$ (exch br s, $1 \mathrm{H}, \mathrm{NH}) ; 8.90$ (exch br s, $1 \mathrm{H}, \mathrm{NH}_{2}$ ). Anal. Calcd for $\mathrm{C}_{15} \mathrm{H}_{15} \mathrm{BrN}_{4} \mathrm{O}_{4}(395.21)$ : C, 45.59; H, 3.83; N, 14.18; Found: C, 45.68; H, 3.82; N, 14.21.

\subsubsection{Ethyl 1-[(4-bromophenylcarbamoyl)methyl]-5-amino-1,6-dihydro-3-methyl-6-} oxopyridazine-4-carboxylate, 16b. Yield $=94 \% ; \mathrm{mp}=217-219{ }^{\circ} \mathrm{C}(\mathrm{EtOH}) .{ }^{1} \mathrm{H}-\mathrm{NMR}\left(\mathrm{CDCl}_{3}\right) \delta$ $1.43\left(\mathrm{t}, 3 \mathrm{H}, \mathrm{CH}_{2} \mathrm{CH}_{3}, J=7.2 \mathrm{~Hz}\right) ; 2.52\left(\mathrm{~s}, 3 \mathrm{H}, \mathrm{N}=\mathrm{CCH}_{3}\right) ; 4.40\left(\mathrm{q}, 2 \mathrm{H}, \mathrm{CH}_{2} \mathrm{CH}_{3}, J=7.2 \mathrm{~Hz}\right) ; 4.91$ (s, $2 \mathrm{H}, \mathrm{NCH}_{2}$ ); 7.43 (s, 4H, Ar); 8.52 (exch br s, $1 \mathrm{H}, \mathrm{NH}$ ); 9.21 (exch br s, $2 \mathrm{H}, \mathrm{NH}_{2}$ ). Anal. Calcd for $\mathrm{C}_{16} \mathrm{H}_{17} \mathrm{BrN}_{4} \mathrm{O}_{4}$ (409.23): C, 46.96; H, 4.19; N, 13.69; Found: $\mathrm{C}, 47.09 ; \mathrm{H}, 4.18 ; \mathrm{N}, 13.65$. 


\subsubsection{General procedures for $17 \mathrm{a}$ and $17 \mathrm{~b}$}

Compounds 17a-b were obtained starting from 16a-b following the same procedure described for 6a-f. The final desired compounds were purified by crystallization from ethanol, followed by column flash chromatography using $\mathrm{CH}_{2} \mathrm{Cl}_{2} / \mathrm{MeOH}$ 98:2 as eluent.

5.1.16.1. Methyl 1-[(4-bromophenylcarbamoyl)methyl]-5-(3-methoxyphenylamino)-1,6dihydro-3-methyl-6-oxopyridazine-4-carboxylate, 17a. Yield $=12 \% ; \mathrm{mp}=194-195{ }^{\circ} \mathrm{C}(\mathrm{EtOH})$. ${ }^{1} \mathrm{H}-\mathrm{NMR}\left(\mathrm{CDCl}_{3}\right) \delta 2.33\left(\mathrm{~s}, 3 \mathrm{H}, \mathrm{CCH}_{3}\right) ; 3.20\left(\mathrm{~s}, 3 \mathrm{H}, \mathrm{COOCH}_{3}\right) ; 3.82\left(\mathrm{~s}, 3 \mathrm{H}, \mathrm{OCH}_{3}\right) ; 4.97(\mathrm{~s}, 2 \mathrm{H}$, $\left.\mathrm{NCH}_{2}\right) ; 6.64(\mathrm{~s}, 1 \mathrm{H}, \mathrm{Ar}) ; 6.70(\mathrm{~d}, 1 \mathrm{H}, \mathrm{Ar}, J=8.4 \mathrm{~Hz}) ; 6.77(\mathrm{~d}, 1 \mathrm{H}, \mathrm{Ar}, J=8.4 \mathrm{~Hz}) ; 7.26(\mathrm{t}, 1 \mathrm{H}, \mathrm{Ar}, J$ $=8.4 \mathrm{~Hz}) ; 7.42(\mathrm{~s}, 4 \mathrm{H}, \mathrm{Ar}) ; 7.90($ exch br s, $1 \mathrm{H}, \mathrm{NH}) ; 8.59$ (exch br s, $1 \mathrm{H}, \mathrm{NH}) .{ }^{13} \mathrm{C}-\mathrm{NMR}\left(\mathrm{CDCl}_{3}\right)$

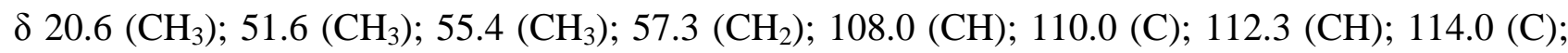
$115.0(\mathrm{CH}) ; 117.0(\mathrm{C}) ; 121.5(2 \times \mathrm{CH}) ; 130.2(\mathrm{CH}) ; 131.9(2 \times \mathrm{CH}) ; 136.5(\mathrm{C}) ; 138.8(\mathrm{C}) ; 139.4$ (C); 145.5 (C); 157.0 (C); 161.3 (C); 165.4 (C). Anal. Calcd for $\mathrm{C}_{22} \mathrm{H}_{21} \mathrm{BrN}_{4} \mathrm{O}_{5}$ (501.33): C, 52.71; H, 4.22; N, 11.18; Found: C, 52.87; H, 4.23; N, 11.16 .

5.1.16.2. Ethyl 1-[(4-bromophenylcarbamoyl)methyl]-5-(3-methoxyphenylamino)-1,6dihydro-3-methyl-6-oxopyridazine-4-carboxylate, 17b. Yield $=17 \% ; \mathrm{mp}=185-187{ }^{\circ} \mathrm{C}(\mathrm{EtOH})$. ${ }^{1} \mathrm{H}-\mathrm{NMR}\left(\mathrm{CDCl}_{3}\right) \delta 1.02\left(\mathrm{t}, 3 \mathrm{H}, \mathrm{CH}_{2} \mathrm{CH}_{3}, J=7.2 \mathrm{~Hz}\right) ; 2.33\left(\mathrm{~s}, 3 \mathrm{H}, \mathrm{N}=\mathrm{CCH}_{3}\right) ; 3.58\left(\mathrm{q}, 2 \mathrm{H}, \mathrm{CH}_{2} \mathrm{CH}_{3}\right.$, $J=7.2 \mathrm{~Hz}) ; 3.80\left(\mathrm{~s}, 3 \mathrm{H}, \mathrm{OCH}_{3}\right) ; 4.98\left(\mathrm{~s}, 2 \mathrm{H}, \mathrm{NCH}_{2}\right) ; 6.65(\mathrm{~s}, 1 \mathrm{H}, \mathrm{Ar}) ; 6.70(\mathrm{~d}, 1 \mathrm{H}, \mathrm{Ar}, J=8.4 \mathrm{~Hz})$; $6.75(\mathrm{~d}, 1 \mathrm{H}, \mathrm{Ar}, J=8.4 \mathrm{~Hz}) ; 7.25(\mathrm{t}, 1 \mathrm{H}, \mathrm{Ar}, J=8.4 \mathrm{~Hz}) ; 7.41(\mathrm{~s}, 4 \mathrm{H}, \mathrm{Ar}) ; 7.92($ exch br s, $1 \mathrm{H}, \mathrm{NH})$; $8.80($ exch br s, $1 \mathrm{H}, \mathrm{NH}) .{ }^{13} \mathrm{C}-\mathrm{NMR}\left(\mathrm{CDCl}_{3}\right) \delta 13.7\left(\mathrm{CH}_{3}\right) ; 20.7\left(\mathrm{CH}_{3}\right) ; 55.4\left(\mathrm{CH}_{3}\right) ; 57.2\left(\mathrm{CH}_{2}\right) ; 61.5$ $\left(\mathrm{CH}_{2}\right) ; 107.9(\mathrm{CH}) ; 108.1(\mathrm{C}) ; 112.1(\mathrm{CH}) ; 114.9(\mathrm{CH}) ; 117.0(\mathrm{C}) ; 121.5(2 \times \mathrm{CH}) ; 130.1(\mathrm{CH})$; 131.9 (2 x CH); 136.7 (C); 138.5 (C); 139.6 (C); 145.4 (C); 157.1 (C); 160.3 (C); 164.8 (C); 165.2 (C). Anal. Calcd for $\mathrm{C}_{23} \mathrm{H}_{23} \mathrm{BrN}_{4} \mathrm{O}_{5}$ (515.36): C, 53.60; H, 4.50; N, 10.87; Found: C, 53.47; H, 4.49; N, 10.90.

5.1.17. 1-[(4-Bromophenylcarbamoyl)-methyl]-5-(3-methoxyphenylamino)-1,6-dihydro-3methyl-6-oxopyridazine-4-carboxylate, 18. 
To prepare 18, $0.12 \mathrm{mmol}$ of $\mathbf{1 7 a}$ were suspended in $2 \mathrm{~N} \mathrm{NaOH}(2 \mathrm{~mL})$, and the reaction was stirred for $1 \mathrm{~h}$ at room temperature. The mixture was then diluted with ice-cold water and acidified with $6 \mathrm{~N} \mathrm{HCl}$. The resulting precipitate was recovered by suction and purified by column flash chromatography using $\mathrm{CH}_{2} \mathrm{Cl}_{2} / \mathrm{MeOH} 9: 1$ as eluent. Yield $=39 \% ; \mathrm{mp}=211-213{ }^{\circ} \mathrm{C}(\mathrm{EtOH}) .{ }^{1} \mathrm{H}-$ NMR $\left(\mathrm{CD}_{3} \mathrm{OD}-\mathrm{d}_{4}\right) \delta 2.39\left(\mathrm{~s}, 3 \mathrm{H}, \mathrm{N}=\mathrm{CCH}_{3}\right) ; 3.76\left(\mathrm{~s}, 3 \mathrm{H}, \mathrm{OCH}_{3}\right) ; 4.93\left(\mathrm{~s}, 2 \mathrm{H}, \mathrm{NCH}_{2}\right) ; 6.57-6.69(\mathrm{~m}$,

3H, Ar); $7.14(\mathrm{t}, 1 \mathrm{H}, \mathrm{Ar}, J=8.4 \mathrm{~Hz}) ; 7.53-7.54(\mathrm{~m}, 4 \mathrm{H}, \mathrm{Ar}) .{ }^{13} \mathrm{C}-\mathrm{NMR}\left(\mathrm{MeOD}-\mathrm{d}_{4}\right) \delta 19.7\left(\mathrm{CH}_{3}\right)$; $54.3\left(\mathrm{CH}_{3}\right) ; 55.0\left(\mathrm{CH}_{2}\right) ; 107.2(\mathrm{CH}) ; 109.9(\mathrm{CH}) ; 114.1(\mathrm{CH}) ; 116.2(\mathrm{C}) ; 117.0(\mathrm{C}) ; 119.5(\mathrm{C})$; 121.5 (2 x CH); $128.8(\mathrm{CH}) ; 131.4(2 \times \mathrm{CH}) ; 136.9(\mathrm{C}) ; 137.5(\mathrm{C}) ; 141.1(\mathrm{C}) ; 145.0(\mathrm{C}) ; 157.5(\mathrm{C})$; 159.9(C); 166.0 (C). Anal. Calcd for $\mathrm{C}_{21} \mathrm{H}_{19} \mathrm{BrN}_{4} \mathrm{O}_{5}$ (487.30): C, 51.76; H, 3.93; N, 11.50; Found: C, 51.90; H, 3.92; N, 11.47 .

5.1.18. $\quad N$-(4-Bromophenyl)-2-(3,4-dimethyl-7-oxoisoxazolo[3,4-d]pyridazin-6(7H)-yl) acetamide, 20.

Compound 20 was obtained starting from 19 [22] following the same procedure described for 5a, d, e. Finally, compound 20 was purified by crystallization from EtOH. Yield = 46\%; $\mathrm{mp}=$ $227-228{ }^{\circ} \mathrm{C}(\mathrm{EtOH}) .{ }^{1} \mathrm{H}-\mathrm{NMR}\left(\mathrm{CDCl}_{3}\right) \delta 2.52\left(\mathrm{~s}, 3 \mathrm{H}, \mathrm{N}=\mathrm{CCH}_{3}\right) ; 2.90\left(\mathrm{~s}, 3 \mathrm{H}, \mathrm{C}=\mathrm{CCH}_{3}\right) ; 4.93(\mathrm{~s}, 2 \mathrm{H}$, $\left.\mathrm{NCH}_{2}\right) ; 7.40-7.45(\mathrm{~m}, 4 \mathrm{H}, \mathrm{Ar}) ; 8.25$ (exch br s, $\left.1 \mathrm{H}, \mathrm{NH}\right)$. Anal. Calcd for $\mathrm{C}_{15} \mathrm{H}_{13} \mathrm{BrN}_{4} \mathrm{O}_{3}(377.19)$ : C, 47.76; H, 3.47; N, 14.85; Found: C, 47.82; H, 3.46; N, 14.88.

5.1.19. $\quad N$-(4-Bromophenyl)-2-[3-(2-dimethylaminovinyl)-4-methyl-7-oxoisoxazolo[3,4-d] pyridazin-6(7H)-yl]acetamide, 21.

A suspension of intermediate $20(0.79 \mathrm{mmol})$ in DMF/DMA $(4.5 \mathrm{~mL})$ was heated at $90{ }^{\circ} \mathrm{C}$ for $3 \mathrm{~h}$ in the dark. After cooling, ice-cold water was added to the mixture, and the precipitate formed was recovered through filtration under vacuum. Yield $=88 \% ; \mathrm{mp}=228-229{ }^{\circ} \mathrm{C}(\mathrm{EtOH}) .{ }^{1} \mathrm{H}-$ $\operatorname{NMR}\left(\mathrm{CDCl}_{3}\right) \delta 2.47\left(\mathrm{~s}, 3 \mathrm{H}, \mathrm{N}=\mathrm{CCH}_{3}\right) ; 2.60\left(\mathrm{~s}, 3 \mathrm{H}, \mathrm{NCH}_{3}\right) ; 2.89\left(\mathrm{~s}, 3 \mathrm{H}, \mathrm{NCH}_{3}\right) ; 4.91(\mathrm{~s}, 2 \mathrm{H}$, $\left.\mathrm{NCH}_{2}\right) ; 5.22(\mathrm{~d}, 1 \mathrm{H}, \mathrm{CH}=\mathrm{CH}, \mathrm{J}=12.4 \mathrm{~Hz}) ; 7.38-7.46(\mathrm{~m}, 4 \mathrm{H}, \mathrm{Ar}) ; 7.62(\mathrm{~d}, 1 \mathrm{H}, \mathrm{CH}=\mathrm{CH}, \mathrm{J}=12.4$ 
$\mathrm{Hz}$ ); 8.65 (exch br s, $1 \mathrm{H}, \mathrm{NH}$ ). Anal. Calcd for $\mathrm{C}_{18} \mathrm{H}_{18} \mathrm{BrN}_{5} \mathrm{O}_{3}$ (432.27): C, 50.01; H, 4.20; N, 16.20; Found: C, 50.15; H, 4.19; N, 16.17.

5.1.20. 2-[5-Amino-4-(3-dimethylaminoacryloyl)-3-methyl-6-oxo-5,6-dihydro-4H-pyridazin-1yl]-N-(4-bromo-phenyl)acetamide, 22.

To a stirred solution of $21(0.19 \mathrm{mmol})$ in anhydrous $\mathrm{CH}_{3} \mathrm{CN}(5 \mathrm{~mL}), \mathrm{Mo}(\mathrm{CO})_{6}(0.21 \mathrm{mmol})$ and a catalytic amount of $\mathrm{H}_{2} \mathrm{O}(0.1 \mathrm{~mL})$ were added at $50{ }^{\circ} \mathrm{C}$. The reaction was then carried out at reflux for $1.5 \mathrm{~h}$ [28]. The solvent was removed under vacuum, and ice-cold water was added to the mixture. After $1 \mathrm{~h}$ stirring in an ice-bath, the precipitate was recovered by suction and suspended in $\mathrm{CH}_{2} \mathrm{Cl}_{2}$. The resulting precipitate was filtered, and the pure 22 was obtained through evaporation of the organic layer under vacuum and purification by crystallization from $\mathrm{EtOH}$. Yield $=46 \% ; \mathrm{mp}=$ 208-209 ${ }^{\circ} \mathrm{C}(\mathrm{EtOH}) .{ }^{1} \mathrm{H}-\mathrm{NMR}$ (DMSO) $\delta 2.08\left(\mathrm{~s}, 3 \mathrm{H}, \mathrm{N}=\mathrm{CCH}_{3}\right) ; 2.57$ (s, 3H, NCH ); 2.60 (s, 3H, $\left.\mathrm{NCH}_{3}\right) ; 4.91\left(\mathrm{~s}, 2 \mathrm{H}, \mathrm{NCH}_{2}\right) ; 6.41(\mathrm{~d}, 1 \mathrm{H}, \mathrm{CH}=\mathrm{CH}, \mathrm{J}=7.2 \mathrm{~Hz}) ; 7.48-7.54(\mathrm{~m}, 4 \mathrm{H}, \mathrm{Ar}) ; 7.82(\mathrm{~d}, 1 \mathrm{H}$, $\mathrm{CH}=\mathrm{CH}, \mathrm{J}=5.6 \mathrm{~Hz}$ ); 8.78 (exch br s, $\left.2 \mathrm{H}, \mathrm{NH}_{2}\right) ; 10.44$ (exch br s, 1H, NH). Anal. Calcd for $\mathrm{C}_{18} \mathrm{H}_{20} \mathrm{BrN}_{5} \mathrm{O}_{3}$ (434.29): C, 49.78; H, 4.64; N, 16.13; Found: C, 49.81; H, 4.63; N, 16.11.

\subsubsection{2-[5-Amino-3-methyl-6-oxo-4-(1H-pyrazol-3-yl)-6H-pyridazin-1-yl]- $N$-(4-bromo-} -phenyl)acetamide, 23.

Hydrazine hydrate $(1.38 \mathrm{mmol})$ was slowly added drop wise to a solution of intermediate 22 $(0.69 \mathrm{mmol})$ in $4 \mathrm{~mL}$ of $96 \% \mathrm{EtOH}$, and the reaction was refluxed for $3 \mathrm{~h}$. After cooling, the solvent was removed under vacuum. Ice-cold water was added, and the precipitate was recovered by filtration under vacuum. A second batch of compound $\mathbf{2 3}$ was obtained through extraction of the aqueous phase with $\mathrm{CH}_{2} \mathrm{Cl}_{2}(3 \times 15 \mathrm{~mL})$, drying over $\mathrm{Na}_{2} \mathrm{SO}_{4}$, and evaporation under vacuum. Yield $=67 \% ; \mathrm{mp}=229-230{ }^{\circ} \mathrm{C}(\mathrm{EtOH}) .1 \mathrm{H}-\mathrm{NMR}\left(\mathrm{CDCl}_{3}\right) \delta 2.44\left(\mathrm{~s}, 3 \mathrm{H}, \mathrm{N}=\mathrm{CCH}_{3}\right) ; 4.98\left(\mathrm{~s}, 2 \mathrm{H}, \mathrm{NCH}_{2}\right) ;$ $6.60(\mathrm{~d}, 1 \mathrm{H}, \mathrm{Ar}, \mathrm{J}=1.6 \mathrm{~Hz}) ; 6.80($ exch br s, 1H, NH); 7.40-7.45 (m, 4H, Ar); $7.75(\mathrm{~d}, 1 \mathrm{H}, \mathrm{Ar}, \mathrm{J}=$ $2.0 \mathrm{~Hz}$ ); 8.98 (exch br s, $1 \mathrm{H}, \mathrm{NH}) ; 9.03$ (exch br s, $2 \mathrm{H}, \mathrm{NH}_{2}$ ). Anal. Calcd for $\mathrm{C}_{16} \mathrm{H}_{15} \mathrm{BrN}_{6} \mathrm{O}_{2}$ (403.23): C, 47.66; H, 3.75; N, 20.84; Found: C, 47.52; H, 3.76; N, 20.88. 


\subsubsection{2-[5-Amino-3-methyl-4-(1-methyl-1H-pyrazol-3-yl)-6-oxopyridazin-1(6H)-yl]- $N$-(4- bromophenyl)acetamide, 24.}

$\mathrm{K}_{2} \mathrm{CO}_{3}(0.87 \mathrm{mmol})$ was added to a solution of intermediate $23(0.43 \mathrm{mmol})$ in $4 \mathrm{~mL}$ of anhydrous DMF. After $2 \mathrm{~h}$ stirring, $1.19 \mathrm{mmol}$ of $\mathrm{CH}_{3} \mathrm{I}$ were added, and the reaction was carried out for additional $3 \mathrm{~h}$ at $90^{\circ} \mathrm{C}$. After cooling, ice-cold water was added, and the mixture was extracted with $\mathrm{CH}_{2} \mathrm{Cl}_{2}$. The organic phase was dried over $\mathrm{Na}_{2} \mathrm{SO}_{4}$ and evaporated. Yield $=46 \% ; \mathrm{mp}=232$ $233{ }^{\circ} \mathrm{C}(\mathrm{EtOH}) .{ }^{1} \mathrm{H}-\mathrm{NMR}\left(\mathrm{CDCl}_{3}\right) \delta 2.44\left(\mathrm{~s}, 3 \mathrm{H}, \mathrm{N}=\mathrm{CCH}_{3}\right) ; 4.01\left(\mathrm{~s}, 3 \mathrm{H}, \mathrm{NCH}_{3}\right) ; 4.97(\mathrm{~s}, 2 \mathrm{H}$, $\left.\mathrm{NCH}_{2}\right) ; 6.50(\mathrm{~d}, 1 \mathrm{H}, \mathrm{Ar}, \mathrm{J}=2.0 \mathrm{~Hz}) ; 7.38-7.42(\mathrm{~m}, 4 \mathrm{H}, \mathrm{Ar}) ; 7.44\left(\right.$ exch br s, $2 \mathrm{H}, \mathrm{NH}_{2}$, ); 7.45-7.50 (m, 1H, Ar); 9.02 (exch br s, 1H, NH). Anal. Calcd for $\mathrm{C}_{17} \mathrm{H}_{17} \mathrm{BrN}_{6} \mathrm{O}_{2}$ (417.26): C, 48.93; H, 4.11; N, 20.14; Found: C, 48.76; H, 4.10; N, 20.18.

\subsubsection{General procedures for $25 \mathrm{a}$ and $25 \mathrm{~b}$}

Compounds 25a-b were obtained starting from $\mathbf{2 4}$ following the same general procedure described for 6a-f. After removal of the solvent in vacuo, compound 25a was obtained by crystallization from ethanol and preparative TLC using ethyl acetate as eluent.

\subsubsection{4. $N$-(4-Bromophenyl)-2-[5-(3-methoxyphenylamino)-3-methyl-4-(1-methyl-1H-pyrazol-} 3-yl)-6-oxo-6H-pyridazin-1-yl]acetamide, 25a. Yield = 15\%; $\mathrm{mp}=112-113{ }^{\circ} \mathrm{C}(\mathrm{EtOH}) .{ }^{1} \mathrm{H}-\mathrm{NMR}$ $\left(\mathrm{CDCl}_{3}\right) \delta 2.29\left(\mathrm{~s}, 3 \mathrm{H}, \mathrm{N}=\mathrm{CCH}_{3}\right) ; 3.67\left(\mathrm{~s}, 3 \mathrm{H}, \mathrm{NCH}_{3}\right) ; 3.72\left(\mathrm{~s}, 3 \mathrm{H}, \mathrm{OCH}_{3}\right) ; 5.01\left(\mathrm{~s}, 2 \mathrm{H}, \mathrm{NCH}_{2}\right) ;$ $5.99(\mathrm{~d}, 1 \mathrm{H}, \mathrm{Ar}, \mathrm{J}=2.4 \mathrm{~Hz}) ; 6.30(\mathrm{~s}, 1 \mathrm{H}, \mathrm{Ar}) ; 6.42(\mathrm{~d}, 1 \mathrm{H}, \mathrm{Ar}, \mathrm{J}=8.0 \mathrm{~Hz}) ; 6.5(\mathrm{~d}, 1 \mathrm{H}, \mathrm{Ar}, \mathrm{J}=8.4$ $\mathrm{Hz}) ; 6.97(\mathrm{t}, 1 \mathrm{H}, \mathrm{Ar}, \mathrm{J}=8.0 \mathrm{~Hz}) ; 7.07($ exch br s, 1H, NH); 7.42-7.48 (m, 4H, Ar); $7.81(\mathrm{~d}, 1 \mathrm{H}, \mathrm{Ar}, \mathrm{J}$ $=2.4 \mathrm{~Hz}) ; 8.89$ (exch br s, $1 \mathrm{H}, \mathrm{NH}) .{ }^{13} \mathrm{C}-\mathrm{NMR}\left(\mathrm{CDCl}_{3}\right) \delta 21.4\left(\mathrm{CH}_{3}\right) ; 38.7\left(\mathrm{CH}_{3}\right) ; 55.1\left(\mathrm{CH}_{3}\right) ; 57.7$ $\left(\mathrm{CH}_{2}\right) ; 107.6(\mathrm{CH}) ; 108.0(\mathrm{CH}) ; 110.2(\mathrm{CH}) ; 115.0(\mathrm{CH}) ; 116.9(\mathrm{C}) ; 121.6(2 \mathrm{CH}) ; 125.0(\mathrm{CH})$; $126.5(\mathrm{CH}) ; 131.9(2 \mathrm{CH}) ; 135.2(\mathrm{C}) ; 136.8(\mathrm{C}) ; 137.5(\mathrm{C}) ; 139.8(\mathrm{C}) ; 145.0(\mathrm{C}) ; 146.3(\mathrm{C}) ; 157.0$ (C); 160.2 (C); 165.4 (C). Anal. Calcd for $\mathrm{C}_{24} \mathrm{H}_{23} \mathrm{BrN}_{6} \mathrm{O}_{3}$ (523.38): C, 55.08; H, 4.43; N, 16.06; Found: C, 55.23; H, 4.42; N, 16.11 .

5.1.25. $N$-(4-Bromophenyl)-2-[5-(4-methoxyphenylamino)-3-methyl-4-(1-methyl-1H-pyrazol3-yl)-6-oxo-6H-pyridazin-1-yl]acetamide, 25b. Yield $=64 \% ; \mathrm{mp}=103-104{ }^{\circ} \mathrm{C}(\mathrm{EtOH}) .{ }^{1} \mathrm{H}-\mathrm{NMR}$ 
$\left(\mathrm{CDCl}_{3}\right) \delta 2.21\left(\mathrm{~s}, 3 \mathrm{H}, \mathrm{N}=\mathrm{CCH}_{3}\right) ; 3.67\left(\mathrm{~s}, 3 \mathrm{H}, \mathrm{NCH}_{3}\right) ; 3.75\left(\mathrm{~s}, 3 \mathrm{H}, \mathrm{OCH}_{3}\right) ; 5.00\left(\mathrm{~s}, 2 \mathrm{H}, \mathrm{CH}_{2} \mathrm{CO}\right) ;$ 5.93 (s, 1H, Ar); 6.58-6.59 (m, 2H, Ar); 6.73-6.75 (m, 2H, Ar); 7.40-7.46 (m, 4H, Ar); 7.71 (s, 1H, Ar); 8.91 (exch br s, $1 \mathrm{H}, \mathrm{NH}) .{ }^{13} \mathrm{C}-\mathrm{NMR}\left(\mathrm{CDCl}_{3}\right) \delta 21.2\left(\mathrm{CH}_{3}\right) ; 38.6\left(\mathrm{CH}_{3}\right) ; 55.5\left(\mathrm{CH}_{3}\right) ; 57.5\left(\mathrm{CH}_{2}\right)$; $107.8(\mathrm{CH}) ; 112.9(\mathrm{CH}) ; 113.6(2 \mathrm{CH}) ; 116.9(\mathrm{C}) ; 121.5(2 \mathrm{CH}) ; 125.0(\mathrm{CH}) ; 126.0(\mathrm{CH}) ; 130.1(\mathrm{C})$; $131.0(\mathrm{CH}) ; 131.5(\mathrm{C}) ; 132.0(\mathrm{CH}) ; 136.8(\mathrm{C}) ; 138.2(\mathrm{C}) ; 144.2(\mathrm{C}) ; 148.5(\mathrm{C}) ; 156.7(\mathrm{C}) ; 157.0$ (C); 165.4 (C). Anal. Calcd for $\mathrm{C}_{24} \mathrm{H}_{23} \mathrm{BrN}_{6} \mathrm{O}_{3}$ (523.38): C, 55.08; H, 4.43; N, 16.06; Found: C, $55.17 ; \mathrm{H}, 4.43 ; \mathrm{N}, 16.10$.

\subsubsection{General procedures for $27 \mathrm{a}$ and $27 \mathrm{~b}$}

Compounds 27a-b were obtaining starting from appropriate substrate 26a [29] and 26b [30] following the same procedure described for $\mathbf{5 b}$-c, $\mathbf{5 f}$. The desired final compounds were purified by column flash chromatography using, as eluent, cyclohexane/ethyl acetate 1:2 for compound $\mathbf{2 7 a}$ and $\mathrm{CH}_{2} \mathrm{Cl}_{2} / \mathrm{MeOH}$ 9.5:0.5 for compound 27b.

5.1.26.1. 2-(3-Amino-5-methyl-2-oxopyridin-1(2H)-yl)-N-(4-bromophenyl)acetamide, 27a. Yield $=34 \% ; \mathrm{mp}=151-153{ }^{\circ} \mathrm{C}$ dec. $(\mathrm{EtOH}) .{ }^{1} \mathrm{H}-\mathrm{NMR}\left(\mathrm{CDCl}_{3}\right) \delta 2.06\left(\mathrm{~s}, 3 \mathrm{H}, \mathrm{N}=\mathrm{CCH}_{3}\right) ; 4.64(\mathrm{~s}$, $2 \mathrm{H}, \mathrm{NCH}_{2}$ ); 6.51 (exch br s, 1H, NH); 6.66 (s, 1H, Ar); 7.36-7.47 (m, 4H, Ar); 9.64 (exch br s, 2H, $\mathrm{NH}_{2}$ ). Anal. Calcd for $\mathrm{C}_{14} \mathrm{H}_{14} \mathrm{BrN}_{3} \mathrm{O}_{2}$ (336.18): C, 50.02; H, 4.20; N, 12.50; Found: C, 50.16; H, $4.21 ; \mathrm{N}, 12.47$.

5.1.26.2. 2-(5-Amino-3-methyl-6-oxopyridazin-1(6H)-yl)-N-(4-bromophenyl)acetamide， $27 \mathrm{~b}$. Yield $=29 \% ; \mathrm{mp}=241-244{ }^{\circ} \mathrm{C}$ dec. $(\mathrm{EtOH}) .{ }^{1} \mathrm{H}-\mathrm{NMR}\left(\mathrm{CDCl}_{3}\right) \delta 2.22\left(\mathrm{~s}, 3 \mathrm{H}, \mathrm{N}=\mathrm{CCH}_{3}\right) ; 4.90(\mathrm{~s}$, 2H, $\mathrm{NCH}_{2}$ ); 5.88 (exch br s, 2H, $\mathrm{NH}_{2}$ ); 6.19 (s, 1H, Ar); 7.33-7.39 (m, 4H, Ar); 8.91 (exch br s, 2H, $\mathrm{NH}_{2}$ ). Anal. Calcd for $\mathrm{C}_{13} \mathrm{H}_{13} \mathrm{BrN}_{4} \mathrm{O}_{2}$ (337.17): C, 46.31; H, 3.89; N, 16.62; Found: C, 46.44; H, $3.90 ; \mathrm{N}, 16.67$.

\subsubsection{General procedures for $28 \mathrm{a}$ and $28 \mathrm{~b}$}

Compounds $\mathbf{2 8 a - b}$ were obtaining starting from appropriate substrate $\mathbf{2 7 a - b}$ following the same procedure described for 6a-f. The desired final compounds were purified by column flash 
chromatography using, as eluent, cyclohexane/ethyl acetate 1:2 for compound 28a and $\mathrm{CH}_{2} \mathrm{Cl}_{2} / \mathrm{MeOH}$ 9.5:0.5 for compound $\mathbf{2 8 b}$.

\subsubsection{N-(4-Bromophenyl)-2-[3-(3-methoxyphenylamino)-5-methyl-2-oxopyridin-1(2H)-} yl $]$ acetamide, 28a. Yield $=11 \% ; \mathrm{mp}=210-213{ }^{\circ} \mathrm{C}(\mathrm{EtOH}) .{ }^{1} \mathrm{H}-\mathrm{NMR}\left(\mathrm{CDCl}_{3}\right) \delta 2.08(\mathrm{~s}, 3 \mathrm{H}$, $\left.\mathrm{N}=\mathrm{CCH}_{3}\right) ; 3.80\left(\mathrm{~s}, 3 \mathrm{H}, \mathrm{OCH}_{3}\right) ; 4.71\left(\mathrm{~s}, 2 \mathrm{H}, \mathrm{NCH}_{2}\right) ; 6.51($ exch br s, $1 \mathrm{H}, \mathrm{NH}) ; 6.59(\mathrm{~d}, 1 \mathrm{H}, \mathrm{Ar}, \mathrm{J}=$

$7.3 \mathrm{~Hz}) ; 6.73(\mathrm{~m}, 2 \mathrm{H}, \mathrm{Ar}) ; 6.77(\mathrm{~d}, 1 \mathrm{H}, \mathrm{Ar}, \mathrm{J}=7.2 \mathrm{~Hz}) ; 7.05(\mathrm{~s}, 1 \mathrm{H}, \mathrm{Ar}) ; 7.25(\mathrm{~s}, 1 \mathrm{H}, \mathrm{Ar}) ; 7.36-7.41$ (m, 4H, Ar); 9.51 (exch br s, $1 \mathrm{H}, \mathrm{NH}$ ). Anal. Calcd for $\mathrm{C}_{21} \mathrm{H}_{20} \mathrm{BrN}_{3} \mathrm{O}_{2}$ (442.31): C, 57.02; H, 4.56; N, 9.50; Found: C, 57.19; H, 4.57; N, 9.48.

\subsubsection{N-(4-Bromophenyl)-2-[5-(3-methoxyphenylamino)-3-methyl-6-oxopyridazin-1(6H)-} yl]-acetamide, 28b. Yield = 16\%; oil. ${ }^{1} \mathrm{H}-\mathrm{NMR}\left(\mathrm{CDCl}_{3}\right) \delta 2.27\left(\mathrm{~s}, 3 \mathrm{H}, \mathrm{N}=\mathrm{CCH}_{3}\right) ; 3.82(\mathrm{~s}, 3 \mathrm{H}$, $\left.\mathrm{OCH}_{3}\right) ; 4.94\left(\mathrm{~s}, 2 \mathrm{H}, \mathrm{NCH}_{2}\right) ; 6.43($ exch br s, 1H, NH); 6.64 (s, 1H, Ar); 6.71-6.76 (m, 2H, Ar); 6.81 (m, 1H, Ar); 7.35 (m, 1H, Ar); 7.38-7.43 (m, 4H, Ar); 8.68 (exch br s, 1H, NH). Anal. Calcd for $\mathrm{C}_{20} \mathrm{H}_{19} \mathrm{BrN}_{3} \mathrm{O}_{2}$ (443.29): C, 54.19; H, 4.32; N, 12.64; Found: C, 54.31; H, 4.31; N, 12.61.

\subsection{Biology}

\subsubsection{Cell culture}

Human promyelocytic leukemia HL-60 cells stably transfected with FPR1 (FPR1-HL60), FPR2 (FPR2-HL60), or FPR3 (FPR3-HL60) (kind gift from Dr. Marie-Josephe Rabiet, INSERM, Grenoble, France) were cultured in RPMI 1640 medium supplemented with $10 \%$ heat-inactivated fetal calf serum, $10 \mathrm{mM}$ HEPES, $100 \mu \mathrm{g} / \mathrm{ml}$ streptomycin, $100 \mathrm{U} / \mathrm{ml}$ penicillin, and G418 (1 $\mathrm{mg} / \mathrm{mL}$ ), as previously described [32]. Wild-type HL-60 cells were cultured under the same conditions, but without G418. Rat basophilic leukemia (RBL-2H3) cells transfected with mouse Fpr1 (Fpr1-RBL) or mouse Fpr2 (Fpr2-RBL) were cultured in DMEM supplemented with 20\% (v/v) FBS, $10 \mathrm{mM}$ HEPES, $100 \mu \mathrm{g} / \mathrm{ml}$ streptomycin, $100 \mathrm{U} / \mathrm{ml}$ penicillin, and G418 (250 $\mu \mathrm{g} / \mathrm{ml})$. Wild-type HL-60 and RBL-2H3 cells were cultured under the same conditions, but without G418. 


\subsubsection{Isolation of human neutrophils}

Blood was collected from healthy donors in accordance with a protocol approved by the Institutional Review Board at Montana State University. Neutrophils were purified from the blood using dextran sedimentation, followed by Histopaque 1077 gradient separation and hypotonic lysis of red blood cells, as previously described [33]. Isolated neutrophils were washed twice and resuspended in Hank's balanced salt solution (HBSS) without $\mathrm{Ca}^{2+}$ and $\mathrm{Mg}^{2+}\left(\mathrm{HBSS}^{-}\right)$. Neutrophil preparations were routinely $>95 \%$ pure, as determined by light microscopy, and $>98 \%$ viable, as determined by trypan blue exclusion.

\subsubsection{Isolation of mouse neutrophils}

Mouse bone marrow neutrophils were isolated from bone marrow leukocyte preparations, as described previously [34]. In brief, bone marrow leukocytes were flushed from tibias and femurs of BALB/c mice with HBSS, filtered through a $70 \mu \mathrm{m}$ nylon cell strainer (BD Biosciences, Franklin Lakes, NJ) to remove cell clumps and bone particles, and resuspended in $\mathrm{HBSS}^{-}$at $10^{6}$ cells $/ \mathrm{ml}$. Bone marrow leukocytes were resuspended in $3 \mathrm{ml}$ of $45 \%$ Percoll solution and layered on top of a Percoll gradient consisting of $2 \mathrm{ml}$ each of 50, 55, 62, and 81\% Percoll solutions in a conical 15-ml polypropylene tube. The gradient was centrifuged at $1600 \mathrm{~g}$ for $30 \mathrm{~min}$ at $10^{\circ} \mathrm{C}$, and the cell band located between the 61 and $81 \%$ Percoll layers was collected. The cells were washed, layered on top of $3 \mathrm{ml}$ of Histopaque 1119 , and centrifuged at $1600 \mathrm{~g}$ for $30 \mathrm{~min}$ at $10^{\circ} \mathrm{C}$ to remove contaminating red blood cells. The purified neutrophils were collected, washed, and resuspended in HBSS- ${ }^{-}$All animal use was conducted in accordance with a protocol approved by the Institutional Animal Care and Use Committee at Montana State University.

\subsection{4. $\mathrm{Ca}^{2+}$ mobilization assay}

Changes in intracellular $\mathrm{Ca}^{2+}$ were measured with a FlexStation II scanning fluorometer using a FLIPR 3 calcium assay kit (Molecular Devices, Sunnyvale, CA) for human neutrophils and HL-60 cells, as described previously [35]. All active compounds were evaluated in wild-type HL-60 and RBL cells to verify that the agonists are inactive in non-transfected cells. Human neutrophils, 
HL-60 or RBL cells, suspended in HBSS $^{-}$containing 10 mM HEPES, were loaded with Fluo-4 AM dye (Invitrogen; $1.25 \mu \mathrm{g} / \mathrm{mL}$ final concentration) and incubated for $30 \mathrm{~min}$ in the dark at $37{ }^{\circ} \mathrm{C}$. After dye loading, the cells were washed with $\mathrm{HBSS}^{-}$containing $10 \mathrm{mM}$ HEPES, resuspended in HBSS containing $10 \mathrm{mM}$ HEPES, and aliquotted into the wells of a flat-bottomed, half-area-well black microtiter plates $\left(2 \times 10^{5}\right.$ cells/well $)$. The compound of interest was added from a source plate containing dilutions of test compounds in HBSS with $10 \%$ dimethyl sulfoxide (DMSO), and changes in fluorescence were monitored $\left(\lambda_{\mathrm{ex}}=485 \mathrm{~nm}, \lambda_{\mathrm{em}}=538 \mathrm{~nm}\right)$ every $5 \mathrm{~s}$ for $240 \mathrm{~s}$ at room temperature after automated addition of compounds. Maximum change in fluorescence, expressed in arbitrary units over baseline, was used to determine agonist response. Responses were normalized to the response induced by $5 \mathrm{nM} f \mathrm{MLF}$ (Sigma Chemical Co., St. Louis, MO) for FPR1-HL60 cells and human neutrophils, or $5 \mathrm{nM}$ WKYMVm (Calbiochem, San Diego, CA) for murine neutrophils, FPR2-HL60, FPR3-HL60, Fpr1-RBL, and Fpr2-RBL cells, which were assigned a value of 100\%. Curve fitting (5-6 points) and calculation of median effective concentration values $\left(\mathrm{EC}_{50}\right)$ were performed by nonlinear regression analysis of the concentration-response curves generated using Prism 5 (GraphPad Software, Inc., San Diego, CA).

\subsubsection{Cell migration assay}

Human neutrophils were suspended in HBSS containing 2\% (v/v) fetal bovine serum (FBS) $\left(2 \times 10^{6}\right.$ cells $\left./ \mathrm{mL}\right)$, and cell migration was analyzed in 96-well ChemoTx chemotaxis chambers (Neuroprobe, Gaithersburg, MD), as previously described [32]. Briefly, lower wells were loaded with $30 \mu \mathrm{L}$ of HBSS containing 2\% (v/v) FBS and the indicated concentrations of test compound, DMSO (negative control), or $1 \mathrm{nM} f \mathrm{MLF}$ as a positive control. Neutrophils were added to the upper wells and allowed to migrate through the $5.0 \mu \mathrm{m}$ pore polycarbonate membrane filter for $60 \mathrm{~min}$ at $37{ }^{\circ} \mathrm{C}$ and $5 \% \mathrm{CO}_{2}$. The number of migrated cells was determined by measuring ATP in lysates of transmigrated cells using a luminescence-based assay (CellTiter-Glo; Promega, Madison, WI), and luminescence measurements were converted to absolute cell numbers by comparison of the values with standard curves obtained with known numbers of neutrophils. The results are expressed as 
percentage of negative control and were calculated as follows: (number of cells migrating in response to test compounds/spontaneous migration in response to control medium) $\times 100$. $\mathrm{EC}_{50}$ values were determined by nonlinear regression analysis of the concentration-response curves generated using Prism 5 software.

\subsection{Molecular modeling}

We used the FPR1 and FPR2 homology models created previously [20, 36]. Both models are based on the crystal structure of the bovine rhodopsin receptor. Before docking, structures of compounds 8a, 8e, and 13a-c were built and optimized using HyperChem 7.0 software with the MM+ force field and saved in Tripos MOL2 format. The ligand structures were then imported into MVD with the options "Create explicit hydrogens", "Assign charges (calculated by MVD)", and "Detect flexible torsions in ligands" enabled. The molecules were docked into FPR1 and FPR2 using the search spaces as applied in our previous publications [20,31] and with a rigid receptor structure. MolDock score functions were applied with $0.3 \AA$ grid resolution. Ligand flexibility was accounted for with respect to torsion angles auto-detected in MVD. The "Internal HBond" option was activated in the "Ligand evaluation" menu of Docking Wizard. Thirty docking runs were performed for each molecule. The option "Return multiple poses for each run" was enabled, and the post-processing options "Energy minimization" and "Optimize H-bonds" were applied after docking. Similar poses were clustered at a RMSD threshold of $1 \AA$. 


\section{Acknowledgements}

This work was supported in part by the EPSRC through a Proxomics Project Award EP/I017887/1 (AC), National Institutes of Health IDeA Program COBRE grant GM110732 (MTQ) and grant AI033503 (RDY), an equipment grant from the M.J. Murdock Charitable Trust (MTQ), a USDA

National Institute of Food and Agriculture Hatch project (MTQ), Montana University System Research Initiative 51040-MUSRI2015-03, and the Montana State University Agricultural Experiment Station (MTQ).

\section{Conflict of interest}

The authors declare to have no financial/commercial conflict of interest.

\section{Graphical abstract}

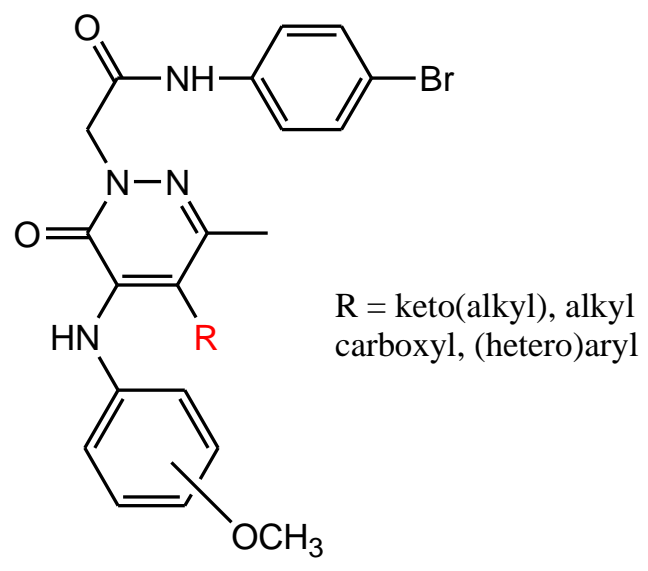

Active as FPR agonists in the low micromolar range 


\section{References}

[1] C. Nathan, Neutrophils and immunity: challenges and opportunities, Nat. Rev. Immunol., 6 (2006) 173-182.

[2] D.W. Gilroy, T. Lawrence, M. Perretti, A.G. Rossi, Inflammatory resolution: new opportunities for drug discovery, Nat. Rev. Drug Discov., 3 (2004) 401-416.

[3] N. Dufton, M. Perretti, Therapeutic anti-inflammatory potential of formyl-peptide receptor agonists, Pharmacol.Ther., 127 (2010) 175-188.

[4] N. Dufton, R. Hannon, V. Brancaleone, J. Dalli, H.B. Patel, M. Gray, F. D'Acquisto, J.C. Buckingham, M. Perretti, R.J. Flower, Anti-inflammatory role of the murine formyl-peptide receptor 2: ligand-specific effects on leukocyte responses and experimental inflammation, J. Immunol., 184 (2010) 2611-2619.

[5] R.D. Ye, F. Boulay, J.M. Wang, C. Dahlgren, C. Gerard, M. Parmentier, C.N. Serhan, P.M. Murphy, International Union of Basic and Clinical Pharmacology. LXXIII. Nomenclature for the Formyl Peptide Receptor (FPR) Family, Pharmacol. Rev., 61 (2009) 119-161.

[6] F.N. Gavins, Are formyl peptide receptors novel targets for therapeutic intervention in ischaemia-reperfusion injury?, Trends Pharmacol. Sci., 31 (2010) 266-276.

[7] Y. Le, Y. Yang, Y. Cui, H. Yazawa, W. Gong, C. Qiu, J.M. Wang, Receptors for chemotactic formyl peptides as pharmacological targets, Int. Immunopharmacol., 2 (2002) 1-13.

[8] A. Mollica, A. Stefanucci, R. Costante, F. Pinnen, Role of formyl peptide receptors (FPR) in abnormal inflammation responses involved in neurodegenerative diseases, Antiinflamm. Antiallergy Agents Med. Chem., 11 (2012) 20-36.

[9] M.P. Wood, A.L. Cole, C.R. Eade, L.M. Chen, K.X. Chai, A.M. Cole, The HIV-1 gp41 ectodomain is cleaved by matriptase to produce a chemotactic peptide that acts through FPR2, Immunology, 142 (2014) 474-483. 
[10] F.W. Rossi, N. Prevete, N. Montuori, P. Ragno, C. Selleri, G. Marone, A. de Paulis, Hp(2-20) peptide of Helicobacter pylori and the innate immune receptors: specific role(s) of the formyl peptide receptors, Infez. Med., 20 Suppl 2 (2012) 19-25.

[11] C.P. Xu, H.R. Zhang, F.L. Chen, X.H. Yao, Z.Q. Liang, R. Zhang, Y. Cui, C. Qian, X.W. Bian, Human malignant glioma cells expressing functional formylpeptide receptor recruit endothelial progenitor cells for neovascularization, Int. Immunopharmacol., 10 (2010) 1602-1607.

[12] S. Pieretti, A. Di Giannuario, M. De Felice, M. Perretti, G. Cirino, Stimulus-dependent specificity for annexin 1 inhibition of the inflammatory nociceptive response: the involvement of the receptor for formylated peptides, Pain, 109 (2004) 52-63.

[13] S. Cardini, J. Dalli, S. Fineschi, M. Perretti, G. Lungarella, M. Lucattelli, Genetic ablation of the fpr1 gene confers protection from smoking-induced lung emphysema in mice, Am. J. Respir. Cell Mol. Biol., 47 (2012) 332-339.

[14] I.A. Schepetkin, A.I. Khlebnikov, M.P. Giovannoni, L.N. Kirpotina, A. Cilibrizzi, M.T. Quinn, Development of Small Molecule Non-peptide Formyl Peptide Receptor (FPR) Ligands and Molecular Modeling of Their Recognition, Curr. Med. Chem., 21 (2014) 1478-1504.

[15] O. Corminboeuf, X. Leroy, FPR2/ALXR agonists and the resolution of inflammation, J. Med. Chem., 58 (2015) 537-559.

[16] I.A. Schepetkin, L.N. Kirpotina, A.I. Khlebnikov, N. Cheng, R.D. Ye, M.T. Quinn, Antagonism of human formyl peptide receptor 1 (FPR1) by chromones and related isoflavones, Biochem. Pharmacol., 92 (2014) 627-641.

[17] A. Cilibrizzi, Crocetti, L., Giovannoni, M.P., Graziano, A., Vergelli, C., Bartolucci, G., Soldani, G., Quinn, M.T., Schepetkin, I.A., Faggi, C. , Synthesis, HPLC enantioresolution, and Xray analysis of a new series of C5-methyl pyridazines as N-formyl peptide receptor (FPR) agonists, Chirality, 25 (2013) 400-408.

[18] A. Cilibrizzi, I.A. Schepetkin, G. Bartolucci, L. Crocetti, P. Dal, V, M.P. Giovannoni, A. Graziano, L.N. Kirpotina, M.T. Quinn, C. Vergelli, Synthesis, enantioresolution, and activity 
profile of chiral 6-methyl-2,4-disubstituted pyridazin-3(2H)-ones as potent $\mathrm{N}$-formyl peptide receptor agonists, Bioorg. Med. Chem., 20 (2012) 3781-3792.

[19] A. Cilibrizzi, M.T. Quinn, L.N. Kirpotina, I.A. Schepetkin, J. Holderness, R.D. Ye, M.J. Rabiet, C. Biancalani, N. Cesari, A. Graziano, C. Vergelli, S. Pieretti, P. Dal, V, M.P. Giovannoni, 6-Methyl-2,4-Disubstituted Pyridazin-3(2H)-ones: A Novel Class of Small-Molecule Agonists for Formyl Peptide Receptors, J. Med. Chem., 52 (2009) 5054-5057.

[20] M.P. Giovannoni, Schepetkin, I.A., Cilibrizzi, A., Crocetti, L., Khlebnikov, A.I., Dahlgren, C., Graziano, A., Dal Piaz, V., Kirpotina, L.N., Zerbinati, S., Vergelli, C., Quinn, M.T. , Further studies on 2-arylacetamide pyridazin-3(2H)-ones: Design, synthesis and evaluation of 4,6disubstituted analogues as formyl peptide receptors (FPRs) agonists, Eur. J. Med. Chem., 64 (2013) $512-528$.

[21] L. Crocetti, C. Vergelli, A. Cilibrizzi, A. Graziano, A.I. Khlebnikov, L.N. Kirpotina, I.A. Schepetkin, M.T. Quinn, M.P. Giovannoni, Synthesis and Pharmacological Evaluation of New Pyridazin-Based Thioderivatives as Formyl Peptide Receptor (FPR) Agonists, Drug Dev. Res., 74 (2013) 259-271.

[22] L. Costantino, G. Rastelli, M.C. Gamberini, M.P. Giovannoni, V. Dal Piaz, P. Vianello, D. Barlocco, Isoxazolo-[3,4-d]-pyridazin-7-(6H)-one as a potential substrate for new aldose reductase inhibitors, J. Med. Chem., 42 (1999) 1894-1900.

[23] M.P. Giovannoni, C. Vergelli, C. Biancalani, N. Cesari, A. Graziano, P. Biagini, J. Gracia, A. Gavalda, V. Dal Piaz, Novel pyrazolopyrimidopyridazinones with potent and selective phosphodiesterase 5 (PDE5) inhibitory activity as potential agents for treatment of erectile dysfunction, J. Med. Chem., 49 (2006) 5363-5371.

[24] M.P. Giovannoni, G. Ciciani, A. Cilibrizzi, L. Crocetti, S. Daniele, L. Di Cesare Mannelli, C. Ghelardini, C. Giacomelli, G. Guerrini, C. Martini, M.L. Trincavelli, C. Vergelli, Further studies on pyrazolo[1',5':1,6]pyrimido[4,5-d]pyridazin-4(3H)-ones as potent and selective human A1 adenosine receptor antagonists, Eur. J. Med. Chem., 89 (2015) 32-41. 
[25] C. Vergelli, G. Ciciani, A. Cilibrizzi, L. Crocetti, L. Di Cesare Mannelli, C. Ghelardini, G. Guerrini, A. Iacovone, M.P. Giovannoni, Synthesis of five and six-membered heterocycles bearing an arylpiperazinylalkyl side chain as orally active antinociceptive agents, Bioorg. Med. Chem., 23 (2015) 6237-6245.

[26] P.G. Baraldi, D. Preti, M.A. Tabrizi, F. Fruttarolo, G. Saponaro, S. Baraldi, R. Romagnoli, A.R. Moorman, S. Gessi, K. Varani, P.A. Borea, N(6)-[(hetero)aryl/(cyclo)alkyl-carbamoylmethoxy-phenyl]-(2-chloro)-5'-N-ethylca rboxamido-adenosines: the first example of adenosinerelated structures with potent agonist activity at the human A(2B) adenosine receptor, Bioorg. Med. Chem., 15 (2007) 2514-2527.

[27] C. Biancalani, M.P. Giovannoni, S. Pieretti, N. Cesari, A. Graziano, C. Vergelli, A. Cilibrizzi, A. Di Gianuario, M. Colucci, G. Mangano, B. Garrone, L. Polenzani, V. Dal Piaz, Further studies on arylpiperazinyl alkyl pyridazinones: discovery of an exceptionally potent, orally active, antinociceptive agent in thermally induced pain, J. Med. Chem., 52 (2009) 7397-7409.

[28] C. Vergelli, M.P. Giovannoni, S. Pieretti, A. Di Giannuario, V. Dal Piaz, P. Biagini, C. Biancalani, A. Graziano, N. Cesari, 4-Amino-5-vinyl-3(2H)-pyridazinones and analogues as potent antinociceptive agents: Synthesis, SARs, and preliminary studies on the mechanism of action, Bioorg. Med. Chem., 15 (2007) 5563-5575.

[29] E. Verissimo, N. Berry, P. Gibbons, M.L. Cristiano, P.J. Rosenthal, J. Gut, S.A. Ward, P.M. O'Neill, Design and synthesis of novel 2-pyridone peptidomimetic falcipain 2/3 inhibitors, Bioorg. Med. Chem. Lett., 18 (2008) 4210-4214.

[30] W.J. Coates, McKillop, A., Preparation of 4-amino-3(2H)-pyridazinones by direct amination of 3(2H)-pyridazinones with hydrazine, Heterocycles, 29 (1989) 1077-1090.

[31] A.I. Khlebnikov, I.A. Schepetkin, L.N. Kirpotina, L. Brive, C. Dahlgren, M.A. Jutila, M.T. Quinn, Molecular docking of 2-(benzimidazol-2-ylthio)-N-phenylacetamide-derived smallmolecule agonists of human formyl peptide receptor 1, J. Mol. Model., 18 (2012) 2831-2843. 
[32] I.A. Schepetkin, L.N. Kirpotina, A.I. Khlebnikov, M. Leopoldo, E. Lucente, E. Lacivita, P. De Giorgio, M.T. Quinn, 3-(1H-indol-3-yl)-2-[3-(4-nitrophenyl)ureido]propanamide enantiomers with human formyl-peptide receptor agonist activity: Molecular modeling of chiral recognition by FPR2, Biochem. Pharmacol., 85 (2013) 404-416.

[33] I.A. Schepetkin, L.N. Kirpotina, A.I. Khlebnikov, M.T. Quinn, High-throughput screening for small-molecule activators of neutrophils: identification of novel $\mathrm{N}$-formyl peptide receptor agonists, Mol. Pharmacol., 71 (2007) 1061-1074.

[34] D.W. Siemsen, N. Malachowa, I.A. Schepetkin, A.R. Whitney, L.N. Kirpotina, B. Lei, F.R. Deleo, M.T. Quinn, Neutrophil isolation from nonhuman species, Methods Mol. Biol., 1124 (2014) $19-37$.

[35] L.N. Kirpotina, A.I. Khlebnikov, I.A. Schepetkin, R.D. Ye, M.J. Rabiet, M.A. Jutila, M.T. Quinn, Identification of novel small-molecule agonists for human formyl peptide receptors and pharmacophore models of their recognition, Mol. Pharmacol., 77 (2010) 159-170.

[36] C. Movitz, L. Brive, K. Hellstrand, M.J. Rabiet, C. Dahlgren, The annexin I sequence gln(9)ala(10)-trp(11)-phe(12) is a core structure for interaction with the formyl peptide receptor 1, J. Biol. Chem., 285 (2010) 14338-14345. 


\section{Figure Legends}

Figure 1. General structure of FPR1/FPR2 agonist, based on pyridazin-3(2H)-one scaffold.

Figure 2. Docking of compounds 8a and 8e into the FPR1 homology model. Panel A. Docking poses of compounds $\mathbf{8 a}$ (violet) and 8e (light-blue) into the FPR1 binding site of FPR1. The ligand binding site is represented by a surface colored according to electrostatic properties (red negatively charged areas, blue - positively charged areas). Panel B. Docking pose of compound $8 \mathbf{a}$ and residues of FPR 1 within $4 \AA$ from the pose. H-bonds are shown as light-blue dashed lines.

Figure 3. Docking of compounds 13a-c into the FPR2 homology model. Panel A. Docking poses of compounds 13a (blue), 13b (green), and 13c (yellow) with a fragment of the FPR2 surface (cut for clarity). Panel B. Docking pose of compound 13a and residues of FPR2 within $4 \AA$ from the pose. H-bonds are shown as light-blue dashed lines. Panel C. Docking pose of compound 13c and residues of FPR2 within $4 \AA$ from the pose. H-bonds are shown as light-blue dashed lines. 